\title{
Fetal circulatory responses to acute hypoxaemia : studies in the chick embryo
}

Citation for published version (APA):

Mulder, A. L. M. (2002). Fetal circulatory responses to acute hypoxaemia : studies in the chick embryo. [Doctoral Thesis, Maastricht University]. Universiteit Maastricht. https://doi.org/10.26481/dis.20020426am

Document status and date:

Published: 01/01/2002

DOI:

10.26481/dis.20020426am

Document Version:

Publisher's PDF, also known as Version of record

\section{Please check the document version of this publication:}

- A submitted manuscript is the version of the article upon submission and before peer-review. There can be important differences between the submitted version and the official published version of record.

People interested in the research are advised to contact the author for the final version of the publication, or visit the DOI to the publisher's website.

- The final author version and the galley proof are versions of the publication after peer review.

- The final published version features the final layout of the paper including the volume, issue and page numbers.

Link to publication

\footnotetext{
General rights rights.

- You may freely distribute the URL identifying the publication in the public portal. please follow below link for the End User Agreement:

www.umlib.nl/taverne-license

Take down policy

If you believe that this document breaches copyright please contact us at:

repository@maastrichtuniversity.nl

providing details and we will investigate your claim.
}

Copyright and moral rights for the publications made accessible in the public portal are retained by the authors and/or other copyright owners and it is a condition of accessing publications that users recognise and abide by the legal requirements associated with these

- Users may download and print one copy of any publication from the public portal for the purpose of private study or research.

- You may not further distribute the material or use it for any profit-making activity or commercial gain

If the publication is distributed under the terms of Article $25 \mathrm{fa}$ of the Dutch Copyright Act, indicated by the "Taverne" license above, 
FETAL CIRCULATORY RESPONSES TO ACUTE HYPOXAEMIA

STUDIES IN THE CHICK EMBRYO 
Printed by Unigraphic Maastricht ISBN 90-5681-134-7

Copyright @ 2002 A.L.M. Mulder. All rights reserved 


\section{FETAL CIRCULATORY RESPONSES TO ACUTE HYPOXAEMIA}

\section{STUDIES IN THE CHICK EMBRYO}

\section{PROEFSCHRIFT}

ter verkrijging van de graad van doctor aan

de Universiteit Maastricht

op gezag van de Rector Magnificus,

Prof. Dr. A.C. Nieuwenhuijzen Kruseman, volgens het besluit van het College van Decanen, in het openbaar te verdedigen

op vrijdag 26 april 2002 om 14.00 uur

door

Antonius Leonardus Maria Mulder 


\section{PROMOTOR :}

Prof. dr. C.E. Blanco

CO-PROMOTOR :

Dr. D.A. Giussani (Cambridge University, Verenigd Koninkrijk)

BEOORDELINGSCOMMISSIE

Prof. dr. R.A.M.G. Donckerwolcke (voorzitter)

Prof. dr. M. van den Bor (Katholieke Universiteit Nijmegen)

Prof. dr. M.A. Hanson (University of Southampton, Verenigd Koninkrijk)

Prof. dr. J. G. Nijhuis

Prof. dr. H. A. J. Struijker Boudier

The studies described in this thesis were performed at the Research Institute Growth and Development (GROW), Maastricht University, The Netherlands.

Publication if this thesis was kindly supported by Christiaens BV, Abbott Diagnostics Division, Friso Kindervoeding - Friesland Nutrition, Mead Johnson and Nutricia Nederland BV 


\section{CONTENTS}

$\begin{array}{lll}\text { CHAPTER } 1 \text { General Introduction } & 7\end{array}$

1.1 Introduction and aims of the study 8

1.2 The fetal response to acute hypoxaemia 11 review of the literature

1.3 The chick embryo 23

1.4 Materials and Methods 29

$\begin{array}{lll}1.5 & \text { References } & 37\end{array}$

CHAPTER 2 Cardiac Output distribution in the chick embryo from 47 stage 36 to 45

Cardiovascular Research 34 (1997) 525-528

CHAPTER 3 Cardiac Output distribution in response to hypoxia in the chick embryo in the second half of the incubation time Journal of Physiology (1998) 508.1 pp.281-287

CHAPTER 4 Developmental changes in plasma catecholamine concentrations during normoxia and acute hypoxia in the chick embryo Journal of Physiology (2000) 527.3 pp.593-599

CHAPTER 5 Alpha-adrenergic contribution to the cardiovascular response to acute hypoxaemia in the chick embryo American Journal of Physiology, Regulatory Integrative and Comparative Physiology (2001) 281: R2004-2010

CHAPTER 6 Sympathetic control of the cardiovascular response to acute hypoxaemia in the chick embryo American Journal of Physiology, Regulatory Integrative and Comparative Physiology, (2002) 282 in press

CHAPTER 7 Summary and General Discussion

DANKWOORD 

INTRODUCTION $\mid \mathbf{7}$

Chapter 1

General Introduction 


\subsection{INTRODUCTION AND AIMS OF THE STUDY}

\section{INTRODUCTION}

In the last decade obstetric, perinatal and neonatal care has improved considerably. However, 1- 4.5 per 1000 babies born alive develop cerebral palsy (Pschirrer \& Yeomans, 2000). The causes of cerebral palsy are various and often remain uncertain. Perinatal ischaemia / hypoxaemia is a well recognised risk factor, but accounts for only 8 to $10 \%$ of cerebral palsy (CP) cases (Blair \& Stanley, 1988; Pschirrer \& Yeomans, 2000). Therefore, recently more attention has been paid to prenatal risk factors. Magnetic resonance imaging studies in children with CP have demonstrated cerebral malformations most likely to have been originated during pregnancy, before birth (Truwit $\theta t$ al. 1992). This supports the concept that prenatal insults might be an important cause of cerebral palsy, although it remains uncertain to what extent.

During normal pregnancies the maternal uterine environment provides optimal conditions for fetal growth and development. Under certain pathological situations however the intra-uterine conditions for the fetus might become sub-optimal and fetal adaptation will occur. Maternal pathology like hypertension, preeclampsia, HELLP syndrome, drug or nicotine abuse may result in placental dysfunction (Salafia et al. 1995), leading to fetal growth retardation, most probably due to fetal hypoxaemia and malnutrition (Buescher et al. 1998; Okamura et al. 1990). Furthermore, acute episodes of fetal hypoxaemia and ischaemia may occur during pregnancy and labour due to uterine contractions and umbilical cord compression (Itskovitz et al. 1983; Woudstra et al. 1991). During brief periods of ischaemic starvation the fetus reduces its rate of metabolism and utilizes proteins and carbohydrates derived from tissue reservoirs. However, in contrast to other nutrients, oxygen is not stored which makes the fetus completely dependent on its steady supply and on cardiovascular responses in order to survive periods of hypoxaemia and minimize organ damage. The characteristics of these responses depend upon the stage of fetal development (Iwamoto et al. 1989; Giussani et al. 1994c; Fletcher et al. 2000b) and cardiovascular defences might be weak in premature fetuses.

Physiological understanding of the fetal responses to hypoxia provides clinical possibilities to monitor fetal wellbeing. Traditionally, the fetal responses to hypoxaemia have been studied in the ovine fetus using experimental protocols such as maternal hypoxaemia (Cohn et al. 1974; Peeters et al. 1979), ligation of the uterine artery (Jensen \& Berger, 1991), partial 
compression of the umbilical cord (Giussani et al. 1997; Gardner et al. 2001), embolisation of a part of the placenta (Block et al. 1990) or placental carunclectomy (Robinson et al. 1979). The latter three techniques can be used to induce chronic hypoxaemic conditions. The different nature of these insults makes the interpretation of the fetal responses difficult. First, the results might be influenced by the degree and duration of adverse intrauterine conditions produced by the instrumentation; Second, both maternal and placental factors, induced by the insult, might influence the fetal responses to hypoxaemia. For example, during maternal hypoxia, stress hormones such as cortisol (Boddy et al. 1974b) from the mother might cross the placenta or vasoactive substances like prostaglandins (Thorburn, 1992) and adenosine (Yoneyama et al. 1996) might be secreted by the placenta and reach the fetal circulation. The contribution of these placento-maternal mechanisms to the fetal response to acute hypoxaemia has not been fully elucidated.

The present study was designed to investigate the isolated fetal response to hypoxaemia in an animal model which is not dependent on the mother during gestation: the chick embryo. The chick embryo develops completely independent of the mother animal, there is no placenta within the egg, all nutrients are present in the egg and gas exchange takes place with the environmental air via the egg shell.

\section{OBJECTIVES OF THE STUDY}

Studies in mammalian animals have shown that hypoxia triggers several protective mechanisms in the fetus (Hanson, 1988; Giussani et al. 1994c). The mature fetal response to hypoxia is characterized by a transient bradycardia, a rise in blood pressure and a centralization of the cardiac output favouring vital organs like the brain, heart and adrenals. Initially this response involves a chemoreflex, mediated by peripheral chemoreceptors in the carotid body (Giussani et al. 1993). Their activation initiates an increase in vagal activity to the heart, resulting in bradycardia, and an increase in sympathetic activity, which produces vasoconstriction in the carcass and a rise in systemic blood pressure. Later endocrine mechanisms contribute to the response, in particular the rise in fetal plasma catecholamines and vasopressin, which contribute to the vasoconstriction and bradycardia (Rurak, 1978; Cohen et al. 1982). In addition, local vasoactive substances, such as NO, endothelin-1 and adenosine are involved in peripheral vascular responses (Green, 2001). Few studies describe the ontogenic changes of this response during development. Studies in fetal sheep show changes in the response to acute hypoxaemia with progression of gestation (Iwamoto et al. 1989; Fletcher et al. 2000b). Moreover, it is not clear to what extent different mechanisms, such as 
10 CHAPTER 1

sympathetic activation and catecholamine release, contribute to the response at different stages of development.

The objective of the study was to describe and characterise the fetal response to acute hypoxia and its ontogenic maturation, in an animal model which is independent of the mother. Changes in cardiac output distribution to several organs and catecholamine release were studied as indicators of the response.

The following aims were formulated:

1. What is the distribution of the cardiac output in the chick embryo under basal conditions and how is it comparable to the mammalian fetus?

2. Does acute hypoxaemia in the chick embryo result in centralization of the cardiac output in favour of vital organs such as the brain, heart and adrenals?

3. What is the role of catecholamines and the sympathetic nervous system in mediating this response?

4. Does the response to acute hypoxaemia change during development of the chick embryo? 


\subsection{THE FETAL RESPONSE TO ACUTE HYPOXAEMIA REVIEW OF THE LITERATURE}

1.2.1 Cardiovascular response to acute hypoxaemia
1.2.1.1
Heart rate
1.2.1.2
Blood pressure
1.2.1.3
Cardiac output

1.2.2 Endocrine response to acute hypoxaemia

1.2.3. Metabolic response to acute hypoxaemia

1.2.4. Maturation of the fetal hypoxaemic response

1.2.5. Summary 


\subsubsection{CARDIAC OUTPUT}

In fetal sheep, acute hypoxaemia produces a change in the distribution of the combined left and right ventricular output. In late gestation under physiological conditions the combined cardiac output of the sheep fetus is approximately $480 \mathrm{ml}$. $\mathrm{min}^{-1} \mathrm{~kg}^{-1}$ fetal weight (Jensen et al. 1991). About $55 \%$ of the cardiac output is distributed to the fetal body and $45 \%$ to the placenta. The distribution of the cardiac output to the different tissues is shown in Fig 1.

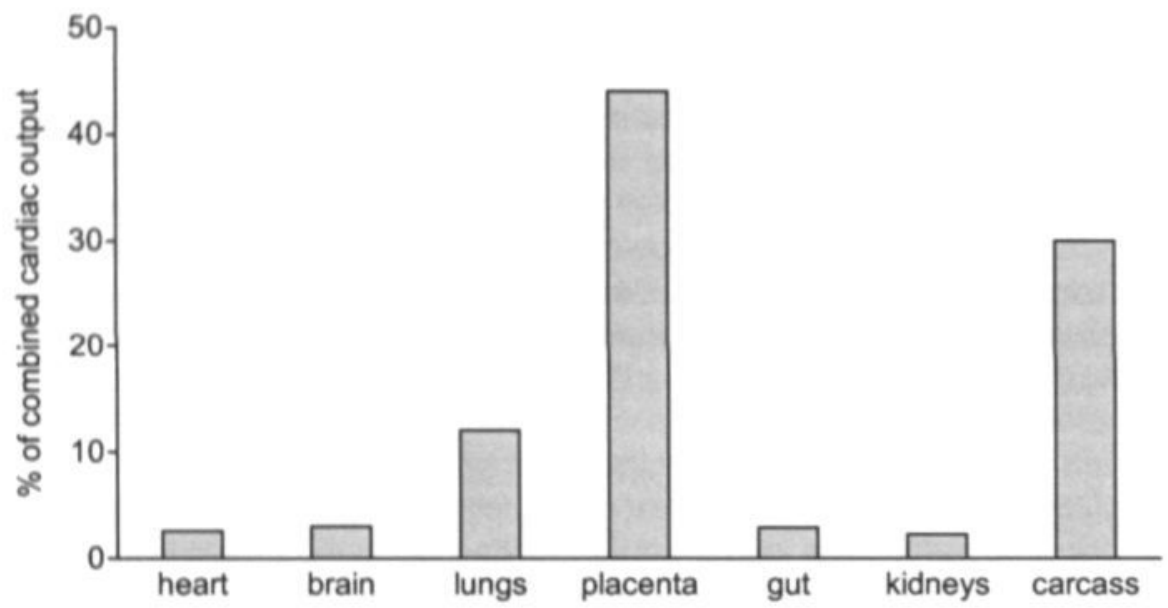

Fig 1 Distribution of the combined cardiac output (adapted from Jensen et al., 1991)

During fetal hypoxaemia the combined cardiac output is maintained as long as blood pH is within normal limits. When hypoxaemia is accompanied by acidosis the cardiac output falls (Cohn et al. 1974). In general, fetal hypoxaemia induces a circulatory centralization of blood flow in favour of the heart, the brain and the adrenals at the expense of the peripheral organs, including lungs, kidneys, gastrointestinal tract and carcass as shown in Figure 1.2 (Cohn et al. 1974; Peeters et al. 1979; Jensen et al. 1991). The precise pattern of redistribution depends on the type of hypoxic challenge used and the degree of maturation of the unborn animal.

Umbilical blood flow is maintained but umbilical venous blood is preferentially directed through the ductus venosus and the foramen ovale to the upper body, maintaining oxygen delivery to the heart and the brain (Jensen \& Berger, 1991). 


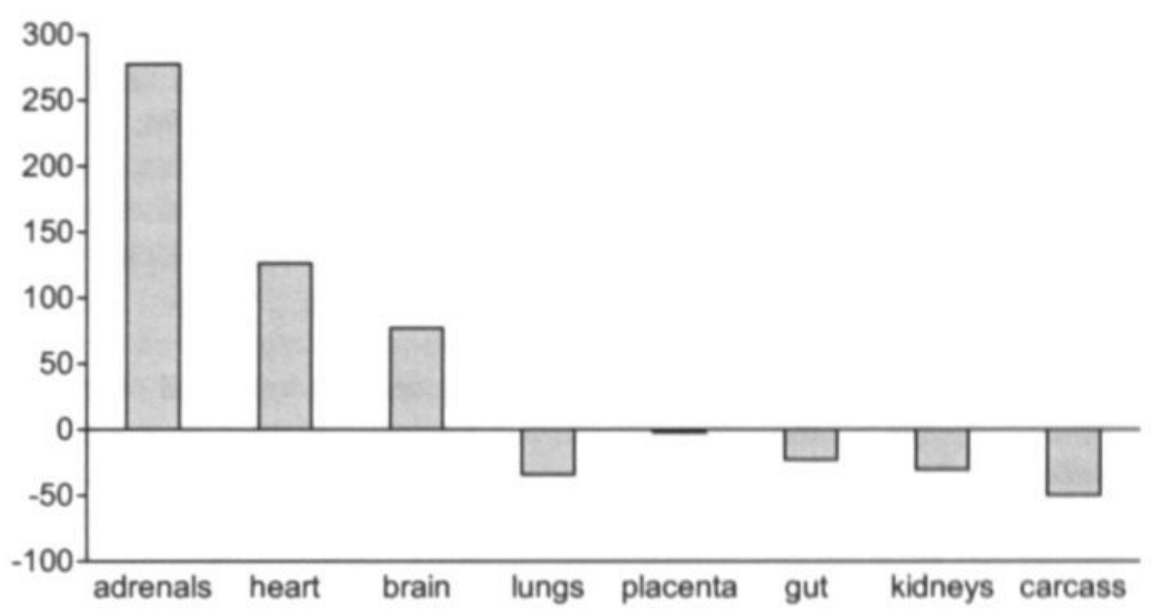

Figure 1.2 Redistribution of organ blood flow (\% change from baseline) during graded reduction of uterine blood flow (adapted from Jensen et al., 1991)

Blood flow to the brain increases during fetal hypoxaemia produced by maternal hypoxaemia, reduction in umbilical blood flow and reduction in uterine blood flow. However, during severe asphyxia caused by prolonged arrest of uterine blood flow, blood flow to the brain does not increase (Jensen et al. 1987). The increase in blood flow to the brain might be explained by at least two important mechanisms during hypoxaemia. First, acute hypoxaemia causes a rise in blood pressure and an increase in peripheral vascular resistance, resulting in a shift of blood flow towards vascular beds with lower vascular resistance (Giussani et al. 1993). Second, local release of vasodilator substances such as NO (van Bel et al. 1995; Green et al. 1996) and adenosine (Kurth \& Wagerle, 1992; Newman et al. 2001) results in lower vascular resistance in the cerebral vascular bed. The contribution of the rise in peripheral vascular resistance in redistributing the cardiac output away from ancillary vascular beds towards the brain and heart is not clear and it might be species dependent. Alpha-adrenergic blockade with phentolamine in fetal sheep exposed to one hour of hypoxaemia resulted in death in 5 out of 14 animals (Giussani et al. 1993). The surviving 9 fetuses showed an attenuated rise in blood pressure and no increase in peripheral vascular resistance while the decrease in carotid vascular resistance and increase in carotid blood flow was not affected (Giussani et al. 1993). The same protocol performed in llama fetuses resulted in death of all fetuses (Giussani et al. 1999). 
Coronary blood flow is also increased during fetal hypoxaemia. Myocardial blood flow is an inverse function of arterial oxygen content (Peeters et al. 1979). Oxygen delivery to the myocardium is maintained by increasing blood flow as oxygen content decreases. Again, the rise in peripheral vascular resistance and local vasodilator mechanisms contribute to this response. The mechanisms by which hypoxaemia induces coronary vasodilatation include $\beta_{2}$ adrenoreceptor stimulation (Feigl, 1998) and local release of adenosine and NO (Reller et al. 1995).

Blood flow to the adrenals increases during fetal hypoxaemia. Therefore, the adrenals are considered as "central" organs along with the brain and the heart. Blood flow increases to both the adrenal cortex and medulla. This change in blood flow during fetal hypoxaemia might be important since the adrenals release large amounts of catecholamines (Comline \& Silver, 1961; Jelinek \& Jensen, 1991) and cortisol (Jones et al. 1977) during hypoxaemia, although the release of cortisol and catecholamines is not solely dependent of blood flow. Denervation of the carotid chemoreceptors does not effect the increase in blood flow to the adrenal glands during hypoxaemia. However, it does delay the increase in plasma cortisol, despite an unaffected increase in plasma ACTH. This suggests a chemoreflex contribution to the release of cortisol in response to hypoxaemia (Giussani et al. 1994a), which may act to sensitise the adrenal cortex to ACTH delivery. The mechanism involved in increasing adrenal blood flow during hypoxaemia is believed to be mediated by local release of VIP (Hinson et al. 1994) and nitric oxide in response to splanchnic stimulation. Infusion of nitric oxide synthase inhibitor L-NAME prevents the increase in blood flow during acute hypoxaemia in fetal llamas (Riquelme et al. 1998).

Blood flow to the carcass, kidneys, gut and lungs decreases during fetal hypoxaemia. Femoral vascular resistance increases, decreasing blood flow to the lower extremities (Giussani et al. 1993). This increase in femoral vascular resistance does not occur after denervation of the carotid sinus and after $\alpha$ adrenoreceptor blockade (Giussani et al. 1993). Renal blood flow decreases (Cohn et al. 1974; Jensen et al. 1991), however, glomerular filtration rate is maintained (Robillard et al. 1981). Only during severe fetal hypoxaemia blood flow to the gut is markedly decreased (Yaffe et al. 1987; Bennet et al. 2000). Also the blood flow to the lungs decreases during hypoxaemia. However, the mechanism is not completely understood. Alpha- and beta-adrenergic receptor blockade and parasympathetic blockade do not change this response (Lewis et al. 1976). Most likely, a low $\mathrm{P}_{\mathrm{a}} \mathrm{O}_{2}$ has direct effects on fetal pulmonary artery smooth muscle cells, resulting in depolarisation and constriction (Cornfield et al. 1994). 


\subsubsection{ENDOCRINE RESPONSE TO ACUTE HYPOXAEMIA}

Carotid sinus denervation in sheep fetuses prevents the initial bradycardia and delays the increase in femoral vascular resistance in response to the onset of hypoxaemia. However, as hypoxaemia progresses in these fetuses femoral vascular resistance increases to levels comparable to intact fetuses (Giussani et al. 1993). This suggests chemoreflex independent mechanisms mediating peripheral vasoconstriction during hypoxaemia such as the release of vasoactive endocrine substances. Catecholamines are released from the adrenals in response to fetal hypoxaemia by at least two mechanisms. Sympathetic stimulation of the adrenals through the splanchnic nerves results in release of adrenaline and noradrenaline from the chromaffin cells in the adrenal medulla (Comline et al. 1965; Cohen et al. 1982). Secondly, hypoxaemia itself is known to stimulate chromaffin cells to release catecholamines (Rychkov et al. 1998). Catecholamines play an important role in the fetus in the regulation of peripheral vascular resistance since infusion of adrenaline to fetal sheep increases blood pressure and peripheral vascular resistance (Jones \& Ritchie, 1978a), whereas $\alpha$-adrenergic receptor blockade abolishes the rise in peripheral vascular resistance in response to hypoxaemia (Giussani et al. 1993). Also ACTH and cortisol are released from the adrenals in response to hypoxaemia (Jones et al. 1977), however their role in cardiovascular control is poorly understood. Cortisol might influence the effect of other vasoconstrictor hormones like angiotensin II (Tangalakis et al. 1992) and sensitise the peripheral vascular bed to noradrenaline (Schomig et al. 1976). Another candidate contributing to peripheral vasoconstriction is arginine vasopressin (AVP), which is released during fetal hypoxaemia (Rurak, 1978). Exogenous infusion of AVP to the fetus produces vasoconstriction in the carcass (Iwamoto et al. 1979). The role of AVP in the fetal response to acute hypoxaemia is not clear. Pretreatment with V1 AVP antagonist before hypoxaemia partially reversed the fetal hypertension in the study by Perez (Perez et al. 1989). Furthermore, both plasma angiotensin II concentrations (Green et al. 1998) and plasma renin activity (Robillard et al. 1981) increase during fetal hypoxaemia. Although plasma angiotensin II concentrations increase during hypoxaemia it does not appear to play an important role during hypoxaemia since peripheral vascular resistance and blood pressure rise despite the infusion of an angiotensin converting enzyme inhibitor (Green et al. 1998). Recently, neuropeptide Y (NPY) has been shown to increase during fetal hypoxaemia (Fletcher et al. 2000a). 


\subsubsection{METABOLIC RESPONSE TO ACUTE HYPOXAEMIA}

During fetal hypoxaemia the cardiac output is redistributed to the central organs. During mild to moderate hypoxaemia this compensates for the fall in blood oxygen content to maintain oxygen delivery to these organs (Peeters et al. 1979) (Jensen et al. 1991). Oxygen delivery to the adrenals even increases during hypoxaemia (Jensen et al. 1991). The oxygen delivery to various other tissues is decreased and during severe hypoxaemia, especially with acidosis, oxygen delivery to the central organs is also no longer maintained. A fall in oxygen delivery is initially compensated by an increase in oxygen extraction (Itskovitz et al. 1983; Jensen et al. 1991), but when oxygen delivery further decreases oxygen consumption falls (Itskovitz et al. 1983). In fetal sheep a $50 \%$ reduction in arterial oxygen content, induced by reduction of uterine artery blood flow, is associated with a decrease in total oxygen consumption to $56 \%$ of control (Jensen et al. 1991). In vitro studies have also shown that fetal skeletal muscle cells reduce oxygen consumption when oxygen availability decreases (Braems \& Jensen, 1991). Recently, nearinfrared spectroscopy is used to measure oxygen delivery and oxygen consumption. Newman et al. (2000) used this technique in late-gestation fetal sheep to measure haemodynamic and metabolic responses to asphyxia in brain and hindlimb. Moderate asphyxia for $1 \mathrm{hr}$. led to a significant fall in oxygen delivery to the hindlimb by $85 \%$ and to the brain by $61 \%$. Blood flow to the leg, measured as total $\mathrm{Hb}$ concentration, decreased reflecting peripheral vasoconstriction, and to the brain increased. Oxygen consumption was reduced in both tissues. The concentration of oxidized cytochrome oxidase, reflecting the function of the oxidative phosphorylation pathway, decreased in hindlimb, however it increased in brain. This study shows fetal haemodynamic and metabolic adaptations to hypoxia preserving oxidative phosphorylation in the brain. A decrease in oxygen consumption may affect fetal behaviour. Fetal hypoxaemia in near term fetal sheep results in a rapid decrease in fetal breathing and body movements (Boddy et al. 1974a). In addition, the fetal electrocortical activity switches from low voltage, high frequency to high voltage, low frequency waves (Boddy et al. 1974a), which is associated with non-REM sleep with lowering of the oxygen consumption in the brain (Richardson et al. 1985). In fetal sheep plasma glucose concentrations rise progressively during acute hypoxaemia with increasing gestational age (Jones, 1977). This increase is linearly correlated with increases in plasma catecholamines (Jones, 1977), which suggests an important role for catecholamines. Infusion of adrenaline causes a similar rise in plasma glucose concentration together with a fall in plasma insulin concentration (Jones \& Ritchie, 1978b; Padbury et al. 1987). Noradrenaline infusion is less effective in eliciting metabolic responses (Jones \& Ritchie, 1978b). In addition, 
plasma lactate, free fatty acids and ketone bodies also rise in response to hypoxaemia (Jones, 1977), which can also be elicited by infusion of adrenaline (Jones \& Ritchie, 1978b). The metabolic effects of adrenaline infusion show striking resemblance with the effects observed during acute hypoxaemia. Also glucocorticoids might contribute to the fetal metabolic response to acute hypoxaemia. Acute hypoxaemia results in a rise in plasma ACTH concentration together with a rise in plasma cortisol (Akagi \& Challis, 1990). The prepartum rise in plasma cortisol concentrations parallels the rise in fetal glucogenesis towards term (Fowden et al. 1998). In addition, cortisol infusion to sheep fetuses close to term has been shown to stimulate endogenous glucose production (Townsend et al. 1991).

\subsubsection{MATURATION OF THE FETAL HYPOXAEMIC RESPONSE}

Few studies report developmental changes of the fetal response to hypoxaemia. Studies in fetal sheep younger than 110 days gestation $(0.75$ of gestation) show that acute hypoxaemia elicits a tachycardia rather than a bradycardia. Furthermore, the rise in arterial blood pressure is not noted at this early developmental stage (Boddy et al. 1974b; Iwamoto et al. 1989). However, changes in the resistance of the myocardial, cerebral and adrenal vascular beds in response to hypoxaemia are reported in fetal sheep as early as 84-91 days (0.6 gestation) (Iwamoto et al. 1989). In addition, peripheral vasoconstriction is noted from 97-99 days (0.65 gestation) (Iwamoto et al. 1989). Increases in plasma adrenaline, noradrenaline and vasopressin concentrations in response to hypoxaemia are described from day 0.6 gestation fetal sheep (Cohen et al. 1982; Iwamoto et al. 1989; Widmark et al. 1989; Cheung, 1990). The data of these studies suggest an ontogenic increase in adrenaline and noradrenaline release in response to hypoxaemia. In addition, recently Fletcher et al. (2000) described ontogenic changes in the fetal sheep responses to acute hypoxaemia from 125 to 145 days gestation. With advancing gestational age an increase in the magnitude of bradycardia and femoral vascular resistance was noted (Fletcher et al. 2000b). In addition, the magnitude of the AVP and the cortisol responses and the ratio of adrenaline to noradrenaline, all increased in response to hypoxaemia with advancing gestational age (Fletcher et al. 2000c). The developmental changes in the fetal responses to hypoxaemia may be related to the rate at which the cardiovascular system, the chemoreceptor function, the autonomic nervous system and the endocrine mechanisms mature during gestation. 


\subsubsection{SUMMARY}

The mature mammalian fetus has protective mechanisms to withstand hypoxaemia, including transient bradycardia, an increase in arterial blood pressure and peripheral vasoconstriction. Peripheral vasoconstriction largely contributes to the redistribution of the fetal cardiac output away from ancillary circulations towards the adrenal, myocardial and cerebral vascular beds. The physiological mechanisms mediating these cardiovascular responses involve neural, endocrine and local components (Figure 1.3). Initially, hypoxaemia stimulates the peripheral (particularly the carotid) arterial chemoreceptors. Their activation mediates both an increase in efferent vagal activity to the heart, resulting in bradycardia, and an increase in sympathetic outflow, which produces vasoconstriction in the peripheral circulation and contributes to the increase in blood pressure. The rise in blood pressure further contributes to the bradycardia via the baroreflex, but the fall in heart rate is only transient and $B$ adrenergic influences on the heart oppose vagal tone, increasing heart rate towards basal values after a few minutes of hypoxaemia. After this initial chemoreflex response, slower endocrine mechanisms are mediated, including the release of catecholamines and vasopressin, which maintain the peripheral vasoconstriction during the hypoxaemic challenge. As a consequence the cardiac output is redistributed towards the heart, the brain and the adrenal glands, away from the carcass, the lungs, the intestines and rest of the body. Local vasodilator factors like NO and adenosine in heart and brain and VIP in the adrenal glands further contribute to this redistribution. 


\section{INTRODUCTION: REVIEW OF THE LITERATURE | 21}

\section{ACUTE HYPOXAEMIA}

Chemoreceptors

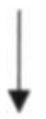

Cardiovascular

centre in medulla
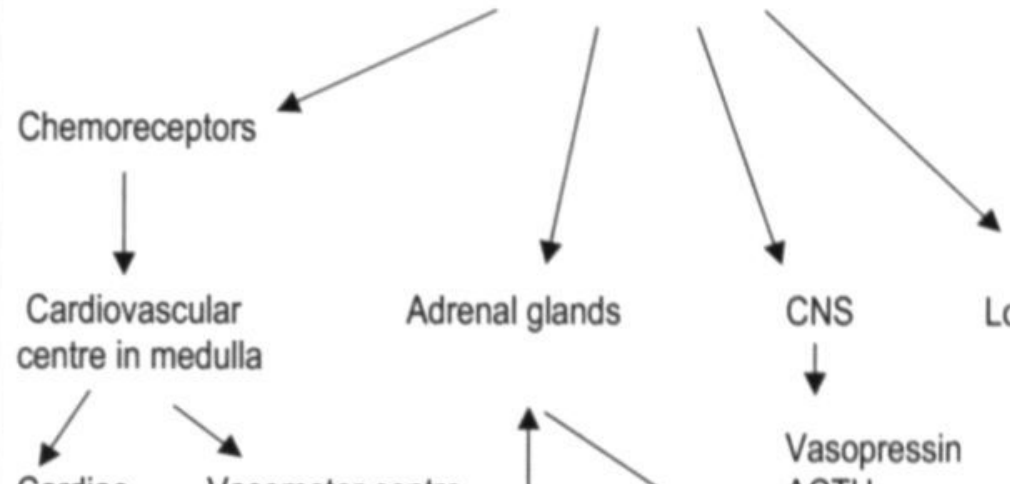

Cardiac

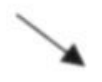

centre

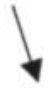

Vagus

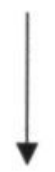

Bradycardia

Adrenal glands

CNS

Local factors

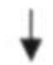

Vasopressin ACTH

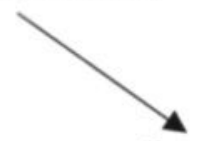

Sympathetic
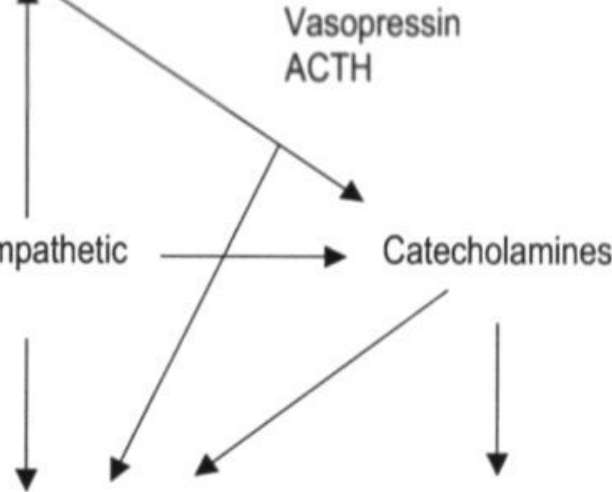

Redistribution

Cardiac Output 
22 ChAPTER 1 


\subsection{THE CHICK EMBRYO}

1.3.1 Choice of the chick embryo

1.3.2 Development of cardiovascular function

1.3.3 Development of respiratory function

1.3.4 Development of cardiovascular control

1.3.4.1 Parasympathetic nervous system

1.3.4.2 Sympathetic nervous system

1.3.4.3 Adrenals 


\section{THE CHICK EMBRYO}

In all experiments presented in this thesis the experimental animal model is the chick embryo during the second half of the incubation period. We used fertilized eggs of the White leghorn. The history of the chick embryo as experimental animal model dates back to antiquity. Aristotle (384-322 B.C.) was the first to give a detailed description of the chick embryo in his Historia Animalium. Nowadays, the chick embryo, in particular during early incubation, is a well-known animal model for cardiovascular research with regard to cardiac development (Clark 1989), angiogenesis (Le Noble et al. 1993), cardiovascular pharmacology and toxicology (Bkaily et al. 1991) and cardiovascular mechanisms (Taber et al. 1992). In addition, recent publications provide abundant information on the chicken genome (Schmid et al. 2000), which shows the conservation of large syntenic regions between the human and chicken genomes (Burt et al. 1999).

\subsubsection{CHOICE OF THE CHICK EMBRYO}

The most important reason for us to start studies on fetal responses in the chick embryo was the fact that, in contrast to mammalian fetuses, the chick embryo offers the possibility to study fetal responses independently of the mother animal. Maternal vasoactive substances like corticosteroids and catecholamines might cross the placenta and influence the fetal responses in a mammalian fetal animal model. In addition, placental factors like prostaglandins and oestrogens might modulate the cardiovascular responses in fetal mammals. The chick embryo is not connected to a placenta. Therefore gas exchange and nutrition must occur in an alternative way. Gas exchange takes place in the chorioallantoic membrane. This well-vascularised membrane is in direct contact with the environmental air through microscopic pores in the shell. The pores allow oxygen to diffuse from the environment to the capillary bed of the chorioallantoic membrane and carbon dioxide, produced by the embryo, to diffuse out of the egg.

All nutrients needed for embryonic development and growth are present in the egg. Most of the energy in the egg is in the yolk as lipids and proteins and a smaller part in the albumen. The nutrients in the yolk are transported to the embryo by the vitelline circulation in the yolk sac. The albumen is partly absorbed by the chorioallantoic circulation and also swallowed by the embryo from day 10 of incubation (Romanoff, 1960). 
Besides being independent of the mother, the chick embryo has several advantages as an experimental model which are summarised in Table 1.1 The incubation time is short (hatching is at 21 days). Only one animal is used in contrast to mammalian studies where both fetus and mother animal are used and eventually sacrificed. The blood vessels of the chorioallantoic membrane are easy accessible via the air cell of the egg, which makes instrumentation less invasive and finally a fertilized egg is relatively cheap.

On the other hand the chick embryo as experimental model has its limitations. The main one is the blood volume of the chick embryo which limits the blood sample volume and sample frequency as well as the volume of fluid that can be injected into the circulation.

Table 1.1

Advantages

Limitations

Independent of mother / placenta

Small blood volume

Short incubation time

Limitation in frequency of blood samples

Limited use of experimental animals

Easy vascular access

Low cost

\subsubsection{DEVELOPMENT OF CARDIOVASCULAR FUNCTION}

The heart starts to develop simultaneous with the development of the extra embryonic and intra embryonic blood vessels, connecting these two vascular systems throughout the incubation period (for review see Tazawa \& Whittow, 2000). Initially the heart is a paired tubular structure that soon forms a single tube at the 7-10 somite stage. During the period between day 3 and day 8 of incubation the internal cardiac structures develop. The interatrial septum closes at day 5 and the interventricular septum at day 8 of incubation as does the aortopulmonary septum. The heart starts to beat around the 9 somite stage ( 30 hours) and blood flow starts around the 13 somite stage (40 hours). Heart rate increases gradually to a maximum of $+/-288 \mathrm{bpm}$ at day 16 of incubation (Tazawa et al. 1991; van Golde et al. 1996) and heart rate variability increases during the second half of the incubation period (Tazawa et al. 1991). Around day 14 and 15 of incubation, heart rate decreases until internal pipping. With advancing incubation time heart mass (Clark, 1989), 
$26 \mid$ CHAPTER 1

stroke volume (Faber et al. 1974) and cardiac output all increase as does the blood pressure.

\subsubsection{DEVELOPMENT OF RESPIRATORY FUNCTION}

During embryonic development there are three different gas exchangers in the egg: the area vasculosa, the chorioallantoic membrane and the lungs (Ackerman \& Rahn, 1981; Tazawa \& Whittow, 2000). Initially gas exchange takes place in the area vasculosa. This is a well vascularised region of the yolk sac, which spreads around the yolk by rapid growth during the first 5 days of incubation. On the second day of incubation the vascular bed of the yolk sac connects with the dorsal aorta and blood starts to flow through the embryo and the area vasculosa. Until day 6 of incubation the area vasculosa is the main gas exchanger (Ackerman \& Rahn, 1981). Around day 6 of incubation the vascular bed of the chorioallantoic membrane reaches the inner shell membrane and takes over respiratory function. In the following 6 days the chorioallantoic membrane spreads over the whole inner shell increasing the surface area from about $25 \mathrm{~cm}^{2}$ to $70 \mathrm{~cm}^{2}$ (Ackerman \& Rahn, 1981). At day 19-20 the chick embryo pips the chorioallantoic membrane with the beak into the air cell of the egg (internal pipping) and at day 21 through the shell (external pipping). The lungs are aerated and take over the respiratory function of the chorioallantoic membrane.

\subsubsection{DEVELOPMENT OF CARDIOVASCULAR CONTROL}

The primary function of the cardiovascular system is to meet the metabolic demands of the embryonic body: delivery of nutrients and removal of metabolic waste products. Early in embryonic development, prior to innervation of the heart, mechanical factors are the most important determinants of cardiovascular function. Initially the afterload for the heart is high as measured by total peripheral vascular resistance, but decreases rapidly with expansion of the vascular bed, also increasing the preload. Myocardial contractility increases during development with increase in myofibril density and alignment (Clark et al. 1986). At this stage, circulating factors like amines may influence cardiac performance. Later in development innervation of the heart takes place and the autonomic nervous system contributes to the regulation of cardiovascular function. 


\subsubsection{PARASYMPATHETIC NERVOUS SYSTEM}

During the second day of incubation the vagus nerve appears in the chick embryo reaching the atrial septum of the heart at day 5 and the sinoatrial region on day 6 of incubation (Romanoff, 1960). Cholinesterase activity can be detected from the $7^{\text {th }}$ day and on day 13 the neural network resembles that seen in the hatched chicken (Rickenbacher \& Muller, 1979). In the isolated chick embryo heart electric field stimulation evokes a cholinergic inhibition on the sinoatrial pacemaker cells from day 12 (Pappano, 1977), suggesting functional efferent integrity from that stage of development. However, the inhibitory effect of acetylcholine can already be demonstrated in the $33-38 \mathrm{hr}$ embryo (Cullis \& Lucas, 1936), long before innervation of the heart takes place. Despite this, studies in chick embryos from day 12 to 21 of incubation using the muscarinic antagonist atropine and the ganglionic blocking agent hexamethonium could not demonstrate a contribution of the parasympathetic nervous system on cardiovascular regulation (Crossley \& Altimiras, 2000).

\subsubsection{SYMPATHETIC NERVOUS SYSTEM}

Sympathetic cardiac nerves arise from the first thoracic sympathetic ganglia on the $7^{\text {th }}$ day of incubation and reach the heart on the $10^{\text {th }}$ day of incubation (Kirby et al. 1980). Catecholamine expressing nerve fibres are detected in the sinoatrial region on the $12^{\text {th }}$ day of incubation and in ventricular musculature on the $16^{\text {th }}$ day (Pappano, 1977). Electric field stimulation of isolated chick embryo hearts shows $\beta$-blocker-sensitive acceleration of the sinoatrial pacemaker for the first time on the $21^{\text {st }}$ day of incubation (Pappano, 1977 ) and in the presence of atropine on the $19^{\text {th }}$ day. However, acceleration of the heart rate is not dependent of innervation alone. Circulating catecholamines may have an effect much earlier. Already after 37 hours of incubation adrenaline is able to accelerate the heart and the receptors that respond to sympathomimetic amines are present and functional prior to sympathetic innervation (Mc Carty \& Sideman, 1960). Intravenous injections of adrenaline or noradrenaline evoke an increase in heart rate and blood pressure in the chick embryo from the $7^{\text {th }}$ day of incubation (Girard, 1973). The presence of vascular $\alpha$ - and $\beta$-adrenergic receptors have been described from the $7^{\text {th }}$ day of incubation (Girard 1967). Studies in chick embryos from day 12 to 21 of incubation have described the effect of $\beta$ - or $\alpha$-adrenoreceptor blockade on cardiovascular regulation. Beta-adrenoreceptor blockade, using propranolol resulted in bradycardia, and $\alpha$-adrenoreceptor blockade resulted in reduced arterial pressure from day 12 (Crossley \& Altimiras 2000). Together, these studies demonstrate an important adrenergic contribution to the control of 
cardiovascular function in the chick embryo. Furthermore, Altimiras and Crossley (2000) described the ontogeny of baroreflex regulation in the chick embryo. Using pharmacological manipulation of the blood pressure baroreflex regulation was present from day $18-19$ of incubation. The baroreflex gain showed maturation over the last days of incubation and was expected to mature further after hatching.

\subsubsection{ADRENAL GLANDS}

In the chick embryo neural crest cells migrate to the dorsolateral area of the aorta to form the sympathetic ganglionic primordia between the third and fourth day of incubation. Presumptive adrenal medullary cells arise from the sympathetic chains on the fourth day of incubation (Dawson, 1953; Sanchez Montesinos et al. 1996). Immunocytochemical studies have shown that among catecholamine synthesizing enzymes, tyrosine hydroxylase is present from day 4 of incubation, dopamine beta-hydroxylase from day 10 and phenylethanolamine $\mathrm{N}$-methyltransferase from day 12 of incubation (Sanchez Montesinos et al. 1996).

Catecholamines are detected in very small amounts from the $4^{\text {th }}$ day in allantoic fluid (Boucek \& Bourne, 1962). In the adrenal gland, adrenaline concentrations are relatively low until day 15 , after which the concentrations increase markedly towards hatching (Wasserman \& Bernard, 1970). Catecholamine concentrations in plasma have been reported for the chick embryo from day 10 of incubation, as has an increase in the plasma concentrations of noradrenaline in response to asphyxia at day 14 (Epple et al. 1992). 


\subsection{MATERIALS AND METHODS}

1.4.1 Incubation

1.4.2 Preparation

1.4.3 Measurement of cardiac output distribution

1.4.4 Measurement of plasma catecholamines

1.4.5 Interventions

1.4.5.1 Acute hypoxaemic insult

1.4.5.2 Alpha adrenoreceptor blockade

1.4.5.3 Sympathetic nervous system blockade 


\section{MATERIALS AND METHODS}

\subsubsection{INCUBATION OF THE EGGS}

For all experiments presented in this thesis we incubated fertilized eggs from the White Leghorn. The eggs were obtained from a commercial brooding company ('t Anker, Ochten, the Netherlands) and stored at $12{ }^{\circ} \mathrm{C}$. Within 2 weeks eggs were incubated at $38{ }^{\circ} \mathrm{C}$ and relative air humidity of $60 \%$ in a commercial automated brooding machine (Polyhatch, Brinsea Products Itd. Sandford UK).

The incubation time for the chick embryo until hatching is approximately 21 days. The larger the egg the longer the incubation period will be. After the egg is laid the egg can be stored at a temperature below the physiological zero $\left(25-27{ }^{\circ} \mathrm{C}\right)$ while the embryo remains in dormancy. At a temperature between $10-12{ }^{\circ} \mathrm{C}$ the eggs can be stored for more than 7 days without a major loss of hatchability. At an ambient temperature between 35 and $39{ }^{\circ} \mathrm{C}$ eggs will hatch. In general, $37.5^{\circ} \mathrm{C}$ is considered to be the optimal ambient temperature for incubation. The in ovo development of the chick embryo passes through 46 stages as described in detail by Hamburger and Hamilton (1951), based on external characteristics of the embryo.

\subsubsection{PREPARATION}

All experiments were performed in a former infant incubator provided with a light microscope (WILD 3M; magnification 10x) as shown in Fig 1. Temperature and humidity were maintained constant at $38{ }^{\circ} \mathrm{C}$ and $60 \%$ respectively. Eggs were transluminated and the air cell was identified. The eggs were placed in a holder after opening the air cell by means of an electrical saw. Then the holder was placed in a Plexiglas box connected to an air supply (Fig 2). The oxygen concentration in the box was changed by supplying different mixtures of $\mathrm{N}_{2}$ and $\mathrm{O}_{2}$ at a constant flow of $5 \mathrm{I} \cdot \mathrm{min}^{-1}$. The gas mixture was warmed and humidified. After moistening the outer shell membrane the vessels in the chorioallantoic membrane became visible and the outer membrane could be removed. Arteries and veins were identified by colour and stream direction of the erythrocytes. A chorioallantoic vein of appropriate size was selected for catheterization. The vein was lifted by means of suture loops, opened with a hooked tip of a 30 Gauche needle and a polyethylene catheter was inserted (Fig 3). 
INTRODUCTION: MATERIALS AND METHODS / 31

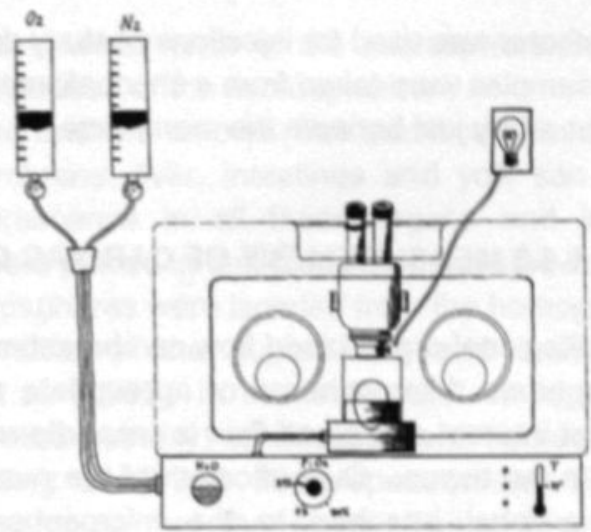

Fig 1 experimental incubator

Fig 2 Plexiglas egg holder

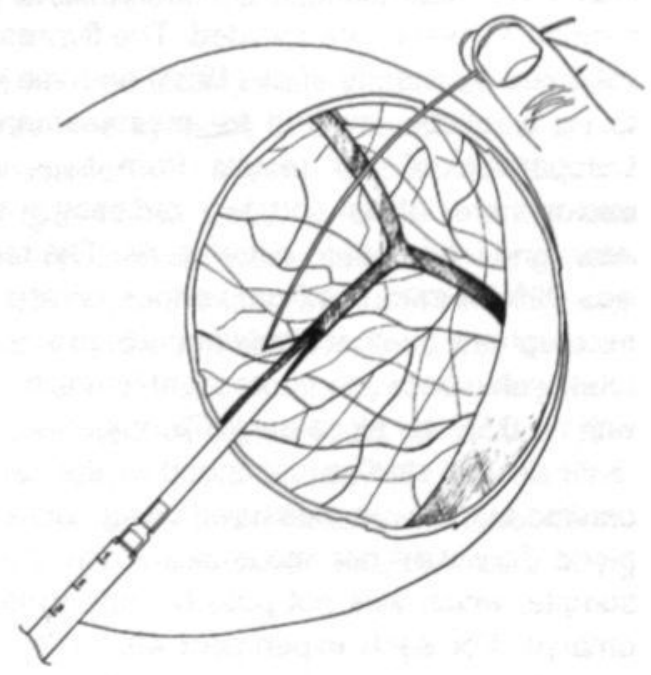

Fig 3 Catheterization 
The catheter was used for injections of study drugs and microsphere solutions. Blood samples were taken from a chorioallantoic artery in the membrane or from a bigger artery just beneath the membrane.

\subsubsection{MEASUREMENT OF CARDIAC OUTPUT DISTRIBUTION}

Regional organ blood flow can be estimated by intravascular injection of microspheres. Microspheres of appropriate size will become trapped in the organ of interest and blood flow is proportional to the number of microspheres found in the tissue. Quantification of the number of microspheres is possible using a label attached to the microspheres. Most common radioactive microspheres are used and radioactivity measured as method for quantification. This method has been validated and is regarded as the "gold standard" for regional blood flow measurement in experimental cardiovascular research (Heymann et al. 1977). Using radioactive microspheres, the fetal distribution of the cardiac output has been measured in non human primate (Behrman et al. 1970), sheep (Rudolph \& Heymann, 1967)and llama (Llanos et al. 1995) fetuses. Recently, microspheres labeled with fluorescence have been introduced as a reliable alternative to radioactive microspheres (Glenny et al. 1993). Quantification of these microspheres requires tissue digestion, microspheres isolation, dye extraction and automated fluorescent spectrophotometry (van Oosterhout et al. 1995). Although this method is more time consuming, the absence of radiation makes it safer and easier to implement. Also the logistic and economic problems of storage and disposal of radioactive waste are avoided. The fluorescent microsphere method has been validated by Glenny et al. (1993) and van Oosterhout et al. (1995) and proves to be a reliable method for measurement of blood flow to various organs. Comparison of the results from two simultaneously injected fluorescent microsphere labels and two radioactive microspheres labels showed good inter- and intramethod correlations. The recovery of microsphere fluorescence was $99 \%$ in samples from various organs (van Oosterhout et al. 1995). With microsphere numbers between 25 and 16,000 microspheres per sample, the relationship between fluorescent intensity and microsphere number was linear with $r>0.99$ for all colours (Glenny et al. 1993).

In the studies described in the present thesis, the distribution of the cardiac output was measured using fluorescent microspheres. Absolute organ blood flow was not measured since this would require a reference blood sample, which was not possible due to the limited blood volume of the chick embryo. For each experiment 40,000 fluorescent microspheres of each dye were injected through the catheter in the chorioallantoic vein. An organ receiving only $1 \%$ of the microspheres would receive 400 microspheres, 
which is enough to minimize the inherent error of the microsphere method from the statistical variation in distribution of the microspheres.

After the experiment ended and the embryo was sacrificed, the heart, lungs, brain, chorioallantoic membrane, liver, intestines and yolk sac were dissected. We determined fluorescence in all these organs and in the remaining carcass. The tissues were placed in test tubes and digested in a $2 \mathrm{M}$ ethanolic- $\mathrm{KOH}$ solution. The microspheres were isolated from the homogenate by repeated centrifugation, removal of the supernatant and rinsing as described by van Oosterhout et al. (1995). In the final pellet the dye was extracted by adding $3 \mathrm{ml}$ of 2-(2-ethoxyethoxy) ethylacetate and fluorescence was counted by fluorometry using a LS-50B fluoro-spectrometer (Perkin Elmer). During fluorometry all samples had the same volume $(3 \mathrm{ml})$, the absolute fluorescent intensity was measured and saved as a database worksheet file using Microsoft Excel. The data were corrected for background fluorescence of the solvent. The sum of fluorescence from the organs and carcass reflected $100 \%$ of the combined left and right ventricular cardiac output. The percentage of cardiac output directed to each organ was calculated by dividing the fluorescence of the organ by the sum of fluorescence of all tissues. Therefore, our results represent relative changes in the total distribution of the cardiac output to the different organs.

Since the chick embryo has a small blood volume we restricted the volumes injected as much as possible and limited the number of injections of microspheres to a maximum of three.

\subsubsection{MEASUREMENT OF PLASMA CATECHOLAMINES}

Blood samples were obtained from puncture of a chorioallantoic artery. Samples were collected in pre-heparinised syringes and drawn in test tubes filled with $25 \mu \mathrm{l}$ glutathione-heparin solution $\left(10 \mathrm{mg} \mathrm{ml}^{-1}\right.$ glutathion, $5000 \mathrm{IU}$ $\mathrm{ml}^{-1}$ heparin). Samples were centrifuged $\left(8^{\circ} \mathrm{C}, 2400 \mathrm{~g}\right)$ for 15 minutes and plasma stored at $-35^{\circ} \mathrm{C}$. Plasma catecholamines were measured using highperformance liquid chromatography (HPLC) at the laboratory of Pharmacology Toxicology, Maastricht University. A sensitive fluorimetric method was used as previously described by van der Hoorn (1989). Prior to chromatography plasma catecholamines were concentrated by liquid-liquid extraction and derivatized with the fluorescent agent 1,2-diphenylethylenediamine. Adrenaline and noradrenaline were quantitated by HPLC with fluorimetric detection. The lower limit of detection of the assay for adrenaline was $0.46 \mathrm{pg}$ $\mathrm{ml}^{-1}$ and for noradrenaline $0.98 \mathrm{pg} \mathrm{ml}^{-1}$. 


\subsubsection{INTERVENTIONS}

\subsubsection{ACUTE HYPOXAEMIC INSULT}

In the experiments the eggs were exposed to acute hypoxia for 5 minutes. The gas mixture in the Plexiglas box was changed to $100 \% \mathrm{~N}_{2}$. In 36 eggs blood samples $(0.3 \mathrm{ml})$ were taken for blood gas analysis using an i-STAT hand held blood analyzer (Abbott Diagnostics Division) to determine the impact of the hypoxic challenge. These data are presented in table 1.2. At day 15 of incubation 5 minutes of hypoxia resulted in hypoxaemia of the embryo, with small changes in $\mathrm{pH}$ and $\mathrm{P}_{\mathrm{a}} \mathrm{CO}_{2}$ within the normal physiological range. Lactate doubled within 5 minutes indicating anaerobic glycolysis. At day 19 basal $P_{\mathrm{a}} \mathrm{O}_{2}$ is lower compared to day 15 due to the limited capacity for gas exchange of the chorioallantoic membrane at this prehatching stage of development. Also basal lactate is increased compared to day 15 of incubation. The 5 minute hypoxic insult resulted in significant hypoxaemia of the chick embryo.

Table 1.2 Arterial pH, blood gas and lactate analyses in chick embryos at day 15 and 19 of incubation

Day 15

Day 19

$\begin{array}{cccc}\text { Normoxia } & \text { Hypoxia } & \text { Normoxia } & \text { Hypoxia } \\ n=10 & n=9 & n=10 & n=7\end{array}$

\begin{tabular}{|c|c|c|c|c|}
\hline Arterial pH & $7.47(7.43-7.50)$ & $7.38(7.24-7.44)^{*}$ & $7.41(7.35-7.48)$ & 7.36 (7.29-7.39) \\
\hline $\mathrm{P}_{\mathrm{a}} \mathrm{CO}_{2}(\mathrm{kPa})$ & $4.31(3.63-4.83)$ & $5.47(4.85-6.10)^{\circ}$ & $4.43(3.71-5.88)$ & $6.00(5.68-7.97)$ \\
\hline $\mathrm{P}_{\mathrm{a}} \mathrm{O}_{2}(\mathrm{kPa})$ & $2.90(2.20-3.70)$ & $1.60(1.35-1.90)^{*}$ & $2.55(2.20-2.70)$ & $1.14(0.80-1.20)$ \\
\hline Lactate (mmol. $\left.\mathrm{I}^{-1}\right)$ & $3.32(2.45-5.45)$ & $6.73(5.56-9.21)^{*}$ & $6.07(4.23-7.92)$ & $6.67(6.22-7.37)$ \\
\hline
\end{tabular}

Values are expressed as median with $25^{\text {th }}$ and $75^{\text {th }}$ percentile. Significant difference with normoxia group (Mann Whitney $\mathrm{U}$ test).

\subsubsection{ALPHA ADRENORECEPTOR BLOCKADE}

For blockade of $\alpha$-adrenergic receptors, phentolamine (Phentolamine, Sigma Chemical Company, $2.5 \mu \mathrm{g} \cdot \mathrm{g}^{-1}$ in $5 \mu \mathrm{l} . \mathrm{g}^{-1}$ embryo) was used. Phentolamine is a competitive $\alpha$-adrenoreceptor antagonist with similar affinities for $\alpha_{1}$ and $\alpha_{2}$ adrenoreceptors. The dose used corresponds with 
doses used in fetal sheep experiments (Giussani et al. 1993) preventing peripheral vasoconstriction in response to hypoxaemia.

\subsubsection{SYMPATHETIC NERVOUS SYSTEM BLOCKADE}

Activity of the sympathetic nervous system was blocked by hexamethonium (Hexamethonium Bromide, Sigma Chemical Company, 25 $\mu \mathrm{g} \cdot \mathrm{g}^{-1}$ in $5 \mu \mathrm{l} . \mathrm{g}^{-1}$ embryo). Hexamethonium is a ganglionic blocking drug impairing neurotransmission in autonomic ganglia acting on the nicotinic receptor. The dose used was reported to be three to four times the dose required to achieve complete blockade of the autonomic nervous system for 6 hours in fetal sheep (Brace \& Brittingham, 1986). 
$36 \mid$ CHAPTER 1 


\subsection{REFERENCES}

ACKERMAN, R. A. \& RAHN, H. (1981). In vivo O2 and water vapor permeability of the hen's eggshell during early development. Respiration Physiology 45, 1-8.

AKAGI, K. \& CHALLIS, J. R. (1990). Hormonal and biophysical responses to acute hypoxemia in fetal sheep at 0.7-0.8 gestation. Canadian Joumal of Physiology and Pharmacology 68, 1527 . 32.

ASSALI, N. S. (1967). Some aspects of fetal life in utero and the changes at birth. American Joumal of Obstetrics and Gynecology 97, 324-31.

ALtimiRAS, J. \& CROSSLEY, D.A. 2ND (2000). Control of blood pressure mediated by baroreflex changes of heart rate in the chicken embryo (Gallus gallus). American Journal of Physiology, Regulatory Integrative and Comparative Physiology 278, R980-986.

BARClAY, A. E., FrANKLIN, K. J. \& PRichaRD, M. M. L. (1944). The foetal circulation and cardiovascular system and the changes that they undergo at birth. Oxford, Blackwell Scientific Publications.

Bartelds, B., van Bel, F., Teitel, D. F. \& Rudolph, A. M. (1993). Carotid, not aortic, chemoreceptors mediate the fetal cardiovascular response to acute hypoxemia in lambs. Pediatric Research 34, 51-5.

Behrman, R. E., lees, M. H., Peterson, E. N., De lannoy, C. W. \& Seeds, A. E. (1970). Distribution of the circulation in the normal and asphyxiated fetal primate. American Journal of Obstetrics and Gynecology 108, 956-69.

Bennet, L., Quaedackers, J. S., Gunn, A. J., Rossenrode, S. \& Heineman, E. (2000). The effect of asphyxia on superior mesenteric artery blood flow in the premature sheep fetus. Journal of Pediatric Surgery 35, 34-40.

Bkaily, G., Jacques, D., Sculptoreanu, A., Yamamoto, T., Carrier, D., Vigneault, D. \& SPERELAKIS, N. (1991). Apamin, a highly potent blocker of the TTX-and Mn2(+)-insensitive fast transient $\mathrm{Na}+$ current in young embryonic heart. Journal of Molecular and Cellular Cardiology 23, 25-39.

BLAIR, E. \& STANLEY, F. J. (1988). Intrapartum asphyxia: a rare cause of cerebral palsy. Journal of Pediatrics 112, 515-9.

Block, B. S., Schlafer, D. H., Wentworth, R. A., Kreitzer, L. A. \& Nathanielsz, P. W. (1990). Regional blood flow distribution in fetal sheep with intrauterine growth retardation produced by decreased umbilical placental perfusion. Joumal of Developmental Physiology 13, 81-5.

BODDY, K., DAWES, G. S., FISHER, R., PINTER, S. \& ROBINSON, J. S. (1974a). Foetal respiratory movements, electrocortical and cardiovascular responses to hypoxaemia and hypercapnia in sheep. Joumal of Physiology (London) 243, 599-618. 
BODDY, K., JONES, C. T., MANTELL, C., RATCLIFFE, J. G. \& RoBinSON, J. S. (1974b). Changes in plasma ACTH and corticosteroid of the maternal and fetal sheep during hypoxia. Endocrinology 94, 588-91.

BOUCEK, R. J. \& BOURNE, B. B. (1962). Catecholamines of the allantoic fluid in the developing chick embryo. Nature 193, 1181-1182.

BRACE, R. A. \& BRITIINGHAM, D. S. (1986). Fetal vascular pressure and heart rate responses to nonlabor uterine contractions. American Joumal of Physiology, Regulatory Integrative and Comparative Physiology 251, R409-16.

BRAEMS, G. \& JENSEN, A. (1991). Hypoxia reduces oxygen consumption of fetal skeletal muscle cells in monolayer culture. Joumal of Developmental Physiology 16, 209-15.

Buescher, U., HertwiG, K., Wolf, C. \& Dudenhausen, J. W. (1998). Erythropoietin in amniotic fluid as a marker of chronic fetal hypoxia. International Journal of Gynaecology and Obstetrics 60, 257-63.

Burt, D. W., Bruley, C., Dunn, I. C., Jones, C. T., RAMAge, A., LAW, A. S., MORRICE, D. R., PATON, I. R., SMith, J., Windsor, D., SAzANOV, A., Fries, R. \& WADDington, D. (1999). The dynamics of chromosome evolution in birds and mammals. Nature 402, 411-3.

CHEUng, C. Y. (1990). Fetal adrenal medulla catecholamine response to hypoxia-direct and neural components. American Journal of Physiology, Regulatory Integrative and Comparative Physiology 258, R1340-6.

Clark, E. B., Hu, N., Dummett, J. L., Vandekieft, G. K., Olson, C. \& TOMANeK, R. (1986). Ventricular function and morphology in chick embryo from stages 18 to 29. American Journal of Physiology, Heart and Circulatory Physiology 250, H407-13.

CLARK, E. B. (1989). Growth, morphogenesis and function: the dynamics of cardiac development. In Fetal, neonatal and infant heart disease., ed. Moller, J. H., Neal, W. \& Lock, J., pp.1-17. Appleton-Century-Crofts, New York.

COHEN, W. R., PIASECKI, G. J. \& JACKSON, B. T. (1982). Plasma catecholamines during hypoxemia in fetal lamb. American Joumal of Physiology, Regulatory Integrative and Comparative Physiology 243, R520-5.

COHN, H. E., SACKS, E. J., HeYMAnN, M. A. \& RudolPh, A. M. (1974). Cardiovascular responses to hypoxemia and acidemia in fetal lambs. American Joumal of Obstetrics and Gynecology 120, 817-24.

COMLINE, R. S. \& SILVER, M. (1961). The release of adrenaline and noradrenaline from the adrenal glands of the foetal sheep. Journal of Physiology (London) 156, 424-444.

COMLINE, R. S., SILVER, I. A. \& SIIVER, M. (1965). Factors responsible for the stimulation of the adrenal medulla during asphyxia in the foetal lamb. Journal of Physiology (London) 178, 211 238.

Cornfield, D. N., Stevens, T., MCMurtry, I. F., ABman, S. H. \& Rooman, D. M. (1994). Acute hypoxia causes membrane depolarization and calcium influx in fetal pulmonary artery smooth 
muscle cells. American Joumal of Physiology, Lung Cellular and Molecular Physiology 266, L469-75.

Crossley, D., 2ND \& ALtimiras, J. (2000). Ontogeny of cholinergic and adrenergic cardiovascular regulation in the domestic chicken (Gallus gallus). American Joumal of Physiology, Regulatory Integrative and Comparative Physiology 279, R1091-8.

CuLlis, W. C. \& LuCAS, C. L. T. (1936). Action of acetylcholine on the aneural chick heart. Joumal of Physiology (London) 86, 53P-55P.

DALTON, K. J., DAWES, G. S. \& PATRICK, J. E. (1977). Diurnal, respiratory, and other ihythms of fetal heart rate in lambs. American Journal of Obstetrics and Gynecology 127, 414-24.

DAWSON, A. B. (1953). Histochemical evidence of early differentiation of the suprarenal gland of the chick. Journal of Morphology 92, 579-595.

EPPLE, A., GiLL, T. S. \& NiB8ıO, B. (1992). The avian allantois: a depot for stress-released catecholamines. General Comparitive Endocrinology 85, 462-76.

FABER, J. J., GREEN, T. J. \& THORnBURG, K. L. (1974). Embryonic stroke volume and cardiac output in the chick. Developmental Biology 41, 14-21.

FEIGL, E. O. (1998). Neural control of coronary blood flow. Journal of Vascular Research 35 , 85-92.

Fletcher, A. J., Edwards, C. M., Gardner, D. S., Fowden, A. L. \& Giussani, D. A. (2000a). Neuropeptide $Y$ in the sheep fetus: effects of acute hypoxemia and dexamethasone during late gestation. Endocrinology 141, 3976-82.

Fletcher, A. J. W., GardneR, D. S., Fowden, A. L. \& Giussani, D. A. (2000b). Ontogenic changes in the fetal cardiovascular responses to acute hypoxaemia in sheep during late gestation. Journal of Physiology (London) 523.P, 179P.

Fletcher, A. J. W., Gardner, D. S., Fowden, A. L. \& Giussani, D. A. (2000c). Ontogeny of pituitary-adrenal responses to acute hypoxaemia in fetal sheep. 4th International Workshop on Developmental Endocrinology, Cambridge, UK.

Gardner, D.S., Fletcher, A.J., Fowden, A.L., Giussani, D.A. (2001). A novel method for controlled and reversible long term compression of the umbilical cord in fetal sheep. Journal of Physiology (London) 535, 217-29.

GIRARD, H. (1967). [Action of noradrenaline and adrenaline on the embryonic circulation of chickens]. Comptes rendus hebdomadaires des seances de l'Academie des sciences. Serie D: Sciences naturelles. 265, 2023-6.

GIRARD, H. (1973). Adrenergic sensitivity of circulation in the chick embryo. American Journal of Physiology 224, 461-9.

Giussani, D. A., Spencer, J. A., MoOre, P. J., Bennet, L. \& Hanson, M. A. (1993). Afferent and efferent components of the cardiovascular reflex responses to acute hypoxia in term fetal sheep. Journal of Physiology (London) 461, 431-49. 
Giussani, D. A., McGarrigle, H. H., Moore, P. J., Bennet, L., Spencer, J. A. \& hanson, M. A. (1994a). Carotid sinus nerve section and the increase in plasma cortisol during acute hypoxia in fetal sheep. Journal of Physiology (London) 477, 75-80.

Giussani, D. A., McGarrigle, H. H., Spencer, J. A., Moore, P. J., Bennet, L. \& hanson, M. A. (1994b). Effect of carotid denervation on plasma vasopressin levels during acute hypoxia in the late-gestation sheep fetus. Journal of Physiology (London) 477, 81-7.

GIUSSANI, D. A., SPEnCER, J. A. D. \& HANSON, M. A. (1994c). Fetal cardiovascular reflex responses to hypoxaemia. Fetal and Maternal Medicine Review 6, 17-37.

Giussani, D. A., Riquelme, R. A., moraga, F. A., mcGarrigle, H. H., Gaete, C. R., SANHUEZA, E. M., HANSON, M. A. \& LLANOS, A. J. (1996). Chemoreflex and endocrine components of cardiovascular responses to acute hypoxemia in the llama fetus. American Journal of Physiology, Regulatory Integrative and Comparative Physiology 271, R73-83.

Giussani, D.A., Unno, N., Jenkins, S.L., Wentworth, R.A., Derks, J.B., COLlins, J.H. \& NATHANIELsz, P.W. (1997). Dynamics of cardiovascular responses to repeated partial umbilical cord compression in late-gestation sheep fetus. American Journal of Physiology, Heart and Circulatory Physiology 273, H2351-60.

Giussani, D. A., Riquelme, R. A., Sanhueza, E. M., hanson, M. A., Blanco, C. E. \& llanos, A. J. (1999). Adrenergic and vasopressinergic contributions to the cardiovascular response to acute hypoxaemia in the llama fetus. Joumal of Physiology (London) 515, 233-41.

GLENNY, R. W., BERNARD, S. \& BRINKLEY, M. (1993). Validation of fluorescent-labeled microspheres for measurement of regional organ perfusion. Journal of Applied Physiology 74 , 2585-97.

Green, L. R., Bennet, L. \& Hanson, M. A. (1996). The role of nitric oxide synthesis in cardiovascular responses to acute hypoxia in the late gestation sheep fetus. Journal of Physiology (London) 497, 271-7.

Green, L. R., McGarrigle, H. H., Bennet, L. \& Hanson, M. A. (1998). Angiotensin II and cardiovascular chemoreflex responses to acute hypoxia in late gestation fetal sheep. Journal of Physiology (London) 507, 857-67.

GREEN, L. R. (2001). Programming of endocrine mechanisms of cardiovascular control and growth. Journal of the Society for Gynecologic Investigation 8, 57-68.

HANSON, M. A. (1988). The importance of baro- and chemoreflexes in the control of the fetal cardiovascular system. Joumal of Developmental Physiology 10, 491-511.

Heymann, M. A., Payne, B. D., Hoffman, J. I. \& Rudolph, A. M. (1977). Blood flow measurements with radionuclide-labeled particles. Progress in Cardiovascular Diseases 20. 55-79.

Hinson, J. P., CAMERon, L. A., Purbrick, A. \& KAPAS, S. (1994). The role of neuropeptides in the regulation of adrenal vascular tone: effects of vasoactive intestinal polypeptide, substance $P$, neuropeptide $Y$, neurotensin, Met-enkephalin, and Leu-enkephalin on perfusion medium flow rate in the intact perfused rat adrenal. Regulatory Peptides 51, 55-61. 
IKEnOUE, T., MARTin, C. B., MURATA, Y., ETtInger, B. B. \& LU, P. S. (1981). Effect of acute hypoxemia and respiratory acidosis on the fetal heart rate in monkeys. American Journal of Obstetrics and Gynecology 141, 797-806.

ITSKOVITZ, J. \& RUDOLPH, A. M. (1982). Denervation of arterial chemoreceptors and baroreceptors in fetal lambs in utero. American Joumal of Physiology, Heart and Circulatory Physiology 242, H916-20.

ITSKOVITZ, J., GOETZMAN, B. W. \& RUDOLPH, A. M. (1982). Effects of hemorthage on umbilical venous return and oxygen delivery in fetal lambs. American Joumal of Physiology, Heart and Circulatory Physiology 242, H543-8.

ITSKOVITZ, J., LAGAMMA, E. F. \& RUDOLPH, A. M. (1983). The effect of reducing umbilical blood flow on fetal oxygenation. American Journal of Obstetrics and Gynecology 145, 813-8.

ITSKOVITZ, J., LAGAMMA, E. F. \& RUDOLPH, A. M. (1987). Effects of cord compression on fetal blood flow distribution and $\mathrm{O} 2$ delivery. American Joumal of Physiology, Heart and Circulatory Physiology 252, H100-9.

IWAMOTO, H. S., Rudolph, A. M., Kell, L. C. \& HeYMann, M. A. (1979). Hemodynamic responses of the sheep fetus to vasopressin infusion. Circulation Research 44, 430-6.

IWAMOto, H. S., RudolPh, A. M., MiRKIN, B. L. \& KEIL, L. C. (1983). Circulatory and humoral responses of sympathectomized fetal sheep to hypoxemia. American Journal of Physiology, Heart and Circulatory Physiology 245, H767-72.

IWAMOto, H. S., Kaufman, T., KEIL, L. C. \& Rudolph, A. M. (1989). Responses to acute hypoxemia in fetal sheep at 0.6-0.7 gestation. American Journal of Physiology, Heart and Circulatory Physiology 256, H613-20.

JACKSON, B. T., PIASECKI, G. J. \& NOVY, M. J. (1987). Fetal responses to altered maternal oxygenation in rhesus monkey. American Journal of Physiology, Regulatory Integrative and Comparative Physiology 252, R94-101.

JelineK, J. \& Jensen, A. (1991). Catecholamine concentrations in plasma and organs of the fetal guinea pig during normoxemia, hypoxemia, and asphyxia. Journal of Developmental Physiology 15, 145-52.

Jensen, A., Hohmann, M. \& Kunzel, W. (1987). Dynamic changes in organ blood flow and oxygen consumption during acute asphyxia in fetal sheep. Journal of Developmental Physiology 9, 543-59.

JENSEN, A. \& BERGER, R. (1991). Fetal circulatory responses to oxygen lack. Journal of Developmental Physiology 16, 181-207.

Jensen, A., Roman, C. \& Rudolph, A. M. (1991). Effects of reducing uterine blood flow on fetal blood flow distribution and oxygen delivery. Journal of Developmental Physiology 15 , 309-23.

JONES, C. T. (1977). The development of some metabolic responses to hypoxia in the foetal sheep. Joumal of Physiology (London) 265, 743-62. 
JONES, C. T., BODDY, K., RoBinson, J. S. \& RATCLIFFE, J. G. (1977). Developmental changes in the responses of the adrenal glands of foetal sheep to endogenous adrenocorticotrophin, as indicated by hormone responses to hypoxaemia. Journal of Endocrinology 72, 279-92.

JONES, C. T. \& RITCHIE, J. W. (1978a). The cardiovascular effects of circulating catecholamines in fetal sheep. Journal of Physiology (London) 285, 381-93.

JONES, C. T. \& RITCHIE, J. W. (1978b). The metabolic and endocrine effects of circulating catecholamines in fetal sheep. Journal of Physiology (London) 285, 395-408.

KIRBY, M. L., MCKEnZIE, J. W. \& WEIDMAN, T. A. (1980). Developing innervation of the chick heart: a histofluorescence and light microscopic study of sympthetic innervation. The Anatomical Record 196, 333-40.

KURTH, C. D. \& WAGERLE, L. C. (1992). Cerebrovascular reactivity to adenosine analogues in 0.6-0.7 gestation and near-term fetal sheep. American Journal of Physiology, Heart and Circulatory Physiology 262, H1338-42.

le noble, F. A., Schreurs, N. H., van Straaten, H. W., SlaAf, D. W., Smits, J. F., Rogg, H. \& STRUIJKER BOUDIER, H. A. (1993). Evidence for a novel angiotensin II receptor involved in angiogenesis in chick embryo chorioallantoic membrane. American Journal of Physiology, Regulatory Integrative and Comparative Physiology 264, R460-5.

LEWIS, A. B., HEYMANN, M. A. \& RUDOLPH, A. M. (1976). Gestational changes in pulmonary vascular responses in fetal lambs in utero. Circulation Research 39, 536-41.

llanos, A. J., Riquelme, R. A., Moraga, F. A., Cabello, G. \& Parer, J. T. (1995). Cardiovascular responses to graded degrees of hypoxaemia in the llama fetus. Reproduction, Fertility and Development 7, 549-52.

MANN, L. I. (1986). Pregnancy events and brain damage. American Journal of Obstetrics and Gynecology 155, 6-9.

MC CARTY, L. P. \& SIDEMAN, F. E. (1960). Measurement of the inotropic effects of drugs on the innervated and noninnervated embryonic chick heart. The Journal of Pharmacology and Experimental Therapeutics 129, 315-321.

MeschiA, G., Cotter, J. R., BReAthnach, C. S. \& BARRON, D. H. (1965). The diffusibility of oxygen across the sheep placenta. Quarterly Journal of Experimental Physiology and Cognate Medical Sciences 50, 466-80.

Newman, J. P., Peebles, D. M., harding, S. R. G., Springett, R. \& Hanson, M. A. (2000). Hemodynamic and metabolic responses to moderate asphyxia in brain and skeletal muscle of late-gestation fetal sheep. Joumal of Applied Physiology 88, 82-90.

Newman, J. P., Peebles, D. M. \& Hanson, M. A. (2001). Adenosine produces changes in cerebral hemodynamics and metabolism as assessed by near-infrared spectroscopy in lategestation fetal sheep in utero. Pediatric Research 50, 217-21. 
OKamura, K., Watanabe, T., Tanigawara, S., Shintaku, Y., Endo, H., IWamoto, M., MUROTSUKI, J. \& YAIMA, A. (1990). Biochemical evaluation of fetus with hypoxia caused by severe preeclampsia using cordocentesis. Journal of Perinatal Medicine 18, 441-7.

PAdBuRY, J. F., Ludlow, J. K., ERVIN, M. G., JACOBS, H. C. \& HUMmE, J. A. (1987). Thresholds for physiological effects of plasma catecholamines in fetal sheep. American Joumal of Physiology, Endocrinology and Metabloism 252, E530-7.

PAPPANO, A. J. (1977). Ontogenetic development of autonomic neuroeffector transmission and transmitter reactivity in embryonic and fetal hearts. Pharmacological Reviews 29, 3-33.

Parer, J. T., Dijkstra, H. R., VRedebregt, P. P., HarRis, J. L., Krueger, T. R. \& Reuss, M. L. (1980). Increased fetal heart rate variability with acute hypoxia in chronically instrumented sheep. European Joumal of Obstetrics, Gynecology and Reproductive Biology 10, 393-9.

Peeters, L. L., Sheldon, R. E., Jones, M. D., Makowski, E. L. \& MeschiA, G. (1979). Blood flow to fetal organs as a function of arterial oxygen content. American Joumal of Obstetrics and Gynecology 135, 637-46.

Perez, R., Espinoza, M., Riquelme, R., Parer, J. T. \& Llanos, A. J. (1989). Arginine vasopressin mediates cardiovascular responses to hypoxemia in fetal sheep. American Journal of Physiology Regulatory Integrative and Comparative Physiology 256, R1011-8.

PSCHIRRER, E. R. \& YEOMANS, E. R. (2000). Does asphyxia cause cerebral palsy? Seminars in Perinatology 24, 215-20.

Reller, M. D., Burson, M. A., LOHR, J. L., MORTON, M. J. \& ThORnBuRg, K. L. (1995). Nitric oxide is an important determinant of coronary flow at rest and during hypoxemic stress in fetal lambs. American Journal of Physiology, Heart and Circulatory Physiology 269, H2074-81.

RICHARDSON, B. S., PATRICK, J. E. \& ABDULJABBAR, H. (1985). Cerebral oxidative metabolism in the fetal lamb: relationship to electrocortical state. American Journal of Obstetrics and Gynecology 153, 426-31.

RICKENBACHER, J. \& MULLER, E. (1979). The development of cholinergic ganglia in the chick embryo heart. Anatomy and Embryology (Berlin) 155, 253-8.

Riquelme, R.A., llanos, J.A., McGarrigle, H.H.G., Sanheza, E.M., Hanson, M.A. \& GIUSSANI, D.A. (1998). Chemoreflex contribution to adrenocortical function during acute hypoxemia in the llama fetus at 0.6 - 0.7 of gestation. Endocrinology 139 2564-2570.

Robillard, J. E., Weitzman, R. E., BURMEISTER, L. \& SMith, F. G. (1981). Developmental aspects of the renal response to hypoxemia in the lamb fetus. Circulation Research 48, 12838.

Robinson, J. S., Kingston, E. J., JONES, C. T. \& THORBURN, G. D. (1979). Studies on experimental growth retardation in sheep. The effect of removal of a endometrial caruncles on fetal size and metabolism. Journal of Developmental Physiology 1, 379-98.

Romanoff, A. L. (1960). The Avian Embryo. Structural and Functional Development. New York, The Macmillan Company. 
Rudolph, A. M. \& HeYMANN, M. A. (1967). The circulation of the fetus in utero. Methods for studying distribution of blood flow, cardiac output and organ blood flow. Circulation Research 21, 163-84.

RURAK, D. W. (1978). Plasma vasopressin levels during hypoxaemia and the cardiovascular effects of exogenous vasopressin in foetal and adult sheep. Journal of Physiology (London) 277, 341-57.

RYchiov, G. Y., AdAMS, M. B., MCMILLeN, I. C. \& RoBeRTS, M. L. (1998). Oxygen-sensing mechanisms are present in the chromaffin cells of the sheep adrenal medulla before birth. Journal of Physiology (London) 509, 887-93.

Salafia, C. M., Ernst, L. M., Pezzullo, J. C., Wolf, E. J., Rosenkrantz, T. S. \& Vintzileos, A. M. (1995). The very low birthweight infant: maternal complications leading to preterm birth, placental lesions, and intrauterine growth. American Joumal of Perinatology 12, 106-10.

Sanchez montesinos, I., Merida Velasco, J. A., Espin Ferra, J. \& Scopsi, L. (1996). Development of the sympathoadrenal system in the chick embryo: an immunocytochemical study with antibodies to pan-neuroendocrine markers, catecholamine-synthesizing enzymes, proprotein-processing enzymes, and neuropeptides. The Anatomical Record 245, 94-101.

Schmid, M., Nanda, I., Gutteneach, M., Steinlein, C., Hoehn, M., Schartl, M., HaAf, T. Weigend, S., Fries, R., Buerstedde, J. M., Wimmers, K., Burt, D. W., SMith, J., A'HARA, S., LaW, A., Griffin, D. K., Bumstead, N., Kaufman, J., ThOMson, P. A., Burke, T., Groenen, M. A., Crooijmans, R. P., Vignal, A., Fillon, V., Morisson, M., Pitel, F., Tixier Boichard, M., ladjali Mohammedi, K., Hillel, J., Maki Tanila, A., Cheng, H. H., Delany, M. E., Burnside, J. \& MizUno, S. (2000). First report on chicken genes and chromosomes 2000. Cytogenetics and Cell Genetics 90, 169-218.

SChomig, A., LUTH, B., Dietz, R. \& GRoss, F. (1976). Changes in vascular smooth muscle sensitivity to vasoconstrictor agents induced by corticosteroids, adrenalectomy and differing salt intake in rats. Clinical Science and Molecular Medicine. Supplement 3, 61s-63s.

TABer, L. A., Keller, B. B. \& ClaRk, E. B. (1992). Cardiac mechanics in the stage-16 chick embryo. Joumal of Biomechanical Engineering 114, 427-34.

TANGALAKIS, K., LUMBers, E. R., MORITZ, K. M., TOWSTOlesS, M. K. \& WintouR, E. M. (1992). Effect of cortisol on blood pressure and vascular reactivity in the ovine fetus. Experimental Physiology 77, 709-17.

tazawa, H., hiraguchi, T., Kuroda, O., Tullett, S. G. \& Deeming, D. C. (1991). Embryonic heart rate during development of domesticated birds. Physiological Zoology 64, 1002-1022.

TAzawa, H. \& Whittow, G. C. (2000). Incubation Physiology. In Sturkie's Avian Physiology, ed. Whittow, G. C., pp.617-634. Academic Press, San Diego, U.S.

ThORBURN, G. D. (1992). The placenta, PGE2 and parturition. Early Human Development 29. 63-73. 
TRUWIT, C. L., BARKOVICH, A. J., KOCH, T. K. \& FERRIERO, D. M. (1992). Cerebral palsy: MR findings in 40 patients. AJNR American Journal of Neuroradiology 13, 67-78.

VAN BEL, F., SOLA, A., ROMAN, C. \& RUDOLPH, A. M. (1995). Role of nitric oxide in the regulation of the cerebral circulation in the lamb fetus during normoxemia and hypoxemia. Biology of the Neonate 68, 200-10.

VAN DER HOORN, F. A., BOOMSMA, F., MAN IN 'T VEld, A. J. \& SCHAleKAMP, M. A. (1989). Determination of catecholamines in human plasma by high-performance liquid chromatography: comparison between a new method with fluorescence detection and an established method with electrochemical detection. Joumal of Chromatography 487, 17-28.

van Golde, J., Mulder, T., v StraAten, H. \& Blanco, C. E. (1996). The chorioallantoic artery blood flow of the chick embryo from stage 34 to 43 . Pediatric Research 40, 867-71.

VAN Golde, J., MuldeR, T. \& BLANCO, C. E. (1997). Changes in mean chorioallantoic artery blood flow and heart rate produced by hypoxia in the developing chick embryo. Pediatric Research 42, 293-8.

VAN Golde, J. C., Mulder, A. L. M. \& Blanco, C. E. (1998). Parasympathetic contribution to the cardiovascular response to acute hypoxia in the chick embryo. Pediatric Research 43. $56 \mathrm{~A}$.

van Oosterhout, M. F., Willigers, H. M., Reneman, R. S. \& Prinzen, F. W. (1995). Fluorescent microspheres to measure organ perfusion: validation of a simplified sample processing technique. Am Journal of Physiology, Heart and Circulatory Physiology 269, H725-33.

Walker, A. M., Cannata, J. P., Dowling, M. H., Ritchie, B. C. \& Maloney, J. E. (1979). Agedependent pattern of autonomic heart rate control during hypoxia in fetal and newborn lambs. Biology of the Neonate 35, 198-208.

WASSERMAN, G. F. \& BERnARD, E. A. (1970). Adrenaline content of the chick embryo adrenal gland during development. Acta Physiologica Latino Americana 20, 171-173.

Widmark, C., Hokegard, K. H., Lagercrantz, H., Lilja, H. \& Rosen, K. G. (1989). Electrocardiographic waveform changes and catecholamine responses during acute hypoxia in the immature and mature fetal lamb. American Journal of Obstetrics and Gynecology 160. 1245-50.

Woudstra, B. R., KIM, C., Aarnoudse, J. G. \& NAthanielsz, P. W. (1991). Myometrial contracture-related increases in plasma adrenocorticotropin in fetal sheep in the last third of gestation are abolished by maintaining fetal normoxemia. Endocrinology 129, 1709-13.

YAFFE, H., PARER, J. T., BLOCK, B. S. \& LLANOS, A. J. (1987). Cardiorespiratory responses to graded reductions of uterine blood flow in the sheep fetus. Journal of Developmental Physiology 9, 325-36.

Yoneyama, Y., SAWA, R., Suzukı, S., Shin, S., Power, G. G. \& ARAKI, T. (1996). The relationship between uterine artery Doppler velocimetry and umbilical venous adenosine 


\section{6| ChAPTER 1}

levels in pregnancies complicated by preeclampsia. American Joumal of Obstetrics and Gynecology 174, 267-71. 
CHAPTER 2

\section{Cardiac Output Distribution in the Chick Embryo}

\section{from stage 36 to 45}

Twan ALM Mulder', Jolanda C van Golde', Frits W Prinzen², Carlos E Blanco'

1 Department of Pediatrics, University Hospital Maastricht, The Netherlands

2 Department of Physiology, Maastricht University, The Netherlands 
$48 \mid$ CHAPTER 2

\section{ABSTRACT}

Objective: The distribution of cardiac output to different organs is well described in the mammalian fetus. Chick embryos are not often used in perinatal cardiovascular research and therefore, it is not known whether they can serve as an animal model for this purpose. In this study we documented cardiac output distribution in chick embryos at increasing incubation time.

Methods: Fertilized eggs from day 10 to 19 with an incubation time of 21 days were studied in three increasing incubation time groups (10-13 days, 14-16 days and 17-19 days). For the experiment, the egg was placed in a holder in an incubator. The egg was opened at the air cell and a small vein of the chorioallantoic membrane was catheterized. 20,000 Fluorescent 15 micron microspheres in $0.2 \mathrm{ml}$ were injected. After 5 minutes, the embryo was sacrificed and the different organs were dissected and digested for microsphere isolation and subsequent fluorescence analysis.

Results: The chorioallantoic membrane, which is the placenta equivalent of the chick embryo, received a relatively large fraction of the combined cardiac output, $52.08 \%$ (Interquartile Range $44.76-57.42 \%$ ) on day $10-13$ and $40.95 \%$ (IQR $30.60-57.84 \%$ ) on day $17-19$. Relatively small fractions were distributed to the heart $2.03 \%$ (IQR $1.46-3.04 \%$ ) on day $10-13$ and $3.18 \%$ (IQR $2.72-4.67 \%$ ) on day $17-19$ and to the brain $3.20 \%$ (IQR $2.59-4.39 \%$ ) on day $10-13$ and $5.02 \%$ (IQR $3.45-6.85 \%$ ) on day $17-19$. As incubation time advanced, the fraction of the combined cardiac output to the chorioallantoic membrane and yolk-sac decreased significantly in favor of the heart and brain.

Conclusion: This distribution shows great similarity to the one found in the mammalian fetus. The chick embryo is an attractive model for perinatal cardiovascular research. 


\section{INTRODUCTION}

A fetus needs large amounts of oxygen and nutrients for development and growth. The distribution of oxygen and nutrients to the fetal organs is dependent on gas exchange area, transport vehicle and cardiac output. In the mammalian fetus, a large fraction of the cardiac output is directed to the placenta, where gas-exchange and nutrients are provided. The distribution of fetal cardiac output (CO) has been studied in sheep (Rudolph \& Heymann, 1970) (Jensen et al. 1991) primate (Behrman et al. 1970) and llama fetuses (Llanos et al. 1995) using radioactive microspheres, both under physiological conditions and abnormal events associated with birth (e.g. asphyxia due to umbilical cord occlusion or hypoxia) (Iwamoto et al. 1989). The early chick embryo in particular is a well known animal model for cardiovascular research with regard to cardiac development (Clark, 1989), angiogenesis (Le Noble et al. 1993), cardiovascular pharmacology and toxicology (Bkaily et al. 1991) (Bkaily, 1992) and cardiovascular mechanics (Taber, et al. 1992). With regard to cardiovascular responses in the late chick embryo (e.g. cardiovascular responses to perinatal events) not much is known.

The chick embryo is not a mammalian and the main difference is the absence of placenta. In the chick embryo, gas-exchange takes place in the chorioallantoic membrane (CAM). This is a well-vascularized membrane attached to the shell of the egg. This membrane, which is in direct contact with the environmental air through micropores in the shell, is the vehicle for gasexchange. Therefore, the CAM can be seen as a placenta-equivalent (Metcalfe \& Stock, 1993). The embryonic circulation in the CAM greatly resembles the umbilical cord circulation in the mammalian fetus (Romanoff, 1960). Furthermore, the fetal shunts over ductus venosus, foramen ovale and ductus arteriosus are also present in the chick embryo. The distribution of the $\mathrm{CO}$ in the chick embryo was summarily documented by Rahn, Matalon and Sotherland using radio-active microspheres (Rahn et al. 1985). They reported on the distribution for CAM, yolk-sac and total embryo in 18 chick embryos from day 17-19 incubation time.

For several years now, fluorescent microspheres have been used to determine organ blood flow and $\mathrm{CO}$ distribution as an alternative to radioactive microspheres (Prinzen \& Glenny, 1994). As far as we know, this method has not been used in chick embryos. In this study we used fluorescent microspheres, injected in a chorioallantoic vein, to determine the $\mathrm{CO}$ distribution in the chick embryo.

The aim of this study was: a) to test the possibility to determine CO distribution in the chick embryo using fluorescent microspheres; b) to examine the changes in $\mathrm{CO}$ distribution in the chick embryo during development; and c) 
$50 \mid$ CHAPTER 2

to evaluate whether the chick embryo is a suitable model for perinatal cardiovascular research.

\section{METHODS}

Fertilized eggs of White Leghorn were incubated in a commercial incubator. The eggs were rotated constantly to avoid adhesions between the embryo and its membranes (Tazawa, 1980). Incubation time until hatching for these eggs is 21 days. Since we wanted to study developmental changes we used chick embryos ranging from day 10 till day 19 of incubation time, corresponding to stage 36 to 45 according to Hamburger and Hamilton (Hamburger \& Hamilton, 1951). Three different incubation time groups were studied: $10-13$ days, $14-16$ days and 17-19 days.

\section{PREPARATION}

To determine the distribution of the $\mathrm{CO}$, a chorioallantoic vein was catheterized to inject fluorescent microspheres. Both catheterization of the chorioallantoic vein and the injecting of fluorescent microspheres were performed in a clinical infant incubator, provided with a light microscope (WILD 3M, magnification 10x). Temperature and humidity were maintained constant at $38^{\circ} \mathrm{C}$ and $60 \%$ respectively. The eggs were candled to identify the air cell and the shell was opened with an electrical saw above the level of the CAM. After opening the egg was placed in a holder under the microscope. Now the outer shell membrane was visible. By moistening it with a $\mathrm{NaCl} 0,9 \%$ solution, the vessels of the CAM became visible. Without damaging the chorioallantoic membrane vessels, the outer shell membrane was removed. A chorioallantoic vein of approximately the same diameter was identified through its bright red color and erythrocyte stream direction. The vein was lifted using sutures, opened with the hooked tip of a 30-Gauche needle and a polyethylene catheter, which was stretched by heat to a diameter of $100 \mu \mathrm{m}$, was inserted. The catheter, flushed with a heparin solution $(10 \mathrm{IU} / \mathrm{ml})$ was connected to a $1.0 \mathrm{ml}$ syringe and fixed to the eggshell with clay.

\section{PROTOCOL}

Five minutes after catheterization, 20000 fluorescent microspheres (Fluospheres ® Molecular Probes Inc., Eugene, Oregon, USA) with a diameter of $15 \mu \mathrm{m}(0.2 \mathrm{ml}$ of a 100,000 microspheres $/ \mathrm{ml} 0.05 \%$ Tween 80 solution) were injected in 1 minute. The dye used was orange. After 5 minutes, the chick embryos were decapitated and the chorioallantoic membrane, brain, heart, lungs, intestine, liver and yolk-sac were dissected. 


\section{METHOD OF MEASUREMENT}

We determined fluorescence in whole organs and in the remaining carcass. The tissues were placed in test tubes and digested in a $2 \mathrm{M}$ ethanolic$\mathrm{KOH}$ solution for 48 hours at $60^{\circ} \mathrm{C}$. The microspheres were isolated from the homogenate by repeated centrifugation, removal of the supernatant and rinsing as described by van Oosterhout (van Oosterhout et al. 1995). In the final pellet the dye was extracted by adding $3 \mathrm{ml}$ of 2-(2-ethoxyethoxy) ethylacetate and fluorescence was counted by fluorimetry using a LS-50B fluori-spectrometer (Perkin Elmer). Since during fluorimetry all samples had the same volume $(3 \mathrm{ml})$, the absolute fluorescence measured, corrected for background, expressed the fraction of $\mathrm{CO}$ that the tissue received.

\section{ANALYSIS OF DATA}

All data were processed using SPSS statistical software. Since not all data obtained were normally distributed, we found it appropriate to express the data as median with interquartile range $\left(25^{\text {th }}-75^{\text {th }}\right.$ percentile). A nonparametric sample test (Mann Whitney $U$ ) was applied to compare the CO distribution within the 3 different groups at the different incubation times. Statistical significance was defined as $P<0.05$.

\section{RESULTS}

The placement of the catheter into the chorioallantoic vein required skill and practice. The major problems encountered were: a) difficulty in inserting the catheter into the vessel lumen and b) bleeding due to damage to the vessel. Our present success rate is about $80 \%$.

We determined the $\mathrm{CO}$ distribution in a total of 72 chick embryos at different incubation times: at days 10-13 $(n=22)$, at days 14-16 $(n=24)$ and at days $17-19(n=26)$. None of the instrumented chick embryos showed pipping or hatching.

In the chick embryo, a large fraction of the CO (median range for the three groups: $41-52 \%$ ) was directed to the CAM. Relatively small fractions were directed to the heart (median range: 2.0-3.8 \%), brain (median range: 3.2-5.0\%), lungs (median range: 0.5-1.0\%), intestine (median range: 2.0-3.8 $\%$ ), and liver (median range: 1.5-3.3\%). The fraction to the yolk-sac in the 1013 days group is substantial (median $11.9 \%$ ), but decreases rapidly with increasing incubation time $(P<0.01)$. (Fig. 1).

The CO distribution to the various organs changed with increasing incubation time. The fractions to the heart, brain, intestine and carcass increased significant $(P<0.05)$ with increasing incubation time, whereas the fractions to CAM and yolk-sac decreased (Fig. 1). 


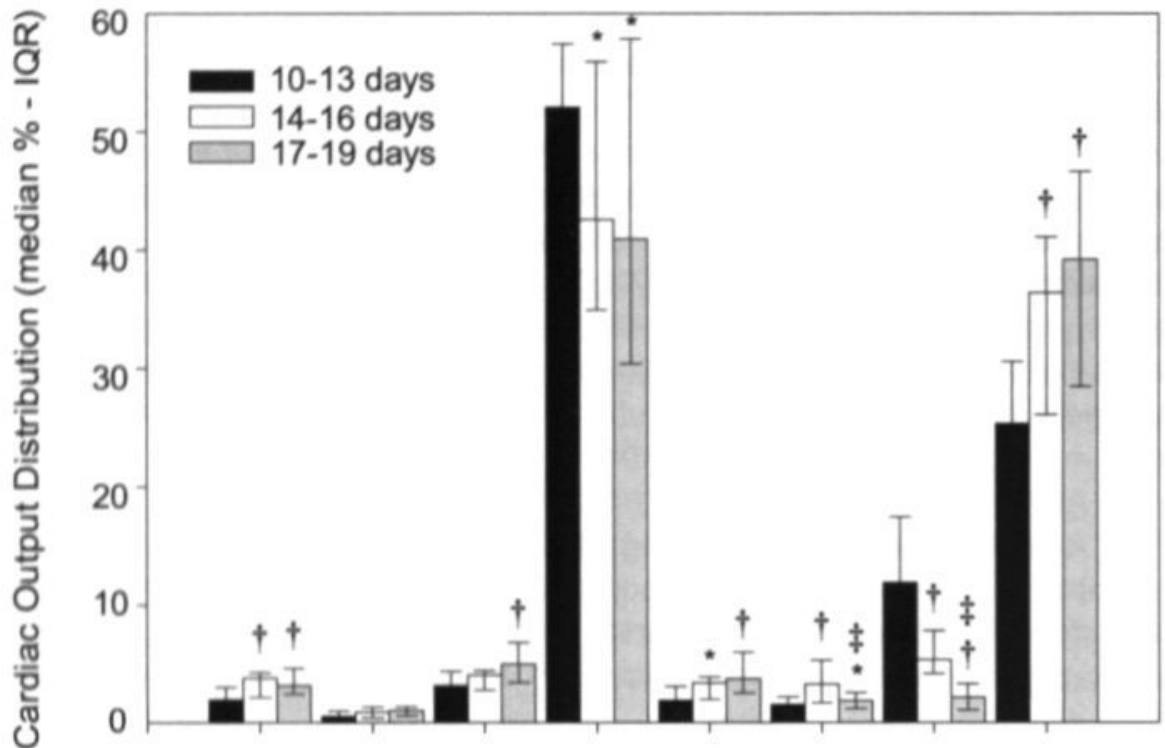

heart lungs brain CAM intestine liver yolk-sac carcass

Fig. 1: Cardiac output distribution for increasing incubation time. Bars represent the median, the range is the interquartile range $\left(25^{\text {th }}-75^{\text {th }}\right.$ percentile $) .^{*}=$ Significant change $(P<0.05)$ compared with $10-13$ days group, $\uparrow=$ Significant change $(P<0.01)$ compared with $10-13$ days group, $\ddagger=$ Significant change compared with 14-16 days group $(P<0.05)$.

\section{DISCUSSION}

In this study, we determined the CO distribution of the chick embryo in the second half of incubation time. Early in this period, there were two vascular beds that received the most important percentage of the combined CO: the CAM and the yolk-sac, both important for gas-exchange and nutrition. However, later in incubation time, these percentages although remaining important, decreased in favour of other organs and tissue.

Oxygen and carbon dioxide concentrations in the air cell of the egg change during incubation time. Oxygen concentration falls from $21 \%$ at day 4 to $12 \%$ at day 20 and carbon dioxide concentration increases from $0.6 \%$ at day 4 to $6 \%$ at day 20 (Romijn \& Roos 1938). Therefore, the opening of the egg's air cell could have had consequences on the embryonic blood gases, with a subsequent influence on the $\mathrm{CO}$ distribution. In a previous study we have shown that $\mathrm{PO}_{2}, \mathrm{PcO}_{2}$ and $\mathrm{pH}$ did not significantly change after the opening of the air cell (van Golde et al. 1996). 
Rudolph and Heymann, (1967) introduced the radioactive microsphere technique for the study of circulation in the fetal lamb (Rudolph \& Heymann, 1967). This technique is now regarded as gold standard for determination of the $\mathrm{CO}, \mathrm{CO}$ distribution and organ blood flow. Recently, the fluorescent microspheres technique was introduced and validated, using the same principles as Rudolph and Heymann. The accuracy is similar to that of the radio-active microsphere method (Van Oosterhout et al. 1995) (Glenny et al. 1993). This method presents the following advantages: it does not require radioactivity and when being used in conjunction with histological techniques, offers the possibility of examining regional distributions within organs. At present, microsphere isolation and analysis are relatively time consuming (Van Oosterhout et al. 1995), but new techniques will be available in the near future. In our study, we chose to use fluorescent microspheres to determine $\mathrm{CO}$ distribution and we can now report that it is suitable for use in chick embryos; injections are possible thanks to downsizing the catheter and isolating of the microspheres and extraction of the dye are possible from chick embryo tissues.

Due to difficult access to the chick embryo and its limited blood volume, it was impossible to take a reference blood sample simultaneously with injection of the microspheres. It was also impossible to place a flowprobe and catheterize the same embryo simultaneously. Therefore, we cannot present the absolute organ flow values of individual animals. In a previous study we measured absolute blood flow to the CAM in chick embryos from day 10 to day 16 of incubation using a Transonic flowprobe (van Golde et al. 1996), and since from the present data we know the fraction of the CO to the CAM, we can estimate the mean combined cardiac output of the chick embryo from day 10-16. We calculated a mean combined $\mathrm{CO}$ of $472 \mathrm{ml} / \mathrm{kg}$.min. (range 330 582 ), which did not change with advancing incubation time. This is similar to the late gestation mammalian fetus (Jensen et al. 1991).

The distribution of the $\mathrm{CO}$ in the chick embryo (16-19 days group) resembles the CO distribution in the near term sheep fetus (Jensen et al. 1991). In the chick embryo the fractions of the cardiac output directed to the heart, brain, intestine and carcass are similar to the fractions found in the sheep fetus (heart: 3 vs. $3 \%$, brain: 5 vs. $3 \%$, intestine: 6 vs. $6 \%$ and carcass: 39 vs. $30 \%$ ). Also the fraction to the CAM $(41 \%)$ is similar to the fraction to the placenta $(44 \%)$ in the sheep fetus. The fractions to the lungs differ. In the chick embryo the lungs receive $1.0 \%$ of the $\mathrm{CO}$ while in the sheep fetus the lungs receive $11.81 \%$. We had expected to observe a higher fraction of the $\mathrm{CO}$ to the lungs in the older embryos since internal pipping and air breathing in the chick embryo starts at around day 20 . However, when opening the air cell in our experiments no internal pipping was seen. 
With increasing incubation time, we observed a change in $\mathrm{CO}$ distribution. The fractions to the heart, brain, liver, intestine and carcass increased significantly $(P<0.05)$. This could be explained by a) a relative lower resistance of the vascular beds in these organs. A lower vascular resistance can be the result of organ growth with subsequent growth of the vascular bed (Rudolph \& Heymann, 1970); b) the result of an increase in metabolic activity of these organs, demanding a greater fraction of $\mathrm{CO}$ controlled by local vaso-active substances producing vasodilatation (Rudolph \& Heymann, 1970), and c) an increase in vascular resistance in the vascular bed of the CAM and yolk-sac.

Recently $\mathrm{Hu}$ observed in early chick embryos that the $\mathrm{CO}$ distribution between the embryo and the extra embryonic vascular bed changed from 18.7 versus $81.3 \%$ at stage 18 to 34.2 versus $65.8 \%$ at stage 24 ( $\mathrm{Hu}$ et al. 1996). Our data showed a further shift from 36 versus $64 \%$ at days $10-13$ (stages 36 39) to 57 versus $43 \%$ at days $17-19$ of incubation (stages $43-45$ ). This indicates that during development of the chick embryo the fraction of the $\mathrm{CO}$ directed to the embryo is continuously increasing. These developmental changes were also documented in fetal sheep by Rudolph and Heymann (Rudolph \& Heymann, 1970). They demonstrated in fetal lambs from 0.6 gestational age to term a significant increase in the fraction of the $\mathrm{CO}$ to the lungs, intestine, and brain at the expense of the placenta.

Most perinatal cardiovascular studies are performed on sheep because of the following advantages: a) its size facilitates catheterization of fetus and b) manipulation of its uterus does not readily trigger labor (Rudolph \& Heymann, 1985). However, there also are some disadvantages: a) the ewe has a long gestation (150 days); b) it is expensive; c) instrumentation of the fetal lamb in utero can be difficult with some failure rate; and d) it is always necessary to operate 2 animals: the fetus and the mother animal. Furthermore, mammals present a close interaction between the fetus and the mother. Maternal factors can affect the fetus. The chick embryo is cheap, easy available and independent of its mother, providing an attractive model to study responses without any influence from maternal factors.

In summary, the $\mathrm{CO}$ distribution in the chick embryo as determined in this study shows a close resemblance to that of the mammalian fetus. Therefore, chick embryos could be considered a feasible model for further perinatal cardiovascular research. Furthermore, the fluorescent microspheres technique is appropriate to determine $\mathrm{CO}$ distribution. This study provides basic cardiovascular data, allowing for the design of future studies that will help in understanding of both the consequences of hypoxia or asphyxia and their underlying mechanisms during fetal cardiovascular development. 


\section{ACKNOWLEDGEMENTS}

The authors thank Johan Hekking, Department of AnatomyEmbryology, for his assistance in instrumenting the chick embryo and Anita Rousseau, Department of Physiology, for her assistance in analyzing the fluorescence

\section{REFERENCES}

Behrman, R. E., Lees, M. H., Peterson, E. N., De Lannoy, C. W. \& Seeds, A. E. (1970). Distribution of the circulation in the normal and asphyxiated fetal primate. American Joumal of Obstetrics and Gynecology 108, 956-69.

BKAILY, G. (1992). Single heart cells as models for studying cardiac toxicology. In In vitro methods in toxicology, ed. Jolles, G. \& Cordier, A., pp.289-334. Academic Press.

BKaIly, G., Jacques, D., Sculptoreanu, A., Yamamoto, T., CarRier, D., Vigneault, D. \& SPERELAKIS, N. (1991). Apamin, a highly potent blocker of the TTX-and Mn2(+)-insensitive fast transient $\mathrm{Na}+$ current in young embryonic heart. Journal of Molecular and Cellular Cardiology 23, 25-39.

CLARK, E. B. (1989). Growth, morphogenesis and function: the dynamics of cardiac development. In Fetal, neonatal and infant heart disease., ed. Moller, J. H., Neal, W. \& Lock, J., pp.1-17. Appleton-Century-Crofts, New York.

GLENNY, R. W., BERNARD, S. \& BRINKLEY, M. (1993). Validation of fluorescent-labeled microspheres for measurement of regional organ perfusion. Journal of Applied Physiology 74, 2585-97.

HAMBURger, V. \& HAMILTON, H. L. (1951). A series of normal stages in the development of the chick embryo. Journal of Morphology 88, 49-98.

Hu, N., NGO, T. D. \& CLARK, E. B. (1996). Distribution of blood flow between embryo and vitelline bed in the stage 18, 21 and 24 chick embryo. Cardiovascular Research 31 Spec No, E127-31.

IWAMOTO, H. S., KAUfMAN, T., KEIL, L. C. \& RudolPH, A. M. (1989). Responses to acute hypoxemia in fetal sheep at 0.6-0.7 gestation. American Journal of Physiology 256, H613-20.

JENSEN, A., Roman, C. \& Rudolph, A. M. (1991). Effects of reducing uterine blood flow on fetal blood flow distribution and oxygen delivery. Journal of Developmental Physiology 15, 309-23.

le Noble, F. A., Schreurs, N. H., van StraAten, H. W., SlaAf, D. W., Smits, J. F., Rogg, h. \& STRUIJKER BOUDIER, H. A. (1993). Evidence for a novel angiotensin II receptor involved in angiogenesis in chick embryo chorioallantoic membrane. American Journal of Physiology 264, R460-5.

llanos, A. J., Riquelme, R. A., Moraga, F. A., Cabello, G. \& Parer, J. T. (1995).

Cardiovascular responses to graded degrees of hypoxaemia in the llama fetus. Reproduction, Fertility and Development 7, 549-52.

MEtCALFE, J. \& STOCK, M. K. (1993). Current topic: oxygen exchange in the chorioallantoic membrane, avian homologue of the mammalian placenta. Placenta 14, 605-13. 
PRINZEN, F. W. \& GLENNY, R. W. (1994). Developments in non-radioactive microsphere techniques for blood flow measurement. Cardiovascular Research 28, 1467-75.

RAHN, H., MATALON, S. \& SOTHERLAND, P. R. (1985). Circulatory changes and oxygen delivery in the chick embryo prior to hatching. Proceedings Cardiovascular shunts, Alfred Benzon Symposium, Copenhagen.

Romanoff, A. L. (1960). The Avian Embryo. Structural and Functional Development. New York, The Macmillan Company.

RomiJn, C. \& RoOs, J. (1938). The air space of the hen's egg and its changes during the period of incubation. Journal of Physiology 94, 365-379.

Rudolph, A. M. \& HeYMANN, M. A. (1967). The circulation of the fetus in utero. Methods for studying distribution of blood flow, cardiac output and organ blood flow. Circulation Research 21, 163-84.

RudolPh, A. M. \& HEYMANN, M. A. (1970). Circulatory changes during growth in the fetal lamb. Circulation Research 26, 289-99.

RudolPh, A. M. \& HEYMANN, M. A. (1985). Methods for studying the circulation of the fetus in utero. In Animal models in fetal medicine, ed. Nathanielsz, P. W., pp.1-57. Perinatology Press, Ithaca.

TABer, L. A., KelleR, B. B. \& CLARK, E. B. (1992). Cardiac mechanics in the stage-16 chick embryo. Joumal of Biomechanical Engineering 114, 427-34.

TAZAWA, H. (1980). Adverse effect of failure to turn the avian egg on the embryo oxygen exchange. Respiration Physiology 41, 137-42.

VAN Golde, J., MULDER, T., v StraAten, H. \& BLANCO, C. E. (1996). The chorioallantoic artery blood flow of the chick embryo from stage 34 to 43. Pediatric Research 40, 867-71.

van Oosterhout, M. F., Willigers, H. M., Reneman, R. S. \& Prinzen, F. W. (1995).

Fluorescent microspheres to measure organ perfusion: validation of a simplified sample processing technique. American Journal of Physiology 269, H725-33. 
ChAPTER 3

Cardiac output distribution in response to hypoxia in the chick embryo in the second half of the incubation time

A.L.M. Mulder ${ }^{1}$, J.C. van Golde ${ }^{1}$, F.W. Prinzen ${ }^{2}$, C.E. Blanco ${ }^{1}$

1 Department of Pediatrics, University Hospital Maastricht, the Netherlands

2 Department of Physiology, Maastricht University, the Netherlands

JOURNAL OF PHYSIOLOGY (1998), 508.1. pp.281-287 
$58 \mid$ CHAPTER 3

\section{SUMMARY}

1. The fetus develops cardiovascular adaptations to protect vital organs in situations such as hypoxia and asphyxia. These include bradycardia, increased systemic blood pressure and redistribution of the cardiac output. The extent to which they involve maternal or placenta influences is not known. The objective of the present work was to study the cardiac output distribution in response to hypoxia in the chick embryo, which is independent of the mother.

2. Fertilised eggs were studied at three incubation times (10-13 days, 1416 days and 17-19 days of a normal incubation time of 21 days). Eggs were placed in a Plexiglas box in which the oxygen concentration could be changed. Eggs were opened at the air cell and a chorioallantoic vein was catheterised. Cardiac output distribution was measured with $15 \mathrm{~mm}$ fluorescent microspheres injected during normoxia, during the last minute of a 5 minute period of hypoxia and after 5 minutes of subsequent reoxygenation.

3. Hypoxia caused a redistribution of the cardiac output in favour of heart $(+17 \%-+160 \%$ of baseline) and brain $(+21 \%-+57 \%$ of baseline) at the expense of liver $(-3 \%-65 \%$ of baseline), yolk-sac $(-46 \%-77 \%$ of baseline $)$ and carcass $(-6 \%-33 \%$ of baseline).

4. The magnitude of the changes in cardiac output distribution to the heart, brain, liver and carcass in response to hypoxia increased with advancing incubation time.

5. The data demonstrate the development of a protective redistribution of the cardiac output in response to hypoxia in the chick embryo from day 10 of incubation. 


\section{INTRODUCTION}

Hypoxia produces a range of protective mechanisms in the mature fetus, in particular effects on the cardiovascular system (Hanson, 1988; Giussani et al. 1994).

The first component of the response to acute hypoxia involves a chemoreflex, mediated by the peripheral (particularly the carotid) arterial chemoreceptors: their activation initiates an increase in vagal efferent activity to the heart, which produces a bradycardia, and an increase in sympathetic activity, which produces a vasoconstriction in the carcass and a rise in systemic blood pressure. Endocrine mechanisms then contribute to the response, in particular the rise in fetal plasma vasopressin and catecholamines, which contribute to the bradycardia and the vasoconstriction respectively (Rurak,1978; Cohen et al. 1984). In addition, the rise in blood pressure may contribute to the bradycardia via a baroreflex, but the fall in heart rate is only transient and $\beta$-adrenergic influences to the heart produce an increase in heart rate after a few minutes of hypoxia.

In contrast to the fall in blood flow to the carcass, blood flow to vital organs, particularly the brain, heart and adrenal glands, increases (Cohn et al. 1974) (Peeters et al. 1979). This appears to be mediated predominantly by the release of local vasodilator substances such as nitric oxide (van Bel et al. 1995) and adenosine (Kurth \& Wagerle, 1992).

The above description concentrates on responses initiated within the fetus. However, because the experimental production of fetal hypoxia usually necessitates making the mother (Boddy et al. 1974) or the placenta (Jensen et al. 1991) hypoxic, it is possible that a substantial component of the fetal responses are not initiated in the fetus itself. For example, hypoxia might produce a rise in maternal catecholamines (Boddy et al. 1974) which will easily cross the placenta. Substances such as prostaglandins (Thorburn, 1992) will also be produced by the placenta during hypoxia and can enter the fetal circulation to produce cardiovascular effects.

Therefore, we decided to study the response to hypoxia in the chick embryo, a developing animal that is independent of its mother in that gas exchange takes place by diffusion through micropores in the egg-shell to the vascular bed in the chorioallantoic membrane (CAM), which can be seen as an equivalent to the placenta (Metcalfe \& Stock, 1993). The chick embryo has the advantage that hypoxia can be simply induced by lowering the oxygen concentration of its environment, it has a short incubation time, is relatively 
resistant to infections, gives easy access to the arteries and veins of the CAM, and is cheap. Therefore, the chick embryo is an attractive animal model for perinatal cardiovascular research.

Not much is known about the response of the chick embryo to hypoxia during the second half of its incubation period, although Tazawa (1981b) reported a decrease in heart rate and blood pressure in response to hypoxia in embryos at 14-16 days. In a previous study, we found that heart rate and blood flow to the CAM decreased in response to hypoxia in chick embryos at 9-16 days (van Golde et al.1996a). This fall in blood pressure appears to contrast with the fetus, in which hypoxia produces an increase.

The aim of the present study was to examine whether the redistribution of the $\mathrm{CO}$ in response to hypoxia in the chick embryo is similar to that found in the mammalian fetus and to examine whether the response to hypoxia changes during the development of the chick embryo. This would permit us to evaluate further the use of the chick embryo for perinatal cardiovascular research by using fluorescent microspheres.

\section{METHODS}

White Leghorn fertilised eggs were incubated in a commercial incubator at a temperature of $38^{\circ} \mathrm{C}$ and a humidity of $60 \%$. Eggs were rotated constantly to avoid adhesions between embryo and its membranes (Tazawa, 1981a). For White Leghorn eggs, incubation time until hatching is 21 days. In the present study, we used chick embryos of 10-19 days incubation, corresponding to stages 36-45 of Hamburger and Hamilton (1951). To document the response to hypoxia, we used 35 chick embryos at three different incubation times: 10 13 days $(n=10), 14-16$ days $(n=13), 17-19$ days $(n=12)$.

\section{PREPARATION}

To determine the distribution of the $\mathrm{CO}$, a chorioallantoic vein was catheterised for injections of fluorescent microspheres. Both catheterisation of the chorioallantoic vein and the injection of fluorescent microspheres were performed in a clinical infant incubator, provided with a light microscope (WILD $3 \mathrm{M}$, magnification 10x). Temperature and humidity were maintained constant at $38^{\circ} \mathrm{C}$ and $60 \%$ respectively. Eggs were opened with an electrical saw at the air cell and placed in a holder within a Plexiglas box. The oxygen concentration in the box was changed by supplying different mixtures of $\mathrm{O}_{2}$ and $\mathrm{N}_{2}$ at a constant flow of $51 \mathrm{~min}^{-1}$. After opening the shell, the outer shell membrane became visible. Moistening this membrane with a $\mathrm{NaCl} 0.9 \%$ 
solution made the vessels of the underlying CAM visible. Without damaging the chorioallantoic membrane vessels, the outer shell membrane was removed. A chorioallantoic vein was identified by its bright red colour and erythrocyte flow direction. The vein was lifted using sutures, opened with the tip of a 30-Gauge needle and a polyethylene catheter, stretched by heat to a diameter of $100 \mu \mathrm{m}$, was inserted. The catheter, flushed with heparinized saline $\left(10 \mathrm{IU} \mathrm{ml}{ }^{-1}\right)$, was connected to a $1.0 \mathrm{ml}$ syringe and fixed to the eggshell with clay.

\section{PROTOCOL}

For the measurement of $\mathrm{CO}$ distribution, fluorescent microspheres were used (Fluospheres ${ }^{\bullet}$ Molecular Probes Inc., Eugene, Oregon, USA) with a diameter of $15 \mu \mathrm{m}$. Spheres were suspended in saline and $0.05 \%$ Tween 80 $\left(100000\right.$ spheres $\mathrm{ml}^{-1}$ ). Five minutes after catheterisation, $0.2 \mathrm{ml}(20000$ spheres) of the suspension of orange fluorescent microspheres was injected. One minute later, the oxygen concentration was changed to $0.0 \%$ by supplying $100 \% \mathrm{~N}_{2}$ to the box. In the last minute of a 5 min period of hypoxia, 20000 yellow-green fluorescent microspheres were injected. Normoxia was re-established and after 5 minutes in reoxygenation 20000 red fluorescent microspheres were injected. The chick embryos were decapitated immediately after the experiment without any prior manipulation and the CAM, brain, heart, lungs, intestine, liver and the yolk-sac were dissected.

Since we injected $0.6 \mathrm{ml}$ fluid in each experiment, it could have affected the $\mathrm{CO}$ distribution in the embryo. Furthermore, the injected microspheres could have occluded part of a vascular bed, which might have effects on the distribution of the following microsphere injection. In order to document any effect of the volume and amount of microspheres injected, we carried out the same protocol as described above without changing the environmental oxygen supply in 11 chick embryos, in three incubation time groups: $10-13$ days: $n=3$, 14-16 days: $n=4,17-19$ days: $n=4$.

In a further group of chick embryos at incubation time 13-15 days $(n=8)$, blood samples were obtained for blood gas analysis by puncturing the chorioallantoic artery. $\mathrm{pH}$ and $\mathrm{PO}_{2}$ values were determined after 2 and 5 minutes of hypoxia. Values were corrected for embryo temperature. 
$62 \mid$ CHAPTER 3

\section{MEASUREMENT OF MICROSPHERE DISTRIBUTION}

Organs and remaining carcass were digested in test tubes in a $2 \mathrm{M}$ ethanolic- $\mathrm{KOH}$ solution. The microspheres were isolated from the homogenate by centrifugation, a method shown to result in recovery of close to $100 \%$ of microspheres (van Oosterhout et al. 1995). The dye was extracted with $3 \mathrm{ml}$ of 2-(2-ethoxyethoxy) ethylacetate and the fluorescence measured by fluorimetry using a LS-50B fluorospectrometer (Perkin, Elmer). No correction for spectral overlap was used since the excitation and emission spectra of the three dyes were well separated. During fluorimetry, all samples had the same volume ( 3 $\mathrm{ml}$ ). The fraction of the $\mathrm{CO}$ that was directed to the tissue was expressed as the level of the fluorescence of the sample, corrected for background, divided by the sum of fluorescence of all tissues.

\section{ANALYSIS OF DATA}

All data were processed using SPSS software (SPSS Inc.). Since not all data obtained were normally distributed, we expressed it as median with interquartile range (IQR). For analysis of the changes in $\mathrm{CO}$ distribution in response to hypoxia, a non-parametric sample test (Wilcoxon signed rank test) was applied. For analysis of changes during development, we used the MannWhitney $U$ rank sum test. Significance was accepted by $P<0.05$.

\section{RESULTS}

To study the possible effects of the amount of microspheres and the volume injected during the experiment, we determined the $\mathrm{CO}$ distribution after each of three injections of fluorescent microspheres without changing the environmental oxygen supply. We did not find any statistically significant difference $(n=11 ; P<0.05)$ between the $C O$ distributions measured after each injection for each organ and each incubation time.

In normoxia a large fraction of the cardiac output was directed to the CAM (median range for the three groups: $40.5-55.6 \%$ ) with relatively small fractions directed to the heart ( range: $1.7-4.0 \%$ ), lungs ( range: $0.4-1.1 \%$ ), brain (range: $3.0-4.2 \%$ ), intestine (range: $1.9-3.6 \%$ ), and liver (range: 1.3 $3.1 \%$ ) (Fig 1). 
Table 1 Cardiac output distribution in the chick embryo in normoxia, hypoxia and after 5 minutes of reoxygenation for three different incubation time groups

\begin{tabular}{llll} 
10-13 days $(\mathbf{n = 1 0})$ & Normoxia & Hypoxia & Reoxygenation \\
\hline Heart & $1.73(1.42-2.73)$ & $2.44(1.97-2.77)$ & $4.34(2.45-5.21)^{*}$ \\
Brain & $3.03(2.64-5.89)$ & $4.01(3.23-4.93)$ & $6.42(4.77-8.83)$ \\
CAM & $55.56(49.04-60.00)$ & $64.48(50.97-71.19)$ & $48.33(37.54-58.72)$ \\
Lungs & $0.41(0.35-0.88)$ & $0.78(0.60-1.33)$ & $0.79(0.64-1.13)$ \\
Intestine & $1.92(1.26-2.75)$ & $2.85(1.64-3.21)$ & $3.47(1.94-4.74)^{\circ}$ \\
Liver & $1.25(0.84-1.74)$ & $1.27(0.76-1.70)$ & $1.81(1.65-2.45)^{\circ}$ \\
Yolk sac & $14.32(4.63-19.48)$ & $2.80(1.74-8.54)$ & $9.18(5.64-14.13)$ \\
Carcass & $22.01(19.44-26.41)$ & $22.30(16.47-24.85)$ & $25.00(22.16-30.31)$ \\
\hline
\end{tabular}

\begin{tabular}{|c|c|c|c|}
\hline $14-16$ days $(n=13)$ & Normoxia & Hypoxia & Reoxygenation \\
\hline Heart & $4.04(2.77-4.54)$ & $5.72(4.45-7.07)+$ & $5.56(4.57-6.50)^{\circ}$ \\
\hline Brain & $4.20(2.97-4.75)$ & $6.40(4.71-8.90)+$ & $8.72(6.22-9.70)+$ \\
\hline CAM & $40.45(33.85-52.86)$ & $56.72(42.89-64.27)^{\bullet}$ & $38.90(29.13-47.01)$ \\
\hline Lungs & $0.89(0.59-2.31)$ & $1.51(0.97-2.73)$ & $1.07(0.54-2.23)$ \\
\hline Intestine & $3.64(3.07-4.44)$ & $2.96(1.91-5.02)$ & $5.56(3.77-7.96) \cdot$ \\
\hline Liver & $3.08(2.26-4.33)$ & $0.82(0.66-1.78) \dagger$ & $1.92(1.60-3.06)^{\bullet}$ \\
\hline Yolk sac & $4.44(2.71-6.05)$ & $0.59(0.47-1.64) \dagger$ & $3.91(2.95-4.38)$ \\
\hline Carcass & $36.22(29.67-41.94)$ & $22.48(17.73-30.31)+$ & $34.50(28.91-43.38)$ \\
\hline $17-19$ days $(n=12)$ & Normoxia & Hypoxia & Reoxygenation \\
\hline Heart & $2.83(2.38-3.32)$ & $6.95(4.40-10.94)^{*}$ & $3.45(2.49-7.66)^{*}$ \\
\hline Brain & $4.10(3.11-5.17)$ & $9.09(7.28-9.85) \dagger$ & $8.83(6.72-11.64) \dagger$ \\
\hline CAM & $55.18(38.04-70.16)$ & $56.65(40.12-75.78)$ & $56.16(34.96-65.03)$ \\
\hline Lungs & $1.05(0.72-1.96)$ & $1.38(0.51-1.66)$ & $0.94(0.45-1.25)$ \\
\hline Intestine & $2.92(2.00-3.42)$ & $1.36(0.76-2.11)^{*}$ & $3.25(2.07-6.94)$ \\
\hline Liver & $1.31(0.73-1.91)$ & $0.48(0.31-0.69)^{*}$ & $1.71(0.92-2.26)$ \\
\hline Yolk sac & $2.29(1.11-3.31)$ & $1.40(0.32-2.61)$ & $1.30(0.79-1.80)+$ \\
\hline Carcass & $31.10(17.08-42.78)$ & $21.39(7.84-27.64)+$ & $25.19(18.19-34.91)$ \\
\hline
\end{tabular}

Presented are median percentage of $\mathrm{CO}$ directed to each organ and interquartile range. * = significant difference compared with normoxia $(P<0.05), \dagger=$ significant difference compared with normoxia $(P<0.01)$. 


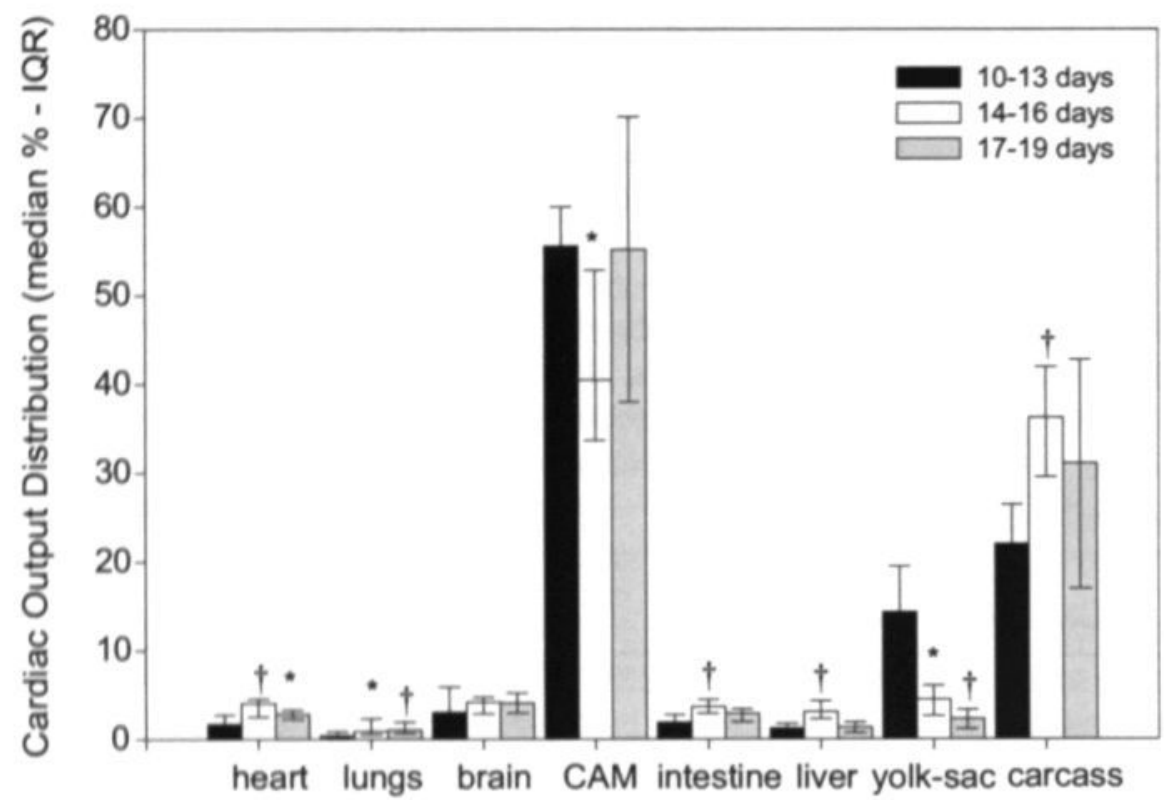

Fig. 1 Cardiac output distribution for increasing incubation time. Bars represent median with interquartile range $(\mathrm{p} 25-\mathrm{p} 75) .^{*}=P<0.05$ compared with $10-13$ days group, $+=P<0.01$ compared with 10-13 days group.

The exposure of the egg to $100 \% \mathrm{~N}_{2}$ induced an isocapnic hypoxaemia with mean $\mathrm{Pa}, \mathrm{O}_{2}$ values after 2 minutes of $9.3 \mathrm{~mm} \mathrm{Hg}$ (IQR: $6.4-11.2 \mathrm{mmHg}$ ) and after 5 minutes of $8.1 \mathrm{mmHg}$ (IQR: 7.3-10.1 $\mathrm{mm} \mathrm{Hg}$ ) with $\mathrm{pH}$ values of 7.43 (IQR: 7.41-7.45) and 7.41 (IQR: 7.41-7.43) respectively.

In response to hypoxia, we found a redistribution of the cardiac output in favour of heart, brain and CAM at the expense of intestine, liver, yolk-sac and carcass in all groups except in the 10-13 day group (Table 1 and Fig. 2). The fractions of $\mathrm{CO}$ directed to heart and brain in both the 14-16 and the 1719 day groups increased significantly $(P<0.05)$. The fraction distributed to the CAM increased in the 14-16 day group, but not in the 17-19 day group. The fractions to liver, yolk-sac and carcass decreased in the 14-16 day group in response to hypoxia. In the 17-19 day group, the fractions to intestine, liver and carcass decreased. 

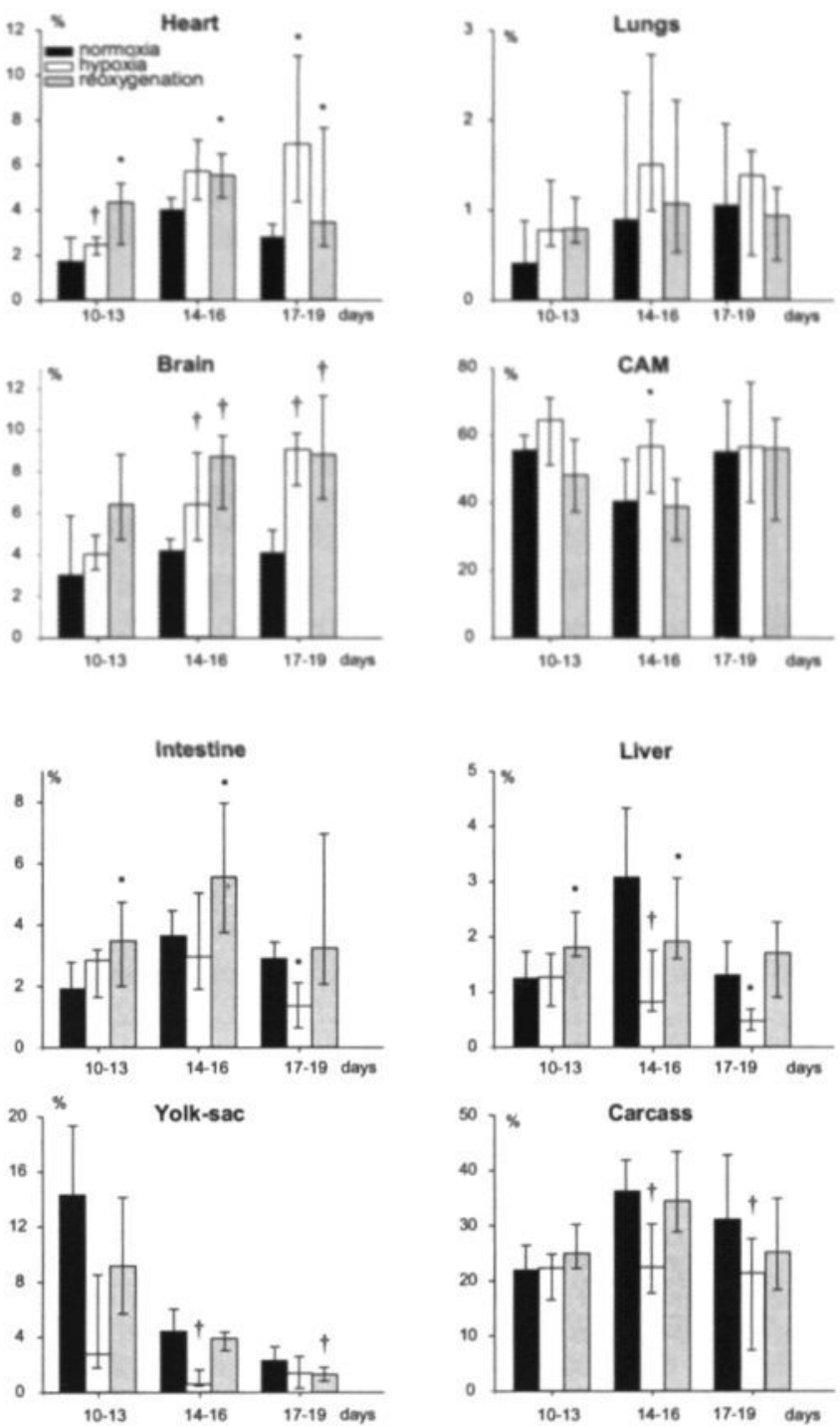

Fig. 2 Cardiac output distribution in the chick embryo in normoxia, hypoxia and after 5 minutes of reoxygenation for three different incubation time groups. Bars represent median percentage of $\mathrm{CO}$ directed to each organ and interquartile range $(p 25-p 75) .^{*}=$ significant difference compared with normoxia $(p<0.05),+=$ significant difference compared with normoxia $(p<0.01)$. 
The changes observed in the organs of the youngest 10-13 day group were statistically not significant and the fraction of the $\mathrm{CO}$ directed to the lungs did not change in any group.

The magnitude of the response expressed as percentage of baseline level increased with increasing incubation time. We found a statistically significant $(P<0.05)$ increase in response between the 10-13 day group and the 17-19 day group for heart, brain, intestine, liver and carcass (Fig 3).

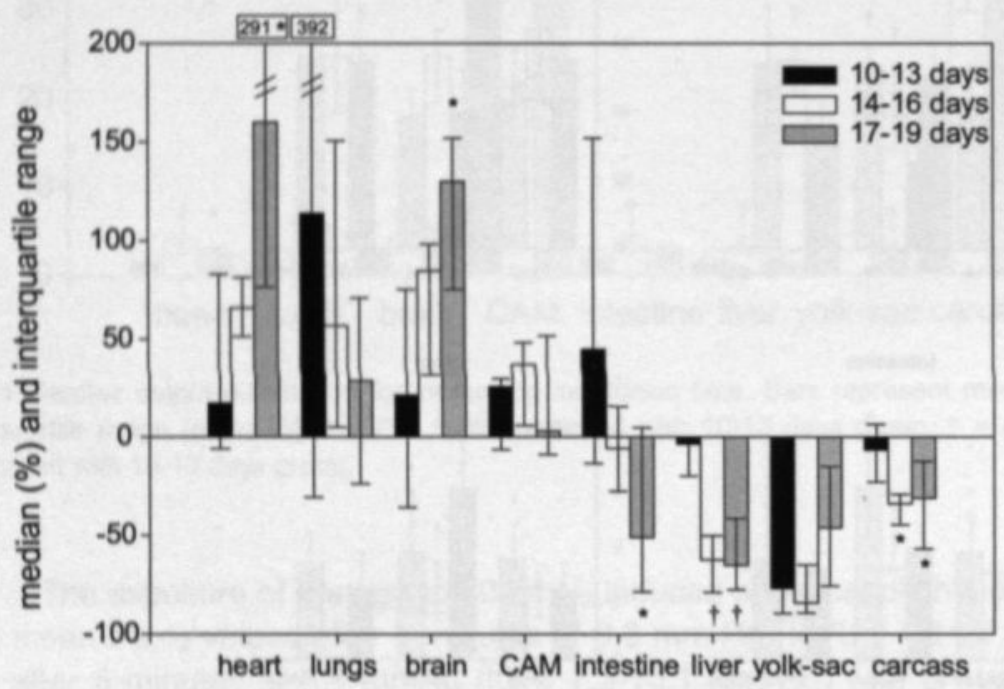

Fig 3 Magnitude of response to hypoxia for increasing incubation time. The bars represent the median change expressed as percentage of baseline level with the interquartile range ( $p 25$ p75). ${ }^{*}=P<0.05$ compared with $10-13$ days group, $+=P<0.01$ compared with $10-13$ days group

Five minutes after the start of reoxygenation, we found that $\mathrm{CO}$ distribution had still not returned to baseline level (Table 1 and Fig. 2). The fraction of the $\mathrm{CO}$ directed to the heart was significantly greater than baseline level $(P<0.05)$ in all three groups. The same was found for the fractions to the brain in the 14-16 day and 17-19 day groups. In the organs in which flow had fallen in hypoxia, it increased during reoxygenation, even being significantly greater than control in the intestine in the 10-13 and 14-16 day groups and 
liver in the 10-13 day group. Flow remained below control in the yolk-sac in the 17-19 day group.

\section{DISCUSSION}

\section{RESPONSE TO HYPOXIA}

in the present study, we found that there was a redistribution of the $\mathrm{CO}$ in response to hypoxia in the chick embryo after 13 days of incubation. During hypoxia the fractions of the CO directed to heart, brain and CAM increased at the expense of intestine, liver, yolk-sac and carcass. The increase in the fraction directed to the heart ranged from 17 to $160 \%$ to the brain from 21 to $130 \%$ and to the CAM from 3 to $37 \%$ of baseline level. The changes in the 10 13 day group were not statistically significant, but became larger and more significant in the older groups. This suggests that there is a development in the compensatory ability of the chick embryo to provide oxygen delivery to these vital organs under hypoxic conditions. The redistribution of the $\mathrm{CO}$ in response to hypoxia, favouring the heart and brain at the expense of intestine, liver and carcass is similar to that found in mammalian fetuses of the sheep (Jensen et al. 1991; Peeters et al. 1979), rhesus monkey (Jackson et al. 1987) and llama (Giussani et al. 1996). Since the chick embryo is independent of the mother, the similarity in response to hypoxia suggests that in the mammalian fetus such responses may occur independently of maternal or placental factors.

The magnitude of the response to hypoxia increased significantly $(P<$ $0.05)$ as incubation time advanced. In the youngest (10-13 days) group, there was no change compared to baseline $(P>0.05)$. However, the magnitude of the response in the older groups increased significantly $(P<0.05)$. These data suggest a maturation of this protective reflex in the second half of the incubation time. Iwamoto et al. (1989) have described a similar maturation in the response to hypoxia in the sheep fetus, comparing the response at $60 \%$ of full gestation with that at $70 \%$ full gestation and near term. In the sheep fetus at $60 \%$ of full gestation there was no change in blood flow to the carcass in response to hypoxia, whereas in the fetus at $70 \%$ of full gestation there was a decrease in blood flow to the carcass, suggesting that peripheral vasoconstrictor response has developed by this time (Iwamoto et al. 1989). Not much is known about the development of oxygen sensitive chemoreceptors, such as aortic and carotid bodies, during gestation, but it is reported that afferent chemoreceptor activity is present in fetal sheep at 90 days of gestation ( $60 \%$ gestation; Blanco et al. 1984). In the chick embryo sympathetic nerve axons reach the heart at day 13 but they do not release 
sufficient neurotransmitter to change cardiac function until day 16 (Hu \& Clark, 1989). Parasympathetic neurones reach the heart at day 13 but are also not functional until day 16 (Hu \& Clark, 1989). However, adrenergic and cholinergic receptors have been identified in the myocardium and peripheral vascular beds as early as day 3 (Hu \& Clark, 1989). Girard (1973) demonstrated an increasing blood pressure response to noradrenaline in the chick embryo from day 6 to 17. It is not yet clear how much hormonal and neural mechanisms contribute to the distribution of the $\mathrm{CO}$ during hypoxia in the developing chick embryo. Further studies are being conducted to answer this question.

\section{CO DISTRIBUTION AFTER REOXYGENATION}

The cardiac output distribution determined after 5 minutes of reoxygenation differs from baseline level in some tissues. The fraction of the $\mathrm{CO}$ directed to heart, brain, intestine and liver were above baseline and those to CAM, yolk-sac and carcass were below baseline. In a previous study, we reported an overshoot in CAM blood flow during reoxygenation, after a $5 \mathrm{~min}$ period of hypoxia (van Golde et al. 1996a). This suggests that in the reoxygenation phase, $\mathrm{CO}$ increases and blood flow to heart, brain, intestine and liver increase, providing more oxygen and nutrients to these tissues than in normoxia before hypoxia. The effect may be the result of circulating catecholamines and local factors as nitric oxide and adenosine released during the hypoxia period and the immediate posthypoxic period. Recently, a similar response was reported in sheep fetus at $75 \%$ of gestation $1 \mathrm{~h}$ after an $8 \mathrm{~h}$ period of hypoxia (Richardson et al. 1996), in that heart rate and carcass blood flow were increased compared with baseline. They did not find increased blood flow to the brain. Interestingly, we observed changes in $\mathrm{CO}$ distribution in the reoxygenation phase in the youngest (10-13 days) group, whereas we did not observe a response to hypoxia in this group. An explanation might be that the vasodilatory properties of the different vascular beds develop at an earlier stage than the vasoconstrictory properties. 


\section{BASELINE MEASUREMENTS}

Under normoxic conditions, the distribution of $\mathrm{CO}$ in the chick embryo is comparable with that reported in the sheep fetus. Two vascular beds received a major percentage of the combined cardiac output: the CAM and yolk-sac, responsible for gas exchange and nutrient delivery to the chick embryo, respectively, and therefore comparable to the placenta in the mammalian fetus (Metcalfe \& Stock, 1993). Relatively small fractions are distributed to heart, brain, lungs and abdominal organs. This distribution of the cardiac output is similar to the data we previously found in a larger group of chick embryos (Mulder et al. 1997). A similar distribution was reported in the late gestation sheep fetus by Jensen et al. (1991).

\section{THE CHICK EMBRYO AS A MODEL}

In this study we found that in the second half of its incubation time, the chick embryo is a feasible animal for perinatal cardiovascular research in that determining $\mathrm{CO}$ distribution in normoxia, hypoxia and after reoxygenation using fluorescent microspheres is possible.

Fluorescent microspheres were introduced and validated for the study of $\mathrm{CO}, \mathrm{CO}$ distribution and organ blood flow and their accuracy is similar to that of the radio-active microsphere method. They have the advantage that they do not require radioactivity. (Glenny et al. 1993) (van Oosterhout et al. 1995) but a slight disadvantage is that the dye concentration cannot be measured directly. Instead, microspheres have to be isolated from the tissues by digestion. This was successful in all chick embryo tissues in the present and previous study (Mulder et al. 1997) as for many organs of adult animals (Van Oosterhout et al. 1995). The microsphere method would permit determination of absolute organ blood flow data if an arterial reference blood sample could be obtained simultaneously with the microsphere injection. This was not possible due to the difficult access to the chick embryo and the limited blood volume; therefore we are unable to present actual organ blood flow rates.

In order to document any effect of the microsphere and volume injection itself we examined eleven chick embryos, in which we injected the same three dyes of microspheres in the same volume, without inducing hypoxia. Since no significant change was observed we conclude that the injection of fluorescent microspheres and the volume injected did not affect the measurement of the CO perse. 
During incubation the concentrations in the air cell of the egg of both oxygen and carbon dioxide change. Oxygen concentration falls from $21 \%$ at day 4 to $12 \%$ at day 20 and the carbon dioxide concentration increases from $0.6 \%$ at day 4 to $6 \%$ at day 20 (Romijn \& Roos, 1938). Therefore, the opening of the air cell of the egg could have had consequences on the embryonic blood gases, influencing $\mathrm{CO}$ distribution. However, in a previous study we could not demonstrate any change in arterial $\mathrm{PO}_{2}, \mathrm{PCO}_{2}$ and $\mathrm{pH}$ resulting from the opening of the air cell (van Golde et al. 1996).

\section{CONCLUSIONS}

We showed that the chick embryo shows a redistribution of the $\mathrm{CO}$ in response to hypoxia and subsequent reoxygenation. Hypoxia favours blood flow to heart and brain at the expense of intestine, liver, yolk-sac and carcass. The observed redistribution of the $\mathrm{CO}$ in response to hypoxia is not significant at 10-13 day incubation time but develops during the last third of incubation. In the reoxygenation phase $\mathrm{CO}$ is redistributed in favour of heart, brain, intestine and liver compared with baseline measurements, a response which is already present at 10-13 days of incubation.

The present study provides a feasible animal model for hypoxia studies in perinatal cardiovascular research, due to its simplicity and the independence of the chick embryo from maternal influences. This model opens new possibilities for future studies that will help us to understand the consequences of hypoxia and asphyxia and their underlying mechanisms during fetal cardiovascular development.

\section{ACKNOWLEDGEMENTS}

We wish to thank the staff of the laboratories of Anatomy-Embryology and Physiology for their assistance in the study. 


\section{REFERENCES}

Blanco, C. E., DAwES, G. S., HANSON, M. A. \& MC COOKE, H. B. (1984). The response to hypoxia of arterial chemoreceptors in fetal sheep and new-born lambs. Journal of Physiology 351, 25-37.

BODOY, K., DAWES, G.S., FISHER, R.,PINTER, S. \& ROBINSON, J.S. (1974). Foetal respiratory movements, electrocortical and cardiovascular responses to hypoxaemia and hypercapnia in sheep. Journal of Physiology 243, 599-618.

BODDY, K., JONES, C.T., MANTEL, C., RATCLIFFE, J.G. \& RoBinson J.S. (1974), Changes in plasma ACTH and Corticosteroid of the Maternal and Fetal Sheep During Hypoxia. Endocrinology 94, 588-591.

COHEN, W.R., PIASECKI, G.J., COHN, H.E., YOUNG, J.B. \& JACKSON, B.T. (1984). Adrenal secretion of catecholamines during hypoxemia in fetal lambs. Endocrinology 114, 383-390.

COHN, H.E., SACKS, E.J., HEYMANN, M.A. \& RUDOLPH, A.M. (1974). Cardiovascular responses to hypoxemia and acidemia in fetal lambs. American Joumal of Gynaecology and Obstetrics $120,817-824$.

GIRARD, H. (1973). Adrenergic sensitivity of circulation in the chick embryo. American Journal of Physiology 224, 461-469.

GIUSSANI, D. A., SPEnCER, J. A. D. \& HANSON, M. A. (1994). Fetal cardiovascular reflex responses to hypoxaemia. Fetal and Maternal Medicine Review 6, 17-37.

Giussani, D.A., Riquelme, R.A., Moraga, F.A., Mc Garrigle, H.H., Gaete, C.R., SanhuezA, E.M., HANSON, M.A., LLANOS A.J. (1996). Chemoreflex and endocrine components of cardiovascular responses to acute hypoxemia in the llama fetus. American Journal of Physiology 271, R73-R83.

GLENNY, R. W., BERNARD, S. \& BRINKLEY, M. (1993). Validation of fluorescent-labeled microspheres for measurement of regional organ perfusion. Journal of Applied Physiology 74, 2585-2597.

HAMBuRger, V. \& HAMiLTON, H. L. (1951). A series of normal stages in the development of the chick embryo. Journal of Morphology 88, 49-92.

HANSON, M. A. (1988). The importance of baro- and chemoreflexes in the control of the fetal cardiovascular system. Journal of Developmental Physiology 10, 491-511.

HU, N. \& CLARK, E. B. (1989). Hemodynamics of the stage 12 to stage 29 chick embryo. Circulation Research 65, 1665-1670.

IWAMOTO, H. S., KAUfMAN, T., KEIL, L. C. \& RudOLPH, A. M. (1989). Responses to acute hypoxemia in fetal sheep at 0.6-0.7 gestation. American Joumal of Physiology 256, H613-620.

JACKSON, B.T., PIASECKI, G.J., NOVY, M.J. (1987). Fetal responses to altered maternal oxygenation in rhesus monkey. American Joumal of Physiology 252, R94-R101. 
JENSEN, A., ROMAN, C. \& RudOLPH, A. M. (1991). Effects of reducing uterine blood flow on fetal blood flow distribution and oxygen delivery. Journal of Developmental Physiology 15, 309-323.

KURTH, C. D. \& WAGERLE, L. C. (1992). Cerebrovascular reactivity to adenosine analoques on 0.6-0.7 gestation and near-term fetal sheep. American Journal of Physiology 262, H1338H1342.

Metcalfe, J. \& Stock, M. K. (1993). Current Topic: Oxygen Exchange in the Chorioallantoic Membrane, Avian Homoloque of the Mammalian Placenta. Placenta 14, 605-613.

Mulder, A. L. M., van Golde, J. C., Prinzen, F. W. \& Blanco, C. E. (1997). Cardiac output distribution in the chick embryo stage 36 to 45 . Cardiovascular Research 34, 525-528.

Peeters, L. L. H., Sheldon, R. E., Jones, M. D. J., Makowski, E. L. \& Meschia, G. (1979). Blood flow to fetal organs as a function of arterial oxygen content. American Journal of Obstetrics and Gynecology 135, 637-646.

Richardson, B., Korkola, S., Asano, H., Challis, J., Polk, D. \& Fraser, M. (1996). Regional blood flow and the endocrine response to sustained hypoxemia in the preterm ovine fetus. Pediatric Research 40, 337-343.

ROMiJN, C. \& Roos, J. (1938). The air space of the hen's egg and its changes during the period of incubation. Journal of Physiology 94, 365-379.

RURAK, D.W. (1978). Plasma vasopressin levels during hypoxaemia and the cardiovascular effects of exogenous vasopressin in foetal and adult sheep. Journal of Physiology, 277,341357.

TAZAWA, H. (1981a). Adverse effect of failure to turn the avian egg on the embryo oxygen exchange. Respiratory Physiology 41, 137-142.

TAZAWA, H. (1981b). Effect of O2 and CO2 in N2, He and SF6 on chick embryo blood pressure and heart rate. Journal of Applied Physiology 51, 1017-1022.

THORBURN, G.D. (1992). The placenta, $\mathrm{PGE}_{2}$ and parturition. Early Human Development 29, 63-73.

VAN Bel, F., SolA, A., Roman, C. \& Rudolph, A. M. (1995). Role of nitric oxide in the regulation of the cerebral circulation in the lamb fetus during normoxemia and hypoxemia. Biology of the Neonate 68, 200-210.

van Golde, J., Mulder, T. \& Blanco, C. E. (1996a). Changes in mean chorioallantoic blood flow and heart rate elicited by hypoxia in the developing chick embryo. Pediatric Research 39, 69A.

van Golde, J., Mulder, T., Van Straaten, H. \& Blanco, C. E. (1996b). The chorioallantoic artery blood flow of the chick embryo from stage 34 to 43 . Pediatric Research 40, 867-871. 
van Oosterhout, M. F. M. van, Willigers, H. M. M., Reneman, R. S. \& Prinzen, F. W. (1995). Fluorescent microspheres to measure organ perfusion: validation of a simplified sample processing technique. American Joumal of Physiology 269, H725-733. 
$74 \mid$ 
CAtecholamine Response $\mid 75$

ChAPTER 4

\section{Developmental changes in plasma catecholamine} concentrations during normoxia and acute hypoxia in the chick embryo

A.L.M. Mulder', J.M.C.G. van Golde', A.A.C. van Goor', D.A. Giussani ${ }^{2}$ and C.E. Blanco ${ }^{1}$

1 Department of Paediatrics, University Hospital Maastricht, and Research Institute Growth and Development (GROW), Maastricht University, The Netherlands

2 Department of Physiology, University of Cambridge, Downing Street, Cambridge CB2 3EG, United Kingdom 


\section{SUMMARY}

1. In the mammalian fetus, the cardiovascular responses to acute hypoxaemia include a redistribution of the cardiac output away from the periphery towards the adrenal, myocardial and cerebral circulations. A component of the peripheral vasoconstriction is mediated by increased release of catecholamines into the fetal circulation during acute hypoxaemia. Previously, we have shown that the chick embryo also shows an increase in peripheral vascular resistance during acute hypoxaemia and that this response becomes progressively larger towards the end of the incubation period. However, the ontogeny of the catecholaminergic response to acute hypoxaemia has not been investigated in this species.

2. Fertilised chicken eggs were studied at day 10, 13, 16 and 19 of incubation (hatching is at 21 days). At each stage of incubation, blood samples were obtained from the chorioallantoic artery of chick embryos during normoxia and after 5 minutes of hypoxaemia for measurement of plasma concentrations of adrenaline and noradrenaline using HPLC.

3. Basal plasma adrenaline and noradrenaline concentrations by the end of the incubation period were much higher in the chick embryo than values reported for mammalian fetuses during late gestation. During normoxia, basal plasma noradrenaline concentrations remained unchanged during development but plasma adrenaline concentrations showed a developmental increase from < $25.1 \mathrm{pmol} \mathrm{r}^{-1}$ at day 10 to $3 \mathrm{nmol}^{-1}$ at day 19 of incubation. Acute hypoxaemia caused an increase in plasma noradrenaline and adrenaline from day 13 and day 16 of incubation, respectively. In addition, the increase in plasma adrenaline and noradrenaline, and in the ratio of plasma adrenaline to noradrenaline during acute hypoxaemia became progressively larger by the end of incubation period.

4. These data show an ontogenic increase in basal plasma catecholamines and in the catecholaminergic response to acute hypoxaemia in the chick embryo during the last third of the incubation period. 


\section{INTRODUCTION}

In the adult animal, maintenance of cardiovascular function is totally dependent on intact adrenal glands (Addison, 1855; Brown-Sequard, 1856). However, the role of the adrenal gland in fetal cardiovascular function and, more importantly, its contribution to the development of fetal cardiovascular responses to acute stress remains uncertain. Previous studies in the acutely exteriorised sheep fetus, showed that the increase in adrenal amine release, in response to electrical stimulation of either the adrenal gland or the peripheral end of the splanchnic nerves, became progressively larger with increasing gestational age and rose exponentially in the last days of pregnancy (Comline \& Silver, 1961). A progressive increase in the fetal plasma catecholaminergic response during gestation has been confirmed in the chronically instrumented sheep fetus during acute hypoxaemia (Iwamoto et al. 1989; Cheung, 1990).

In response to acute hypoxaemia, the sheep fetus initiates cardiovascular responses that have neural and endocrine components (Hanson, 1988; Giussani et al. 1994). Acute hypoxaemia stimulates a chemoreflex, initiated by the peripheral arterial chemoreceptors, particularly those located in the carotid arteries. Their activation mediates both an increase in efferent vagal activity to the fetal heart, resulting in bradycardia and an increase in sympathetic outflow, which produces vasoconstriction in the peripheral circulation and contributes to an increase in fetal arterial blood pressure (Giussani et al. 1993). After this initial carotid chemoreflex response, slower incoming endocrine mechanisms are stimulated, in particular the release of catecholamines (Cohen et al. 1984) and vasopressin (Rurak, 1978), which maintain the peripheral vasoconstriction during the hypoxaemic challenge (Perez et al. 1989; Giussani et al. 1993). As a consequence, cardiac output is redistributed towards the heart, the brain and the adrenal glands, away from the kidneys, the intestines and the rest of the body (Cohn et al. 1974; Peeters et al. 1979).

The redistribution of the cardiac output in response to acute hypoxaemia has also been documented in the chick embryo in the last third of the incubation period (Mulder et al. 1998). In addition, previous work from our laboratory has shown that the cardiovascular responses to acute hypoxaemia in the chick embryo also show a developmental pattern since peripheral vasoconstriction in response to hypoxaemia became progressively larger in the chick embryo by day 19 of incubation (Mulder et al. 1998). However, the ontogeny of the catecholaminergic response to acute hypoxaemia has not been investigated in this species.

Hence, the aims of the present study were to determine: 1) the plasma concentrations of adrenaline and noradrenaline during the development of chick 
embryos from day 10 of incubation and 2) the effect of increasing incubation time on the chick embryo catecholaminergic response to an episode of acute hypoxaemia.

\section{METHODS}

Fertilised eggs of White Leghorn chickens were incubated in a commercial incubator at $38^{\circ} \mathrm{C}$ and $60 \%$ humidity. Eggs were rotated constantly to avoid adhesions between the embryo and the membranes (Tazawa, 1981). In the present study we used chick embryos at day 10, day 13, day 16 and day 19 of incubation (hatching is at 21 days) which correspond to stages $36,39,42$ and 45 according to Hamburger and Hamilton (Hamburger \& Hamilton, 1951). For each day of incubation a separate group of chick embryos was studied; 60 chick embryos were used in total. Forty embryos were used for the measurement of plasma catecholamine levels at different incubation times $(n=10$ on days 10,13 , 16 , and 19). On each day plasma catecholamine levels were measured during normoxia in five embryos and during hypoxaemia in five other embryos. Twenty chick embryos were used for blood gas analyses during normoxia $(n=12)$ and during hypoxaemia $(n=8)$ between days 13 and 15 of incubation in order to document the magnitude and nature of the hypoxaemic event. All experiments complied with the Dutch law for animal experiments.

\section{PREPARATION}

All blood samples were obtained from punctures in the chorioallantoic artery, between the embryo's umbilicus and the chorioallantoic membrane, where gas exchange takes place. The procedure was performed inside a clinical infant incubator provided with a light microscope (WILD $3 \mathrm{M}$; magnification $\times 10$ ). Temperature and humidity were maintained constant at $38^{\circ} \mathrm{C}$ and $60 \%$, respectively. The eggs were opened at the air cell side and placed in a holder within a Plexiglas box. The oxygen concentration in the box was changed by supplying different warmed and humidified mixtures of $\mathrm{N}_{2}$ and $\mathrm{O}_{2}$ at a constant flow rate of $51 \mathrm{~min}^{-1}$. A small incision was made in the chorioallantoic membrane avoiding damage to the chorioallantoic vessels. A dark red pulsating chorioallantoic artery was identified. The embryo was then left for $15 \mathrm{~min}$ to recover before samples were taken. 


\section{PROTOCOL}

Blood samples were obtained by lifting the chorioallantoic artery using forceps followed by puncture of the artery with a 25 or 27 gauge needle. Samples were withdrawn in pre-heparinised syringes. For measurement of plasma catecholamine concentrations, blood samples $(0.2-1.0 \mathrm{ml})$ were taken from chick embryos on days 10,13,16 and 19 of incubation. Samples were taken from two separate groups: (a) at the 5 th minute of normoxia $\left(21 \% \mathrm{O}_{2}\right.$ in the Plexiglas box) and (b) at the 5th minute of hypoxaemia ( $100 \%$ of $\mathrm{N}_{2}$ in the Plexiglas box).

In order to document the magnitude and nature of the hypoxaemic challenge, blood samples $(0.2 \mathrm{ml})$ were taken from a separate group of chick embryos between days 13 and 15 of incubation for measurement of arterial blood gases and $\mathrm{pH}$ (corrected for the temperature of $38^{\circ} \mathrm{C}$ ). Twelve embryos were sampled after $5 \mathrm{~min}$ of normoxia and eight embryos after $5 \mathrm{~min}$ of hypoxaemia.

Immediately after the experiment the chick embryos were killed by decapitation.

\section{MEASUREMENTS}

Blood gases Blood samples $(0.2 \mathrm{ml})$ were collected in pre-heparinised syringes and analysed at $38^{\circ} \mathrm{C}$ using Radiometer ABL3 blood gas analyser (Copenhagen).

Catecholamines Blood samples $(0.2-1.0 \mathrm{ml})$ were collected into preheparinised syringes. Blood was drawn into test tubes filled with $25 \mu \mathrm{l}$ of glutathione-heparin solution (10 mg ml$~^{-1}$ glutathion, $5000 \mathrm{IU} \mathrm{ml}^{-1}$ heparin). Samples were centrifuged $\left(8^{\circ} \mathrm{C}, 2400 \mathrm{~g}\right)$ for 15 minutes and plasma stored at $-35{ }^{\circ} \mathrm{C}$. Plasma concentrations of adrenaline and noradrenaline were measured using fluorescence High Pressure Liquid Chromatography (HPLC), which has been previously described in detail (van der Hoorn, et al. 1989). The lower limit of detection of the assay was $0.46 \mathrm{pg} \mathrm{ml}^{-1}$ for adrenaline and $0.98 \mathrm{pg} \mathrm{ml}^{-1}$ for noradrenaline.

\section{DATA ANALYSES}

All data were processed using SigmaStat 2.0 software (Jandel Scientific Corporation). Data are expressed as median with interquartile range (IQR, $25^{\text {th }}$ to $75^{\text {th }}$ percentile). For statistical comparison, plasma concentrations of catecholamines that were below the lower detection limit of the assay, were assigned the value for the lower limit of detection. The Mann-Whitney rank sum test for independent samples was applied for analyses of changes in plasma catecholamine concentration between groups. 


\section{RESULTS}

BASELINE CATECHOLAMINE CONCENTRATIONS

Plasma adrenaline increased significantly from non-detectable concentrations at day 10 to $3.0 \mathrm{nmol} \mathrm{I}^{-1}$ (IQR, 1.09-6.60) at day 19. In contrast, plasma noradrenaline concentrations did not increase with incubation time (Table 1).

\section{Table 1}

Plasma catecholamines concentrations in chick embryo from day 10 to 19 of incubation

\begin{tabular}{lll} 
Day 10 & Normoxia $(n=5)$ & Hypoxia $(n=5)$ \\
\hline Adrenaline & $2.51 \times 10^{-3}\left(2.51 \times 10^{-3}-0.22\right)$ & $0.82(0.22-2.02)$ \\
Noradrenaline & $34.70(12.18-170.24)$ & $247.14(170.65-323.27)$
\end{tabular}

\begin{tabular}{lll} 
Day 13 & Normoxia $(n=5)$ & Hypoxia $(n=5)$ \\
\hline Adrenaline & $2.51 \times 10^{-5}\left(2.51 \times 10^{-5}-2.29\right)$ & $3.17(1.96-8.79)$ \\
Noradrenaline & $176.96(82.40-200.38)$ & $543.10(526.61-694.01)$ \\
\hline
\end{tabular}

\begin{tabular}{lll} 
Day 16 & Normoxia $(n=5)$ & Hypoxia $(n=5)$ \\
\hline Adrenaline & $0.33(0.22-5.57)$ & $26.09(12.44-42.90)^{*} \ddagger$ \\
Noradrenaline & $29.85(27.13-285.62)$ & $477.02(278.64-792.25)$
\end{tabular}

\begin{tabular}{lll} 
Day 19 & Normoxia $(n=5)$ & Hypoxia $(n=5)$ \\
\hline Adrenaline & $3.00(1.09-6.60) \dagger$ & $227.49(92.24-302.15)^{*} \ddagger$ \\
Noradrenaline & $63.78(43.98-183.54)$ & $806.97(480.45-1195.74)^{*} \ddagger$
\end{tabular}

Values are expressed in nmol. $\mathrm{r}^{1}$ as the median and 25 th -75 th percentile during normoxia and after 5 minutes of hypoxia.

Significant differences $(P<0.05)$ are as follows : " normoxia vs. hypoxia; $\uparrow v s$. normoxia group at day $10 ; \ddagger v s$. hypoxia group at day 10 .

\section{RESPONSE TO ACUTE HYPOXAEMIA}

Exposure of the chick embryo to $100 \%$ of $\mathrm{N}_{2}$ resulted in significant falls in arterial $\mathrm{PO}_{2}\left(\mathrm{~Pa}, \mathrm{O}_{2}\right)$ and in arterial $\mathrm{PCO}_{2}\left(\mathrm{~Pa}, \mathrm{CO}_{2}\right)$ (Table 2). The median arterial $\mathrm{Pa}, \mathrm{O}_{2}$ in the control group $\left(21 \% \mathrm{O}_{2}\right)$ was $37.7 \mathrm{mmHg}$ (IQR, $\left.30.5-46.8 \mathrm{mmHg}\right)$. At the fifth minute of hypoxaemia the median arterial $\mathrm{Pa}, \mathrm{O}_{2}$ had declined to 8.7 $\mathrm{mmHg}$ (IQR, 6.7-10.6 mmHg). Similarly, the median arterial $\mathrm{Pa}, \mathrm{CO}_{2}$ in the control group $\left(21 \% \mathrm{O}_{2}\right)$ was $34.6 \mathrm{mmHg}(\mathrm{IQR}, 30.3-41.5 \mathrm{mmHg})$. At the fifth minute of hypoxaemia the median arterial $\mathrm{Pa}, \mathrm{CO}_{2}$ had decreased to $23.9 \mathrm{mmHg}$ (IQR, 
22.5-28.7 $\mathrm{mmHg}$ ). Although there was a trend for arterial $\mathrm{pH}$ to increase during the acute hypocapnic hypoxaemic challenge, this trend did not reach significance (Table 2).

Table 2 Arterial blood gases and pH in chick embryos between days 13 and 15 of incubation

\begin{tabular}{lcc}
\hline & $\begin{array}{c}\text { Normoxia } \\
(\mathrm{n}=12)\end{array}$ & $\begin{array}{c}\text { Hypoxia } \\
(\mathrm{n}=8)\end{array}$ \\
\hline Arterial pH & $7.35(7.32-7.42)$ & $7.42(7.41-7.44)$ \\
$\mathrm{P}_{\mathrm{a} \mathrm{CO}_{2}(\mathrm{kPa})}$ & $4.6(4.0-5.5)$ & $3.2(3.0-3.8)^{*}$ \\
$\mathrm{P}_{\mathrm{s}}(\mathrm{OPa})$ & $5.0(4.1-6.2)$ & $1.2(0.9-1.4)^{*}$
\end{tabular}

Values are expressed as median and 25th -75 th percentile (in paracenteses) during normoxia and after 5 minutes of hypoxia. " Significant difference $(P<0.05)$ for normoxia vs hypoxia.

Plasma adrenaline concentration was significantly elevated during acute hypoxaemia from day 16 of incubation (Table 1 and Fig. 1A). Plasma adrenaline concentration increased from $0.33 \mathrm{nmol} \mathrm{I}^{-1}\left(\right.$ IQR, $\left.0.22-5.57 \mathrm{nmol} \mathrm{I}^{-1}\right)$ in normoxia to $26.09 \mathrm{nmol} \mathrm{I}^{-1}\left(\mathrm{IQR}, 12.44-42.90 \mathrm{nmol} \mathrm{I}^{-1}\right)$ during hypoxia at day 16 and from 3.00 $\mathrm{nmol} \mathrm{I}^{-1}\left(\mathrm{IQR}, 1.09-6.60 \mathrm{nmol}^{-1}\right)$ to $227.49 \mathrm{nmol} \mathrm{I}^{-1}\left(\mathrm{IQR}, 92.24-302.15 \mathrm{nmol} \mathrm{I}^{-1}\right.$ ) at day 19 of incubation. Similarly, plasma noradrenaline concentrations increased from $176.96 \mathrm{nmol} \mathrm{I}^{-1}$ (IQR, 82.40-200.38 $\mathrm{nmoll}^{-1}$ ) to $543.10 \mathrm{nmol} \mathrm{I}^{-1}$ (IQR, 526.61$694.01 \mathrm{nmol} \mathrm{I}^{-1}$ ) during hypoxia at day 13 , from $29.85 \mathrm{nmol} \mathrm{I}^{-1}$ (IQR, 27.13-285.62 $\mathrm{nmol} \mathrm{I}^{-1}$ ) to $477.02 \mathrm{nmol} \mathrm{I}^{-1}\left(\right.$ IQR, 278.64-792.25 $\mathrm{nmol} \mathrm{I}^{-1}$ ) at day 16, and from $63.78 \mathrm{nmol} \mathrm{r}^{-1}$ (IQR, 43.98-183.54 $\mathrm{nmol} \mathrm{r}^{-1}$ ) to $806.97 \mathrm{nmol} \mathrm{r}^{-1}$ (IQR, 480.45$\left.1195.74 \mathrm{nmol} \mathrm{r}^{-1}\right)$ at day 19 of incubation. However the increase in plasma noradrenaline at day 16 of incubation did not reach significance $(P=0.056$; Fig1B).

\section{RATIO OF PLASMA ADRENALINE TO NORADRENALINE}

Baseline plasma catecholamine concentrations showed an increase in the ratio of adrenaline to noradrenaline from $1.7 \times 10^{-4}$ at day 10 to $3.0 \times 10^{-2}$ at day 19; however this increase fell below the significance level (Fig. $2 A$ ). In contrast, a significant increase in the ratio of plasma adrenaline to noradrenaline in response to acute hypoxaemia occurred during development from $4.7 \times 10^{-3}$ at day 10 to 0.24 at day 19 (Fig. $2 B$ ). 


\section{$82 \mid$ Chapter 4}

Fig 1 Developmental changes in plasma concentration of catecholamines in response to acute hypoxaemia in the chick embryo

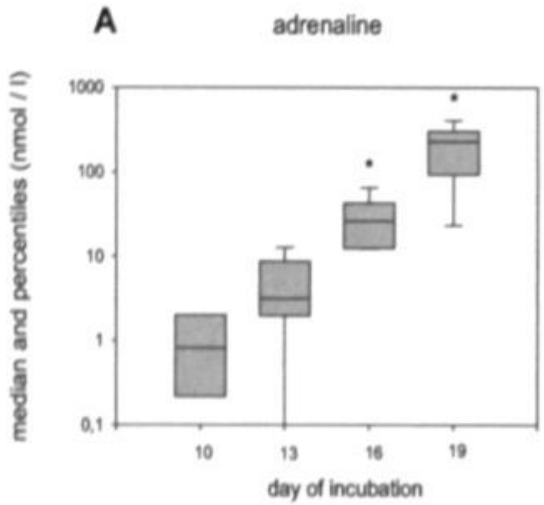

B noradrenaline

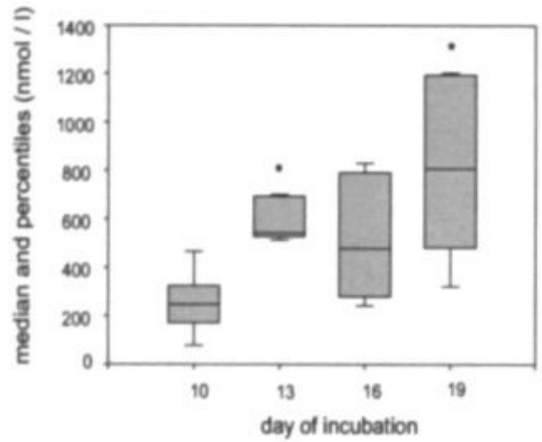

Values are expressed as boxplots representing the $10^{\text {th }}$ percentile, $25^{\text {th }}$ percentile, median, $75^{\text {th }}$ percentile and $90^{\text {th }}$ percentile for plasma adrenaline $(A)$ and noradrenaline $(B)$ at the 5 th minute of acute hypoxaemia on days $10,13,16$ and 19 of incubation. ${ }^{*}$ Significant difference $(P<0.05)$ vs. day 10 of incubation.

Fig 2 Developmental changes in the ratio of plasma concentrations of adrenaline : noradrenaline.

A

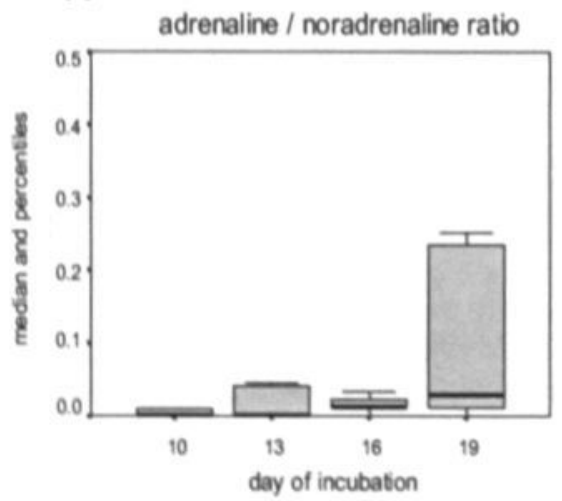

B

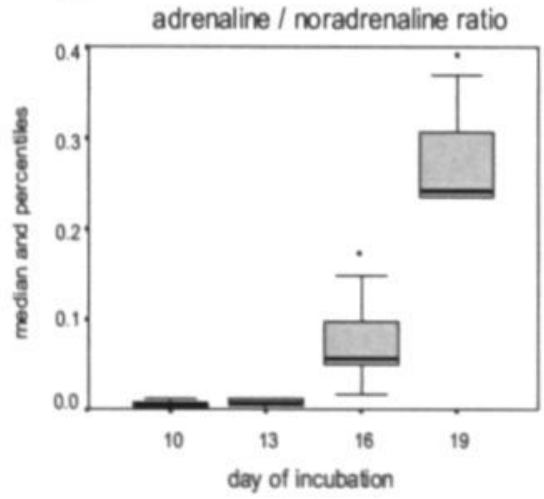

Values are expressed as boxplots representing the10th percentile, $25^{\text {th }}$ percentile, median, $75^{\text {th }}$ percentile and $90^{\text {th }}$ percentile for the ratio of plasma adrenaline to noradrenaline during normoxia $(A)$ and at the 5 th minute of acute hypoxaemia $(B)$ on days $10,13,16$ and 19 of incubation. ${ }^{*}$ Significant difference $(P<0.05):{ }^{*} v$ s. day 10 of incubation. 


\section{DISCUSSION}

The present study describes baseline plasma catecholamine concentrations in the chick embryo during the second half of the incubation period and the catecholaminergic response to an acute hypoxaemic event.

Catecholamines seem to be important during embryonal development since knockout mouse embryos for endothelial PAS domain protein 1 (EPAS1), a hypoxia-inducible transcription factor expressed in endothelial cells and sympatho-adrenal cells, and knockout mouse embryos for tyrosine hydroxylase, which are both unable to synthesise catecholamines, die at mid gestation of cardiovascular failure (Zhou et al. 1995; Kobayashi et al. 1995; Tian et al. 1998). In contrast, previous studies in fetal sheep during late gestation showed no significant effect on basal fetal heart rate or arterial blood pressure of adrenalectomy (Ray et al. 1988; Unno et al. 1999) or of adrenal demedullation by pharmacological treatment (Jones et al. 1987). In combination, these findings suggest that the presence of catecholamines early in gestation is indispensable for the normal development of cardiovascular function and, in contrast, late in gestation circulating catecholamines from the adrenal medulla do not contribute to basal cardiovascular function. Extra-adrenal sources for catecholamine production may develop late in gestation, since para-aortic chromaffin tissue becomes hypertrofic following adrenalectomy (Jones et al. 1987). In addition catecholamines do play an important role late in gestation in the response to an acute hypoxaemic insult, in redistributing the cardiac output away from the periphery to the vital organs, as described in the Introduction.

In the chick embryo, the adrenal medullary cells arise from the sympathetic chains on the fourth day of incubation time (Sanchez-Montesinos et al. 1996) and catecholamines have been detected in very small amounts from day 5 in allantoic fluid (Boucek \& Bourne, 1962). Although the chick embryo heart does not have sympathetic innervation before day 5 of incubation (Romanoff, 1960), catecholamines can be detected in the heart from day 3 of incubation. At that time, catecholamines appear to be accumulated in the yolk and maternal in origin (Ignarro \& Shideman, 1968). After day 14-16 of incubation, adrenergic axons to the heart can release sufficient transmitter to influence right ventricular function (Higgins \& Pappano, 1981). Innervation of the adrenals starts at day 8 of incubation with formation of chromaffin cells, and seems to become functional at day 10 of incubation (Fujita et al. 1976). In the adrenal gland, adrenaline concentration is relatively low until day 15 , after which time it increases markedly towards hatching (Wassermann \& Bernard, 1970). Detection of catecholamines in plasma has been reported for the chick embryo at days 10 and 14 of incubation, as has an increase in the plasma concentration 


\section{4| Chapter 4}

of noradrenaline in response to asphyxia at day 14 (Epple et al. 1992). This sympatho-adrenal development in the second half of gestation resembles that in fetal lamb and fetal human in contrast to sympatho-adrenal development in fetal rat and rabbits, which is later in gestation and partly postnatal (Lagercrantz, 1998). The present study confirms a developmental increase in baseline plasma adrenaline concentration in the chick embryo and extends previous findings to report a developmental increase in the catecholaminergic response to episodes of acute hypoxaemia.

Basal plasma catecholamine concentrations in the chick embryo are very high compared with data obtained from the mammalian fetus. Compared with the sheep fetus near term (Cheung, 1990; Fowden et al. 1998), baseline plasma noradrenaline concentration was 60 -fold higher, and baseline plasma adrenaline concentration was 5-fold higher in the chick embryo on day 19 of incubation. Other reports on plasma catecholamine concentrations in the chick embryo show comparatively high circulating concentrations (Wittmann \& Prechtl, 1991; Epple et al. 1992). In addition, plasma catecholamine concentrations in the adult chicken have been reported to be much higher than those in adult mammals (Kamimura et al. 1995).

In the present study, there was a developmental increase in baseline plasma adrenaline concentration, but not in baseline plasma noradrenaline concentration, from day 10 to day 19 of incubation in the chick embryo. High circulating levels of noradrenaline early in incubation in the chick embryo may be from extra-adrenal sources such as the para-aortic chromaffin tissue, which has been described in the human fetus (Lagercrantz \& Slotkin, 1986) and from sympathetic nerve endings. It is not known to what extent these sources contribute to plasma catecholamine concentrations. That the developmental increase in baseline catecholamine concentration is primarily due to an increase in adrenaline, but not in noradrenaline, concentration has also been described in the sheep fetus (Fowden et al. 1998). Similarly, while basal output of noradrenaline from fetal sheep adrenal glands in vitro did not change with increasing gestation time, basal output of adrenaline showed an exponential rise by the end of gestation (Butler et al. 1995). In sheep, the increase in plasma adrenaline concentration during gestation parallels the pre-partum increase in fetal plasma cortisol concentration (Fowden et al. 1998). It is possible that the pre-parturient increase in fetal plasma cortisol leads to an increase in phenylethanolamine $\mathrm{N}$-methyltransferase (PNMT; Bohn et al. 1981; Padbury, 1989; Adams et al. 1998), the enzyme responsible for the last step of adrenaline synthesis, the conversion of noradrenaline to adrenaline. 
Additional data reported in the present manuscript suggest that the chick embryo is able to increase plasma noradrenaline and adrenaline concentrations in response to an episode of acute hypoxaemia from day 13 and day 16 of incubation, respectively. Furthermore, these catecholaminergic responses to acute hypoxaemia mature with incubation time in the chick embryo, as evidenced by a progressive increase in the plasma concentrations of adrenaline and noradrenaline, and in the ratio of plasma adrenaline to noradrenaline during acute hypoxaemia. These developmental changes in the ability of the chick embryo to mount a significant catecholaminergic response to an episode of acute stress are similar to those reported in the sheep fetus. Iwamoto et al. (1989) and Padbury et al. (1989) reported that the sheep fetus is able to release catecholamines into its circulation at $60 \%$ of gestation. Similarly, fetal sheep and fetal calf plasma concentrations of adrenaline and noradrenaline in response to acute hypoxaemia become progressively larger with increasing gestation (Comline \& Silver, 1961; Widmark et al. 1989). In the sheep and the calf fetus, adrenal medulla adrenaline release may be regulated by sympathetic stimulation of the splanchnic nerves (Comline \& Silver, 1961) and by the direct action of hypoxia on the adrenal gland (Comline \& Silver, 1961, 1966a,b; Cheung, 1990; Rychkov et al. 1998). The latter studies also showed that the direct effect of hypoxia on adrenaline release from the adrenal gland becomes less important towards term, when functional innervation of the adrenal gland is completed.

The present study reports that plasma noradrenaline concentration in response to acute hypoxaemia becomes significantly elevated at day 13 of incubation in the chick embryo. In contrast, plasma adrenaline levels in response to acute hypoxaemia only rise significantly after day 16 of incubation and show a marked response by day 19 . These findings suggest that noradrenaline release in response to acute hypoxaemia at day 13 of incubation is likely to be the result of direct stimulation of chromaffin cells by hypoxia in the chick embryo. In contrast, the exponential increase in plasma adrenaline concentration during acute hypoxaemia after day 16 of incubation parallels the rapid increase in the adrenaline content of the adrenal glands in the chick embryo (Wassermann \& Bernard, 1970), and is likely to reflect the development of neural sympathetic stimulation of the adrenal glands during acute hypoxaemia.

In response to an episode of acute hypoxaemia, the sheep fetus (Cohn et al. 1974) and the chick embryo (Mulder et al. 1998) show a marked peripheral vasoconstriction which aids the redistribution of the cardiac output towards the adrenal, myocardial and cerebral circulations. In the sheep fetus, peripheral vasoconstriction during acute hypoxaemia is triggered by a carotid chemoreflex (Giussani et al. 1993) and is maintained by the release of humoral 
vasoconstrictors such as catecholamines into the fetal circulation (Cohen et al. 1984). The ontogenic increase in the peripheral vasoconstriction during acute hypoxaemia previously reported for the chick embryo (Mulder et al. 1998) parallels the maturation of the catecholaminergic response to acute hypoxaemia in the chick embryo reported in the present study. Hence, the maturation of the catecholaminergic response to acute hypoxaemia in the chick embryo may reflect the development of an important defence mechanism which helps to redistribute cardiac output away from the periphery towards important circulations during situations of acute stress.

In this study we present data on plasma catecholamine concentrations obtained from chick embryos at different incubation times during basal and acute hypoxaemic conditions. It was inherent to the method that we could obtain just one blood sample for each embryo during one specific condition, which might introduce variability in the results since the data comes from different groups of embryos, that is one group for basal conditions and one group for hypoxaemic conditions. On the other hand we believe that the group used for basal concentrations might have suffered somewhat stress situation during the sampling, which could have produced more elevated basal levels. Since the difference between basal and hypoxaemic levels are large, we don't believe that this presents a problem for the interpretation of the results. Moreover it could be that the difference is even larger between basal and hypoxaemic conditions using an unstressed control group.

In conclusion, the data reported in the present manuscript show that baseline plasma catecholamine concentrations in the chick embryo are high compared with those of other species. While plasma noradrenaline concentration remains unchanged from baseline, plasma adrenaline concentration shows a marked increase by the end of the incubation period. In addition, the chick embryo is able to increase plasma adrenaline and noradrenaline concentrations in response to acute hypoxaemia from day 13 of incubation. This catecholaminergic response to acute hypoxaemia matures during incubation since the increases in plasma adrenaline, plasma noradrenaline and the ratio of plasma adrenaline to noradrenaline all become progressively larger as the chick embryo approaches hatching. 


\section{REFERENCES}

AdAMS, M. B., PhILLIPS, I. D., SimonettA, G. \& MCMiLlen, I. C. (1998). Differential effects of increasing gestational age and placental restriction on tyrosine hydroxylase, phenylethanolamine $\mathrm{N}$ - methyltransferase, and proenkephalin A mRNA levels in the fetal sheep adrenal. Joumal of Neurochemistry 71, 394-401.

ADoison, T. (1855). On the constitutional and local effects of the suprarenal capsules. London, S. Highley.

BOHN, M. C., GoLDSTEIN, M. \& BLACK, I. B. (1981). Role of glucocorticoids in expression of the adrenergic phenotype in rat embryonic adrenal gland. Developmental Biology 82, 1-10.

BOUCEK, R. J. \& BOURNE, B. (1962). Catecholamines of the allantoic fluid in the developing chick embryo. Nature 193, 1181-2.

BROWN-SEQUARD, C. E. (1856). Recherches experimentales sur la physiologie et la pathologie des capsules surrenales. Comptes Rendus de I'Academie des Sciences. 43, 422-425.

BUTLER, T. G., SiMONEtTA, G., ROBerTS, M. L. \& MCMillen, I. C. (1995). Impact of gestational age on the catecholamine responses of the fetal sheep adrenal to cholinergic stimulation in vitro. Experimental Physiology 80, 767-77.

CHEUNG, C. Y. (1990). Fetal adrenal medulla catecholamine response to hypoxia-direct and neural components. American Joumal of Physiology 258, R1340-6.

COHEN, W. R., PIASECKI, G. J., COHN, H. E., Young, J. B. \& JACKSON, B. T. (1984). Adrenal secretion of catecholamines during hypoxemia in fetal lambs. Endocrinology 114, 383-90.

CoHn, H. E., SACKS, E. J., HeymanN, M. A. \& RudOLPH, A. M. (1974). Cardiovascular responses to hypoxemia and acidemia in fetal lambs. American Joumal of Obstetrics and Gynecology 120, 817-824.

COMLINE, R. S. \& SiLveR, M. (1961). The release of adrenaline and noradrenaline from the adrenal glands of the foetal sheep. Journal of Physiology 156, 424-44.

COMLINE, R. S. \& SiLveR, M. (1966a). Development of activity in the adrenal medulla of the foetus and new- born animal. British Medical Bulletin 22, 16-20.

COMLINE, R. S. \& SILVER, M. (1966b). The development of the adrenal medulla of the foetal and new-born calf. Journal of Physiology 183, 305-40.

Epple, A., GILL, T. S. \& NiBBio, B. (1992). The avian allantois: a depot for stress-released catecholamines. General and Comparitive Endocrinology 85, 462-76.

FoWden, A. L., MUNDY, L. \& SILVER, M. (1998). Developmental regulation of glucogenesis in the sheep fetus during late gestation. Journal of Physiology 508, 937-47. 
FujITA, H., TANizAWA, Y., HIURA, M. (1976). Ontogenesis of granule formation in adrenal chromaffin cells of the chick. In Chromaffin, Enterochromaffin and Related Cells, ed. Coupland, R. E., Fujita, T. pp 1-12. Elsevier Scientific Publishing Company, Amsterdam.

Giussani, D. A., SPencer, J. A., MOORE, P. J., Bennet, L. \& HANSON, M. A. (1993). Afferent and efferent components of the cardiovascular reflex responses to acute hypoxia in term fetal sheep. Joumal of Physiology 461, 431-49.

GIUssani, D. A., SPEncer, J. A. D. \& HANSON, M. A. (1994). Fetal cardiovascular reflex responses to hypoxaemia. Fetal and Matemal Medicine Review 6, 17-37.

HAMBuRger, V. \& HAMiLTON, H. L. (1951). A series of normal stages in the development of the chick embryo. Joumal of Morphology 88, 49-92.

HANSON, M. A. (1988). The importance of baro- and chemoreflexes in the control of the fetal cardiovascular system. Journal of Developmental Physiology 10, 491-511.

HigGins, D. \& PAPPANO, A. J. (1981). Development of transmitter secretory mechanisms by adrenergic neurons in the embryonic chick heart ventricle. Developmental Biology 87, 148-62.

IGNARRO, L. J. \& SHIDEMAN, F. E. (1968). Norepinephrine and epinephrine in the embryo and embryonic heart of the chick: uptake and subcellular distribution. Joumal of Pharmacology and Experimental Therapeutics 159, 49-58.

IWAMOTO, H. S., KAUfMAN, T., KEIL, L. C. \& RUdOLPH, A. M. (1989). Responses to acute hypoxemia in fetal sheep at 0.6-0.7 gestation. American Journal of Physiology 256, H613-620.

Jones, C. T., Roebuck, M. M., WALKer, D. W., LAgercrantZ, H. \& JOHNSTON, B. M. (1987). Cardiovascular, metabolic and endocrine effects of chemical sympathectomy and of adrenal demedullation in fetal sheep. Joumal of Developmental Physiology 9, 347-67.

KAMIMURA, K., NiSHIMURA, H. \& BAILEY, J. R. (1995). Blockade of beta-adrenoceptor in control of blood pressure in fowl. American Joumal of Physiology 269, R914-22.

KOBAYASHI, K., MORItA, S., SAWAdA, H., MizUguchI, T., YamadA, K., Nagatsu, I., HatA, T., WATANABE, Y., FuJITA, K., NAGATSU, T. (1995). Targeted disruption of the tyrosine hydroxylase locus results in severe catecholamine depletion and perinatal lethality in mice. Joumal of Biological Chemistry 270, 27235-43.

LAGERCRANTZ, H. (1998). Sympathoadrenal mechanisms during development. In Fetal and Neonatal Physiology, ed. Polin, R.A. \& Fox, W.W. pp 220-225. W.B. Saunders Company, Philadelphia.

Lagercrantz, H. \& Slotkin, T. A. (1986). The "stress" of being born. Scientific American 254, $100-7$.

mulder, A. L. M., van Golde, J. C., Prinzen, F. W. \& Blanco, C. E. (1998). Cardiac output distribution in response to hypoxia in the chick embryo in the second half of the incubation time. Joumal of Physiology 508, 281-287. 
PADBURY, J. F. (1989). Functional maturation of the adrenal medulla and peripheral sympathetic nervous system. Baillieres Clinical Endocrinology and Metabolism 3, 689-705.

Peeters, L. L. H., Sheldon, R. E., Jones, M. D. J., MAKowski, E. L. \& MeschiA, G. (1979). Blood flow to fetal organs as a function of arterial oxygen content. American Joumal of Obstetrics and Gynecology 135, 637-646.

Perez, R., Espinoza, M., Riquelme, R., Parer, J. T. \& Llanos, A. J. (1989). Arginine vasopressin mediates cardiovascular responses to hypoxemia in fetal sheep. American Joumal of Physiology 256, R1011-8.

RAY, N. D., TURneR, C. S., RAWASHDEH, N. M. \& Rose, J. C. (1988). Ovine fetal adrenal gland and cardiovascular function. American Joumal of Physiology 254, R706-10.

Romanoff, A. L. (1960). The Avian Embryo. Structural and functional development. The Macmillan Company, New York.

RURAK, D. W. (1978). Plasma vasopressin levels during hypoxaemia and the cardiovascular effects of exogenous vasopressin in foetal and adult sheep. Joumal of Physiology 277, 341-57.

RYCHKOV, G. Y., ADAMS, M. B., MCMILLEN, I. C. \& RoBeRTS, M. L. (1998). Oxygen-sensing mechanisms are present in the chromaffin cells of the sheep adrenal medulla before birth. Journal of Physiology 509, 887-93.

Sanchez-Montesinos, I., Merida-Velasco, J.A., Espin-FerRA, J., Scopsi, L. (1996). Development of the sympathoadrenal system in the chick embryo: An Immunocytochemical study with antibodies to pan-neuroendocrine markers, catecholamine-synthesizing enzymes, proprotein-processing enzymes, and neuropeptides. Anatomical Record 245, 94-101.

TAZAWA, H. (1981). Adverse effect of failure to turn the avian egg on the embryo oxygen exchange. Respiratory Physiology 41, 137-142.

Tian, H., hammer, R. E., Matsumoto, A. M., Russell, D. W. \& MCKNight, S. L. (1998). The hypoxia-responsive transcription factor EPAS1 is essential for catecholamine homeostasis and protection against heart failure during embryonic development. Genes \& Development 12, 3320-4.

UnNo, N., Wong, C. H., Jenkins, S. L., WentWorth, R. A., Ding, X. Y., LI, C., Robertson, S. S., SMOTHERMAN, W. P. \& NATHANiElsz, P. W. (1999). Blood pressure and heart rate in the ovine fetus: ontogenic changes and effects of fetal adrenalectomy. American Journal of Physiology 276, H248-56.

VAN DER HOORN, F. A., BOOMSma, F., MAN IN 'T Veld, A. J. \& SchalekAmp, M. A. (1989). Determination of catecholamines in human plasma by high-performance liquid chromatography: comparison between a new method with fluorescence detection and an established method with electrochemical detection. Journal of Chromatography 487, 17-28.

WASSERMANN, G. F. \& BeRnARD, E. A. (1970). Adrenaline content of the chick embryo adrenal gland during development. Acta Physiologica Latino Americana 20, 171-3. 


\section{0| Chapter 4}

WidMARK, C., HoKegard, K. H., LAgercrantz, H., LILJA, H. \& Rosen, K. G. (1989). Electrocardiographic waveform changes and catecholamine responses during acute hypoxia in the immature and mature fetal lamb. American Joumal of Obstetrics and Gynecology 160, 1245-50.

WITTMANN, J. \& PRECHTL, J. (1991). Respiratory function of catecholamines during the late period of avian development. Respiration Physiology 83, 375-86.

Zhou, Q. Y., QuAife, C. J. \& PALMiteR, R. D. (1995). Targeted disruption of the tyrosine hydroxylase gene reveals that catecholamines are required for mouse fetal development. Nature 374, 640-3. 


\title{
Chapter 5
}

\section{Alpha-adrenergic contribution to the cardiovascular}

\section{response to acute hypoxaemia in the chick embryo}

\author{
A.L.M. Mulder ${ }^{1}$, C.A. van Goor ${ }^{1}$, D.A. Giussani ${ }^{2}$, C.E. Blanco ${ }^{1}$
}

1 Department of Pediatrics, University Hospital Maastricht and Research Institute GROW, Maastricht University, The Netherlands

2 Department of Physiology, University of Cambridge, Downing Street, Cambridge CB2 3EG, United Kingdom 
$92 \mid$ CHAPTER 5

\section{ABSTRACT}

Fetal responses to acute hypoxaemia include bradycardia, increase in blood pressure and peripheral vasoconstriction. Peripheral vasoconstriction contributes to the redistribution of the cardiac output away from ancillary vascular beds toward myocardial, cerebral and adrenal circulations. We investigated the effect of $\alpha$-adrenergic receptor blockade on this fetal response. Fluorescent microspheres were used to measure cardiac output distribution during basal and hypoxaemic conditions with and without phentolamine treatment. Phentolamine altered basal cardiac output distribution, indicating a basal $\alpha$-adrenergic tone, but this was mainly noted at the earlier stages of incubation. During hypoxaemia phentolamine prevented vasoconstriction in the carcass. At day 19 of incubation, the percent cardiac output distributed to the carcass increased by $20 \%$ compared with a decrease in the control group by $17 \%$. Phentolamine markedly attenuated the subsequent redistribution of the cardiac output toward the brain (from $+102 \%$ in the control group to $-25 \%$ in the phentolamine treated group) and the heart (from $+196 \%$ in the control group to $+69 \%$ in the phentolamine-treated group). In the chick embryo $\alpha$-adrenergic mechanisms contribute to the maintenance of basal vascular tone and to the redistribution of the cardiac output away from the peripheral circulations toward the brain and heart during hypoxaemic conditions. 
ALPHA-ADRENERGIC CONTROL $\mid 93$

\section{INTRODUCTION}

The fetus may be exposed to episodes of hypoxaemia during development and, in particular, during the actual processes of labor and delivery (Mann, 1986). The mature mammalian fetus has developed protective mechanisms to survive such hypoxaemic episodes, which include transient bradycardia, an increase in arterial blood pressure and peripheral vasoconstriction (Hanson, 1988) (Giussani et al. 1994b). Peripheral vasoconstriction largely contributes to the redistribution of the fetal cardiac output away from ancillary circulations toward the adrenal, myocardial and cerebral vascular beds (Reuss et al. 1982) (Giussani et al. 1993).

The physiological mechanisms mediating these cardiovascular responses involve neural and endocrine components. Studies in fetal sheep in late gestation have shown that the initial peripheral vasoconstriction in response to hypoxaemia is part of a carotid chemoreflex that is mediated via $\alpha$-adrenergic efferent pathways, inasmuch as it can be abolished by carotid sinus nerve section (Bartelds et al. 1993; Giussani et al. 1993) or by $\alpha$ adrenergic receptor blockade with phentolamine (Giussani $\theta t$ al. 1993). Once the carotid chemoreflex vasoconstriction is triggered, endocrine agents such as catecholamines (Jones \& Robinson, 1975), arginine vasopressin (Giussani et al. 1994a), angiotensin II (Green et al. 1998) and neuropeptide Y (Fletcher et al. 2000) are released into the fetal circulation to maintain peripheral vasoconstriction throughout the duration of the hypoxaemic challenge.

Studies in fetuses of other species have shown that the contribution of neuroendocrine mechanisms to the fetal cardiovascular responses to acute stress may be modified by the intrauterine environment. For example, the fetal llama, a species adapted to the chronic hypobaric hypoxia of life at altitude (Moraga et al. 1996), shows an intense peripheral vasoconstrictor response to acute hypoxaemia that is mediated by up regulated $\alpha$-adrenergic mechanisms (Giussani et al. 1996).

The redistribution of the cardiac output in response to acute hypoxaemia has also previously been documented in the chick embryo in the last half of the incubation period (Mulder et al. 1998). The cardiovascular responses to acute hypoxaemia in the chick embryo show a developmental pattern, with peripheral vasoconstriction becoming progressively more intense by day 19 of incubation (hatching $=21$ days) (Mulder et al. 1998). Additional studies from our laboratory have reported high concentrations of circulating catecholamines in response to acute hypoxaemia in the chick embryo relative to those measured in the sheep fetus at comparable stages of gestation or 
incubation (Mulder et al. 2000). In addition, this plasma catecholaminergic response to acute hypoxaemia also becomes progressively larger with advancing incubation time (Mulder et al. 2000), and in vitro studies, using femoral arteries isolated from chick embryos, have shown pronounced $\alpha_{1-}$ adrenergic contractile responses that also increase from day 15 to day 19 of incubation (Le Noble et al. 2000). Therefore, previous studies largely support the hypothesis that, in the chick embryo, peripheral vasoconstriction and redistribution of the cardiac output away from ancillary circulations are highly dependent on $\alpha$-adrenergic pathways. In the present study, we have tested this hypothesis by investigating the effects of treatment of the chick embryo with the $\alpha$-adrenergic receptor antagonist phentolamine on the redistribution of the cardiac output in response to acute hypoxaemia at different stages of incubation.

\section{METHODS}

\section{PREPARATION}

Fertilized eggs of White Leghorn chickens were maintained in a commercial incubator at a temperature of $38^{\circ} \mathrm{C}$ and $60 \%$ humidity. At the desired incubation time, the eggs were transferred to a clinical infant incubator and catheterized as previously described in detail (Mulder et al. 1997). Briefly, eggs were opened at the air cell and placed in a holder within a Plexiglas box. A polyethylene catheter stretched by heat to a diameter of $100 \mu \mathrm{m}$ was inserted in a chorioallantoic vein. Clay was used to fix the catheter to the eggshell. Later, the catheter was used for injections of fluorescent microspheres and phentolamine or saline solution. Throughout the procedure, the $\mathrm{O}_{2}$ concentration in the box was maintained by supplied mixtures of warmed and humidified $\mathrm{N}_{2}$ and $\mathrm{O}_{2}$, delivered at a constant flow of $5 \mathrm{I} \mathrm{min}^{-1}$.

\section{EXPERIMENTAL PROTOCOL}

Sixty chick embryos were included in this study. At days 11, 15 and 19 of incubation, 10 chick embryos were randomly assigned to a control group and 10 to an experimental group. Cardiac output distribution was measured by injection of $15-\mu \mathrm{m}$ fluorescent microspheres (Fluospheres ${ }^{\circ}$ Molecular Probes Inc, Eugene, OR, USA) suspended in saline and $0.05 \%$ Tween 80 $(1,000,000 \mathrm{spheres} / \mathrm{ml})$. In each control and each experimental group, at each stage of incubation, $0.04 \mathrm{ml}(40,000$ spheres) of the suspension of bluegreen fluorescent microspheres were injected for measurement of basal cardiac output distribution. Thereafter, each control group was injected with saline $(0.9 \% \mathrm{NaCl})$, and each experimental group was treated with phentolamine (Sigma Chemical Company; $2.5 \mu \mathrm{g} \mathrm{g}^{-1}$ in $5 \mu \mathrm{g} \mathrm{g}^{-1}$ embryo). After 
$5 \mathrm{~min}, 40,000$ orange fluorescent microspheres were injected to determine the effect of $\alpha$-adrenergic receptor blockade on basal cardiac output distribution. After 1 min, acute hypoxaemia was induced in the chick embryo by changing the supplied gas mixture to $100 \% \mathrm{~N}_{2}$ for 5 min. Previous studies have shown that this regimen results in a fall in the arterial $\mathrm{PO}_{2}$ of the chick embryo from $5.11 \pm 0.38 \mathrm{kPa}$ to $1.20 \pm 0.21 \mathrm{kPa}$ (Mulder et al. 2000). After $5 \mathrm{~min}$ of hypoxaemia, 40,000 crimson fluorescent microspheres were injected to determine the effect of $\alpha$-adrenergic receptor blockade on cardiac output distribution during the hypoxaemic challenge. At the end of the experiment, 5 min after normoxia was reestablished, all chick embryos were decapitated and the chorioallantoic membrane (CAM), brain, heart, lungs, intestine, liver and the yolk-sac were dissected for measurement of microsphere distribution (Mulder et al. 2000). All experiments complied with the Dutch law for animal experimentation.

\section{MEASUREMENT OF MICROSPHERE DISTRIBUTION}

Organs and the remaining carcass were digested in test tubes in a $2 \mathrm{M}$ ethanol-KOH solution. The microspheres were isolated from the homogenate by centrifugation, a method shown to result in recovery of $\sim 100 \%$ of microspheres (van Oosterhout et al. 1995). The dye was extracted with $3 \mathrm{ml}$ of 2-(2-ethoxyethoxy)ethylacetate, and the fluorescence was measured by fluorometry using a fluorospectrometer (model LS-50B, Perkin Elmer). No correction for spectral overlap was used, since the excitation and emission spectra of the three dyes were well separated. The fraction of cardiac output that was directed to the tissue was expressed as the level of the fluorescence of the sample, corrected for background, divided by the sum of fluorescence of all tissues (Mulder et al. 1998).

\section{ANALYSIS OF DATA}

All data were processed using SPSS statistical software. Values are means \pm SE unless stated otherwise. Within-group comparisons were assessed for statistical significance using the Wilcoxon signed ranks test. Between-group comparisons were assessed using the Mann Whitney $U$ test and the Kruskal-Wallis test. For all statistical comparisons, significance was accepted when $P<0.05$. 


\section{RESULTS}

\section{BASAL CARDIAC OUTPUT DISTRIBUTION}

Baseline data for cardiac output distribution are shown in Fig. 1. The data are from control and experimental groups ( $n=20$ per incubation period) before the injection of saline or phentolamine. Cardiac output was largely distributed to the CAM and the carcass during basal conditions at all stages of incubation studied (Fig. 1). With increasing incubation time, the fractions of the cardiac output directed to the heart, lungs, brain, intestine and carcass increased, and those directed to the yolk sac and CAM decreased (Fig. 1).

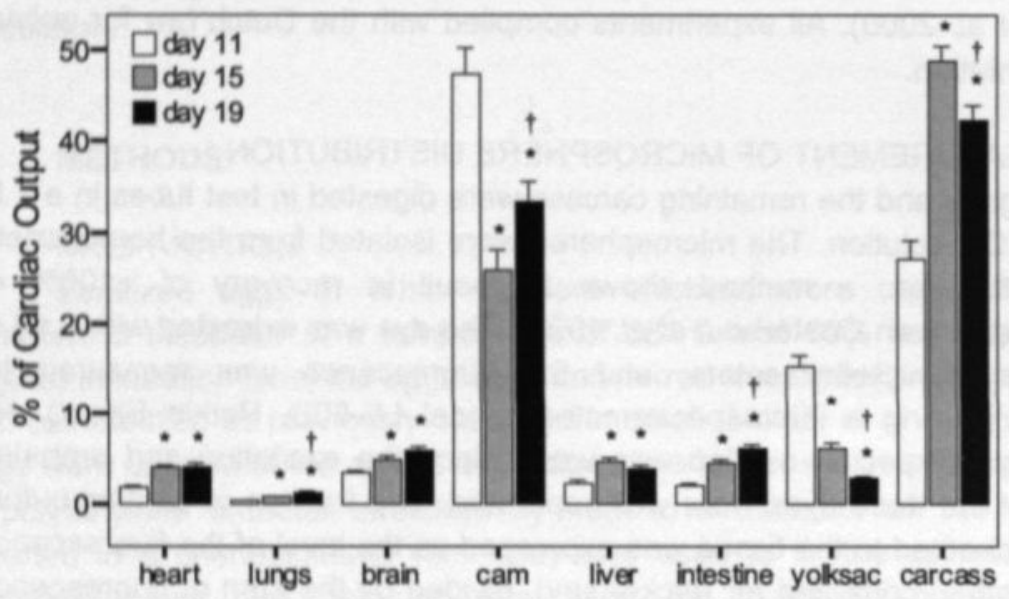

Fig 1 Basal cardiac output distribution at days 11,15 , and 19 of incubation.

Data are derived from both study groups ( $n=20$ per day) before treatment with saline or phentolamine. Bars represent the mean percentage of the cardiac output directed to the organ with the standard error of the mean. "Significant difference $(P<0.05)$ compared with day $11, \dagger$ Significant difference $(P<0.05)$ compared with day 15

\section{EFFECT OF $\alpha$-ADRENERGIC RECEPTOR BLOCKADE ON BASAL CARDIAC OUTPUT DISTRIBUTION}

At day 11, treatment of the chick embryo with phentolamine during basal conditions led to an increase in the fraction of the cardiac output directed to the brain, heart, carcass and intestines but no change in the fraction of the cardiac output directed to the liver (Fig. 2). At day 15, although the fraction of the cardiac output to the carcass still increased after phentolamine treatment during basal conditions, the increases to the heart and intestines fell outside significance, and, in contrast to measurements at 
day 11, there was a fall in the fraction of the cardiac output distributed to the brain and liver. At day 19 of incubation, there was no significant increase in the fraction of the cardiac output directed to any organ, and the fall in cardiac output distribution to the brain and the liver persisted after treatment with phentolamine during basal conditions (Fig. 2).

\section{EFFECT OF $\alpha$-ADRENERGIC RECEPTOR BLOCKADE ON CARDIAC OUTPUT DISTRIBUTION DURING ACUTE HYPOXAEMIA}

With advancing incubation time, cardiac output was preferentially distributed to the brain and heart at the expense of the liver, yolk sac, intestines and carcass during acute hypoxaemia (Fig. 3). The percent changes in cardiac output distribution are summarized in Table 1. At day 11, treatment of the chick embryo with phentolamine during acute hypoxaemia diminished the increase in the fraction of cardiac output directed to the lungs, reversed the increase in cardiac output to the brain and liver, reduced the fall in cardiac output to the yolk sac, and led to an increase in the fraction of cardiac output directed to the carcass (Fig. 3). At day 15, treatment of the chick embryo with phentolamine during hypoxaemia produced similar changes to those measured at day 11, except the fraction of cardiac output directed to the heart was significantly diminished (Fig. 3). The greatest effect of treatment with phentolamine during acute hypoxaemia occurred at day 19 of incubation, when the fraction of cardiac output directed to the heart was substantially reduced, and there was a pronounced reversal in the fraction of cardiac output directed to the brain, intestines, and carcass. 

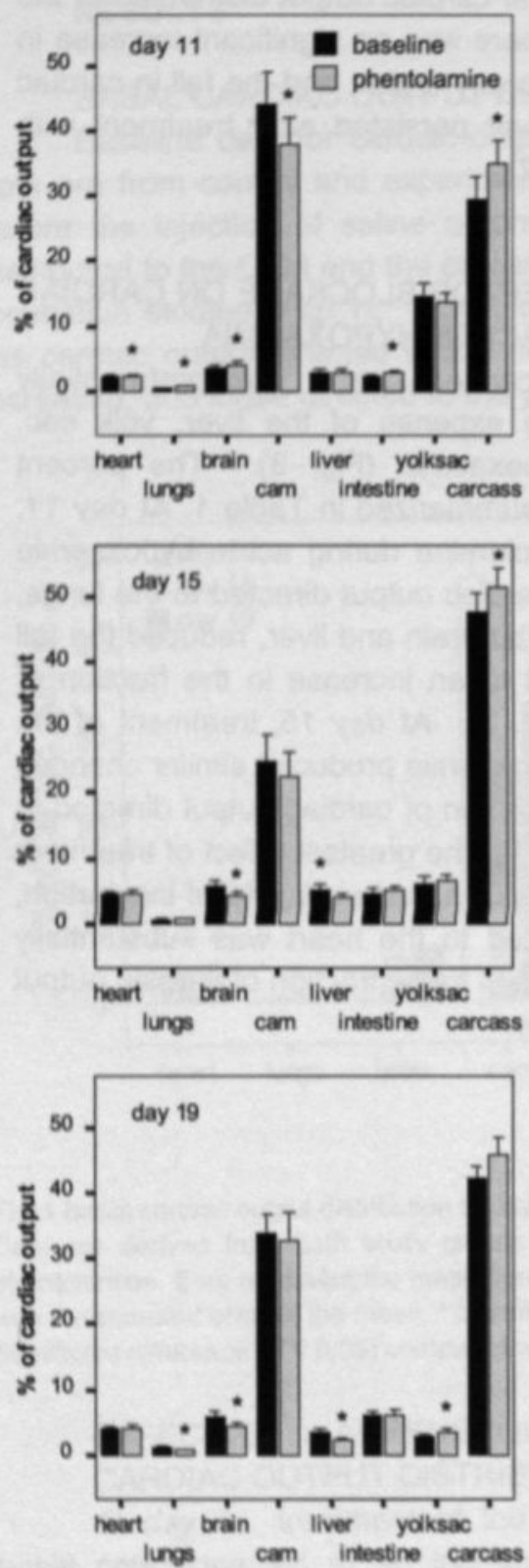

Fig 2 Effect of $\alpha$-adrenergic receptor blockade on basal cardiac output distribution. Cardiac output was measured before (baseline) and after (phentolamine) treatment with phentolamine. Bars represent the mean; error bars, the standard error of the mean. ${ }^{*}$ Significant difference $(P$ $<0.05$ ) compared with baseline. 
Table 1 Percentage change in cardiac output distribution in response to acute hypoxia for phentolamine treated chick embryos and controls for different incubation time groups.

\begin{tabular}{|c|c|c|}
\hline Day 11 & Control & Phentolamine \\
\hline Heart & $59.5(46.6$ to 107.7$)$ & $44.3(27.6$ to 78.3$)$ \\
\hline Lungs & 187.0 (90.1 to 324.4$)$ & $62.5(21.9 \text { to } 138.6)^{*}$ \\
\hline Brain & 61.6 (12.1 to 107.7$)$ & $-18.1(-31.8 \text { to } 9.3)^{\circ}$ \\
\hline CAM & $16.3(8.6$ to 26.8$)$ & $-6.6(-16.6$ to 42.6$)$ \\
\hline Liver & $-16.1(-25.4$ to 32.4$)$ & $-32.7(-39.9 \text { to }-21.8)^{*}$ \\
\hline Intestine & $53.6(42.4$ to 90.1$)$ & 52.7 (36.4 to 86.0$)$ \\
\hline Yolk sac & $-85.8(-89.8$ to -78.5$)$ & $-35.2(-70.7 \text { to } 24.0)^{\circ}$ \\
\hline Carcass & $6.5(1.3$ to 7.8$)$ & $21.9(12.3 \text { to } 64.5)^{*}$ \\
\hline Day 15 & Control & Phentolamine \\
\hline Heart & 130.2 (92.3 to 164.9$)$ & $35.3(10.5 \text { to } 55.8)^{\circ}$ \\
\hline Lungs & 81.6 (26.0 to 167.5$)$ & $87.2(14.2$ to 111.4$)$ \\
\hline Brain & 47.5 (19.2 to 103.5$)$ & $-35.8(-47.5 \text { to }-28.2)^{\circ}$ \\
\hline CAM & 27.3 (9.5 to 59.8 ) & $33.8(-18.9$ to 67.5$)$ \\
\hline Liver & $-71.0(-80.0$ to -43.0$)$ & $-50.5(-61.9$ to -39.1$)$ \\
\hline Intestine & $8.2(-7.7$ to 15.4$)$ & $9.4(-11.4$ to 30.6$)$ \\
\hline Yolk sac & $-88.5(-90.5$ to -79.5$)$ & $-40.1(-68.9 \text { to } 9.5)^{*}$ \\
\hline Carcass & $-10.4(-20.6$ to -2.6$)$ & $0.8(-5.2 \text { to } 23.4)^{*}$ \\
\hline Day 19 & Control & Phentolamine \\
\hline Heart & 196.2 (408.0 to 368.0$)$ & $69.4(27.2 \text { to } 112.5)^{\circ}$ \\
\hline Lungs & $3.3(-79.8$ to 69.6$)$ & $-49.6(-65.8$ to 82.0$)$ \\
\hline Brain & 102.1 (43.0 to 207.0 ) & $-24.6(-54.0 \text { to }-8.9)^{*}$ \\
\hline CAM & $11.3(-22.5$ to 114.4$)$ & $-23.5(-50.1$ to 38.0$)$ \\
\hline Liver & $-70.2(-89.6$ to -40.3$)$ & $-53.2(-61.8$ to -21.2$)$ \\
\hline Intestine & $-82.2(-93.6$ to -51.4$)$ & $-3.8(-14.7 \text { to } 43.2)^{*}$ \\
\hline Yolk sac & $-86.2(-92.3$ to -76.3$)$ & $-16.6(-64.4 \text { to } 62.4)^{*}$ \\
\hline Carcass & $-17.2(-54.3$ to -7.0$)$ & $20.3(-3.4 \text { to } 48.5)^{\circ}$ \\
\hline
\end{tabular}

Values represent median change in cardiac output directed to each organ expressed as percentage of baseline level, with interquartile range $\left(25^{\text {th }}-75^{\text {th }}\right.$ percentile) in parentheses; * $P$ $<0.05$ vs. control. 

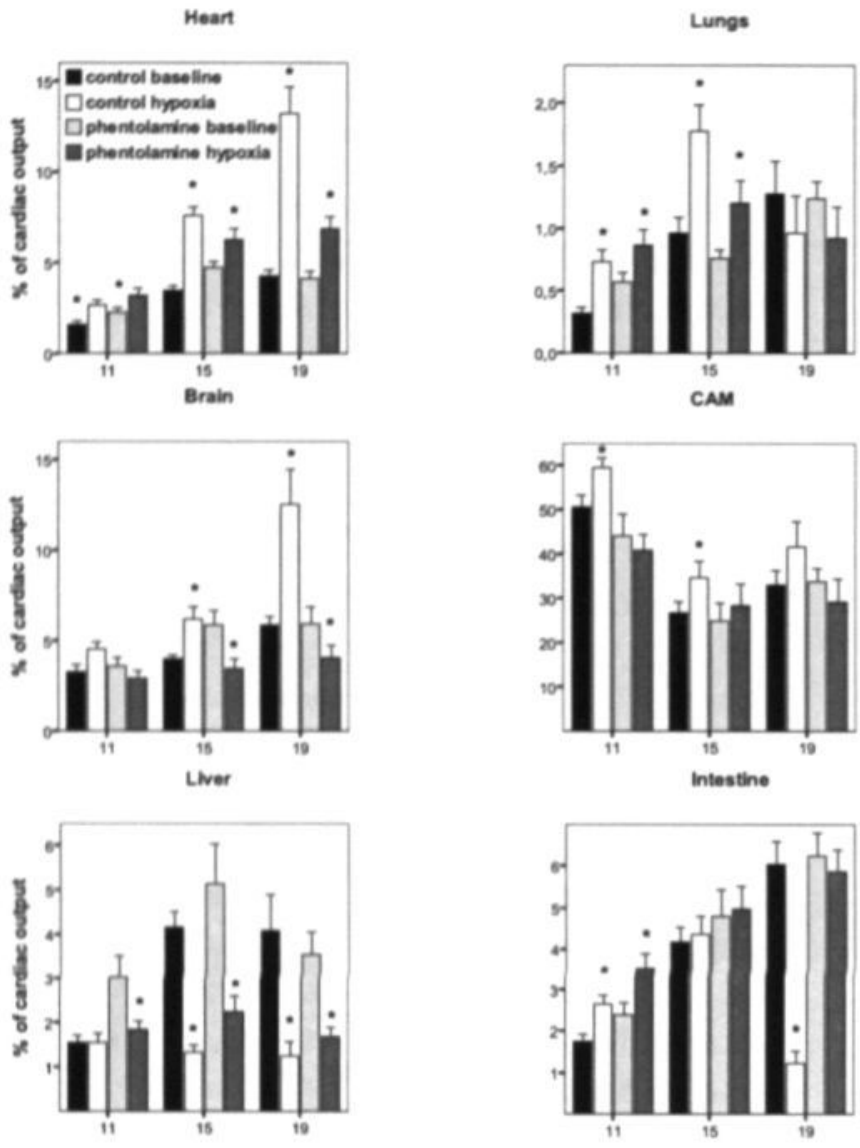

Yolk-sac
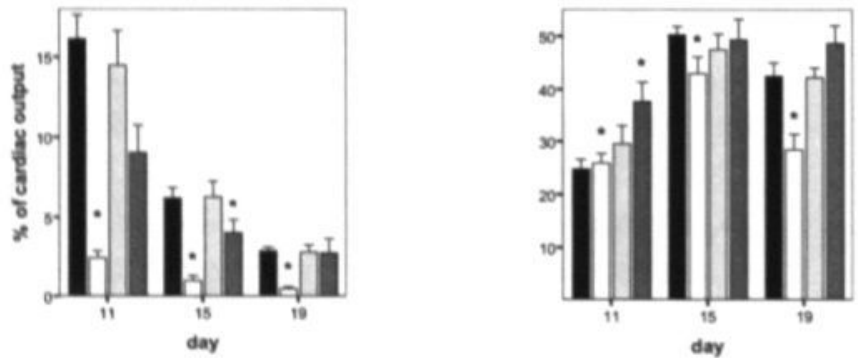

Fig 3 Effect of $\alpha$-adrenergic receptor blockade on cardiac output redistribution in response to acute hypoxemia. Bars represent the mean; error bars, the standard error of the mean.

- Significant difference $(P<0.05)$ compared with baseline. 


\section{DISCUSSION}

The present study in the chick embryo shows that: 1) sympathetic $\alpha$ adrenergic tone plays an important role in the distribution of cardiac output under basal conditions, 2) increased sympathetic $\alpha$-adrenergic tone is largely responsible for the redistribution of cardiac output in response to acute hypoxaemia, and 3) the contribution of the sympathetic $\alpha$-adrenergic tone toward mediating the redistribution of cardiac output away from the carcass toward the heart and brain during acute hypoxaemia increases with advancing incubation time.

The chick embryo, as an experimental model, offers the primary advantage to study the development of fetal cardiovascular responses to adverse conditions without the influence of maternal vasoactive factors. This is not the case for mammalian species, where, for instance, maternal corticosteroids released in response to hypoxaemia might easily cross the placenta and influence the fetal cardiovascular responses to the challenge (3). On the other hand, the chick embryo experimental model also has some limitations. For example, it is not possible to obtain repetitive blood samples or to measure the absolute cardiac output and regional blood flows, primarily because of the small size of the embryos and the limited blood volume.

In the chick embryo, the presence of vascular $\alpha$ - and $\beta$-adrenergic receptors has been reported from day 7 of incubation (Girard, 1967). In addition, intravenous injection of epinephrine and norepinephrine evokes an increase in heart rate and blood pressure in the chick embryo from day 7 of incubation (Girard, 1973). Adrenal medullar cells arise from the sympathetic chains on day 5 of incubation (Dawson, 1953) and catecholamines are detected in very small amounts from that day in allantoic fluid (Boucek \& Bourne, 1962). In the adrenal gland, epinephrine concentrations are relatively low until day 15 , after which the concentrations increase markedly toward hatching (Wasserman \& Bernard, 1970). Catecholamine concentrations in plasma have been reported in the chick embryo from day 10 of incubation, as has an increase in the plasma concentrations of norepinephrine in response to asphyxia at day 14 (Epple et al. 1992). Previous studies in the chick embryo from our laboratory have described an ontogenic increase in catecholamine release in response to acute hypoxaemia (Mulder et al. 2000), that parallels the maturation of the peripheral vasoconstriction that aids the redistribution of cardiac output in favor of vital organs in response to acute hypoxaemia (Mulder et al. 1998). The present study shows that this maturing redistribution in response to acute hypoxaemia is substantially altered by treatment of the chick embryo with the $\alpha$-adrenergic receptor antagonist phentolamine at all age groups studied, but 
$102 \mid$ CHAPTER 5

in particular at day 19 of incubation, suggesting that the mechanisms mediating the redistribution of cardiac output with increasing development are highly dependent on $\alpha$-adrenergic activity in the chick embryo.

\section{BASAL CARDIAC OUTPUT DISTRIBUTION}

In the present study, at day 11 of incubation, the fractions of cardiac output directed to the carcass, heart, lungs, brain and intestine increased under basal conditions after treatment of the chick embryo with the $\alpha$ adrenergic receptor antagonist. Although the differences are small, they suggest the presence of basal sympathetic $\alpha$-adrenergic tone in these vascular beds at this time of incubation. At day 15, only the fraction to the carcass increased with significant decreases in fractions directed to the brain and liver following treatment with phentolamine. This could be explained as a diversion of flow from these organs to the carcass. At day 19, the increase in the fraction of cardiac output directed to the carcass after phentolamine treatment was smaller than at previous stages of incubation. In combination, these data suggest that the contribution of the $\alpha$-adrenergic vascular tone under basal conditions becomes less important with progression of the incubation period. Comparable data from studies in the fetal llama show that $\alpha$-adrenergic blockade with phentolamine at $0.6-0.7$ gestation resulted in significant increases in carotid and femoral artery blood flows (Giussani et al. 1999) under resting conditions. The same treatment in 0.8 gestation fetal sheep had no effect on basal carotid or femoral blood flows (Giussani et al. 1993). Together, these findings support the concept that the vasoconstrictor contribution of sympathetic $\alpha$-adrenergic tone is greater in the carotid and femoral circulations under basal conditions earlier than later in gestation. However, the comparison between experiments in fetal sheep and fetal llamas may not be justified, particularly since the contribution of the $\alpha$-adrenergic system is upregulated in the llama (Giussani et al. 1999). Alternatively, the lack of a significant increase in the fraction of cardiac output directed to the carcass after phentolamine at day 19 of incubation may represent the maturation of $\alpha$-adrenergic-independent vasoconstrictor mechanisms that act to reduce blood flow in this circulation, even in the absence of $\alpha$-adrenergic influences. A possible candidate may be angiotensin II which has been reported to induce a greater pressor response under basal conditions in fetal sheep near term than earlier in gestation (Tangalakis et al. 1992).

\section{RESPONSE TO ACUTE HYPOXAEMIA}

In the present study, treatment of the chick embryo with phentolamine during acute hypoxaemia completely prevented the redistribution of cardiac output in favor of the brain at all stages of incubation studied. Given the proportion of cardiac output distributed to the carcass under basal conditions, 
these results suggest that maintenance of cerebral blood flow during hypoxaemia in the chick embryo is highly dependent on peripheral vasoconstriction and maintenance of arterial blood pressure (not measured in our experiments) despite potential local vasodilator mechanisms, such as the production of nitric oxide and adenosine, which have been shown to be active in the sheep fetus (Kurth \& Wagerle, 1992; van Bel et al. 1995; Green et al. 1996).

Additional results presented in this study show that the fraction of the cardiac output directed to the heart is increased in response to acute hypoxaemia but that, in contrast to the effect on brain blood flow, treatment of the chick embryo with the $\alpha$-adrenergic receptor antagonist attenuated, but did not completely prevent, this response. This suggests that coronary vasodilatation is more dependent than cerebral vasodilatation on mechanisms other than those promoting $\alpha$-adrenergic-mediated peripheral vasoconstriction. Such mechanisms may include $B_{2}$-adrenergic receptor stimulation (Feigl, 1998) and local nitric oxide release induced by hypoxaemia as shown in fetal sheep (Reller et al. 1995). One study in late-gestation fetal sheep reported that blood flow to the heart increased during acute hypoxaemia, but in contrast to the present study, myocardial blood flow increased further after fetal treatment with phenoxybenzamine, another $\alpha$ adrenergic receptor antagonist (Reuss et al. 1982). In that study, blood flow to the heart was measured $\sim 20$ minutes after the onset of hypoxia in the presence of phenoxybenzamine. Therefore, it is likely that the enhancement of myocardial blood flow after treatment of the sheep fetus with the $\alpha$ adrenergic antagonist may have been due to prolonged hypoxaemia with developing acidemia, promoting a greater recruitment of local vasodilator mechanisms. An alternative explanation is that the sheep fetus may be more dependent than the chick embryo on local vasodilator mechanisms to promote an increase in myocardial blood flow during acute hypoxaemia.

Interestingly, in the present study, treatment of the chick embryo with phentolamine had a progressively greater effect on the distribution of the cardiac output to the carcass during acute hypoxaemia with advancing incubation time. Therefore, although treatment with phentolamine during hypoxaemia enhanced carcass blood flow at day 11, it mildly reversed the fall in carcass blood flow at day 15 and it markedly reversed this fall at day 19. Previously, we reported an ontogenic increase in the magnitude of the peripheral vasoconstriction during acute hypoxaemia (Mulder et al. 1998), and that these changes paralleled the maturation of the plasma catecholaminergic response to acute hypoxaemia in the chick embryo (Mulder et al. 2000). Past data, together with the results of the present study, therefore suggest a 


\section{$104 \mid$ CHAPTER 5}

progressively larger contribution of sympathetic $\alpha$-adrenergic neuroendocrine mechanisms mediating peripheral vasoconstriction during acute hypoxaemia as the chick embryo approaches hatching. Maturation of this sympathetic $\alpha$ adrenergic mediated vasoconstriction may reflect the development of an important defense mechanism that helps redistribute cardiac output away from the periphery toward the brain under adverse conditions during incubation in the chick embryo.

\section{PERSPECTIVES}

In the sheep fetus, $\alpha$-adrenergic activity may be increased by both neural and endocrine pathways. For example, increased sympathetic discharge, such as that induced by hypoxaemia, results in norepinephrine release from sympathetic nerve endings (Agata et al. 1986). Sympathetic stimulation of the splanchnic nerve also results in catecholamine release from adrenal medulla (Comline \& Silver, 1961; Edwards \& Jones, 1993). In addition, hypoxia might stimulate the adrenal gland to release catecholamines into plasma by a direct effect on chromaffin cells (Rychkov et al. 1998). Jones et al. (1988) showed that in fetal sheep the increase in plasma epinephrine was totally abolished, and the increase of norepinephrine was reduced $90 \%$ in response to hypoxaemia after adrenal demedullation. This suggests that in fetal sheep the increase in circulating plasma catecholamines in response to hypoxaemia originates primarily in the adrenal medulla. Furthermore, in the sheep fetus, the direct effect of hypoxia on epinephrine release from the adrenal gland becomes less important toward full term, when sympathetic innervation of the adrenal gland is completed (Comline \& Silver, 1966; Cheung, 1990). The present study showed that, in the chick embryo, phentolamine abolished the fall in carcass blood flow in response to hypoxaemia and that this effect became progressively more marked as the chick embryo approached full term. However, the present study cannot discriminate whether the maturation of the $\alpha$-adrenergic activity mediating the ontogenic increase in the peripheral vasoconstrictor response to acute hypoxaemia in the chick embryo is of neural and/or endocrine origin, since phentolamine will antagonize both mechanisms. The origin of the increased $\alpha$ adrenergic activity during acute hypoxaemia as the chick embryo approaches full term is therefore unresolved and will be the subject of subsequent investigations 


\section{ALPHA-ADRENERGIC CONTROL | 105}

\section{ACKNOWLEDGEMENTS}

We thank F.W. Prinzen (Department of Physiology) and J. Hekking (Department of Anatomy-Embryology) for valuable advice on the study.

\section{REFERENCES}

AgAtA, Y., PAdBury, J. F., Ludlow, J. K., POLK, D. H. \& Humme, J. A. (1986). The effect of chemical sympathectomy on catecholamine release at birth. Pediatric Research 20, 1338-44.

Bartelds, B., van Bel, F., Tettel, D. F. \& Rudolph, A. M. (1993). Carotid, not aortic, chemoreceptors mediate the fetal cardiovascular response to acute hypoxemia in lambs. Pediatric Research 34, 51-5.

BOUCEK, R. J. \& BOURNE, B. B. (1962). Catecholamines of the allantoic fluid in the developing chick embryo. Nature 193, 1181-1182.

ChEUNG, C. Y. (1990). Fetal adrenal medulla catecholamine response to hypoxia-direct and neural components. American Journal of Physiology 258, R1340-6.

COMLINE, R. S. \& SILVER, M. (1961). The release of adrenaline and noradrenaline from the adrenal glands of the foetal sheep. Journal of Physiology 156, 424-444.

COMUINE, R. S. \& SILVER, M. (1966). Development of activity in the adrenal medulla of the foetus and new-born animal. British Medical Bulletin 22, 16-20.

DAWSON, A. B. (1953). Histochemical evidence of early differentiation of the suprarenal gland of the chick. Journal of Morphology 92, 579-595.

EDWARDS, A. V. \& JONES, C. T. (1993). Autonomic control of adrenal function. Journal of Anatomy 183, 291-307.

Epple, A., GiLL, T. S. \& NiBBio, B. (1992). The avian allantois: a depot for stress-released catecholamines. General and Comparative Endocrinology 85, 462-76.

FEIGL, E. O. (1998). Neural control of coronary blood flow. Journal of Vascular Research 35. 85-92.

Fletcher, A. J., Edwards, C. M., Gardner, D. S., Fowden, A. L. \& Giussani, D. A. (2000). Neuropeptide $\mathrm{Y}$ in the sheep fetus: effects of acute hypoxemia and dexamethasone during late gestation [In Process Citation]. Endocrinology 141, 3976-82.

GIRARD, H. (1967). [Action of noradrenaline and adrenaline on the embryonic circulation of chickens]. Comptes rendus hebdomadaires des seances de l'Academie des sciences. Serie D: Sciences naturelles. 265, 2023-6.

GIRARD, H. (1973). Adrenergic sensitivity of circulation in the chick embryo. American Journal of Physiology 224, 461-9. 
Giussani, D. A., SPEnCER, J. A., MOORE, P. J., Bennet, L. \& HANSON, M. A. (1993). Afferent and efferent components of the cardiovascular reflex responses to acute hypoxia in term fetal sheep. Journal of Physiology (London) 461, 431-49.

Giussani, D. A., McGarrigle, H. H., Spencer, J. A., Moore, P. J., Bennet, L. \& Hanson, M. A. (1994a). Effect of carotid denervation on plasma vasopressin levels during acute hypoxia in the late-gestation sheep fetus. Journal of Physiology (London) 477, 81-7.

GIUSSANI, D. A., SPEnCER, J. A. D. \& HANSON, M. A. (1994B). Fetal cardiovascular reflex responses to hypoxaemia. Fetal and Maternal Medicine Review 6, 17-37.

Giussani, D. A., Riguelme, R. A., moraga, F. A., mcGarrigle, H. H., Gaete, C. R., SANHUEZA, E. M., HANSON, M. A. \& LLANOS, A. J. (1996). Chemoreflex and endocrine components of cardiovascular responses to acute hypoxemia in the llama fetus. American Journal of Physiology 271, R73-83.

Giussani, D. A., Riquelme, R. A., Sanhueza, E. M., hanson, M. A., Blanco, C. E. \& llanos, A. J. (1999). Adrenergic and vasopressinergic contributions to the cardiovascular response to acute hypoxaemia in the llama fetus. Journal of Physiology (London) 515, 233-41.

GREEN, L. R., BENNET, L. \& HANSON, M. A. (1996). The role of nitric oxide synthesis in cardiovascular responses to acute hypoxia in the late gestation sheep fetus. Joumal of Physiology (London) 497, 271-7.

Green, L. R., McGarrigle, H. H., Bennet, L. \& Hanson, M. A. (1998). Angiotensin II and cardiovascular chemoreflex responses to acute hypoxia in late gestation fetal sheep. Journal of Physiology (London) 507, 857-67.

HANSON, M. A. (1988). The importance of baro- and chemoreflexes in the control of the fetal cardiovascular system. Journal of Developmental Physiology 10, 491-511.

JONES, C. T. \& Robinson, R. O. (1975). Plasma catecholamines in foetal and adult sheep. Journal of Physiology (London) 248, 15-33.

Jones, C. T., Roebuck, M. M., WalkeR, D. W. \& JOhnSton, B. M. (1988). The role of the adrenal medulla and peripheral sympathetic nerves in the physiological responses of the fetal sheep to hypoxia. Journal of Developmental Physiology 10, 17-36.

KURTH, C. D. \& WAGERLE, L. C. (1992). Cerebrovascular reactivity to adenosine analogues in 0.6-0.7 gestation and near-term fetal sheep. American Journal of Physiology 262, H1338-42.

le noble, F. A., Ruijtenbeek, K., Gommers, S., de Mey, J. G. \& Blanco, C. E. (2000). Contractile and relaxing reactivity in carotid and femoral arteries of chicken embryos. American Journal of Physiology 278, H1261-8.

MANN, L. I. (1986). Pregnancy events and brain damage. American Joumal of Obstetrics and Gynecology 155, 6-9.

moraga, F., monge, C., Riquelme, R. \& Llanos, A. J. (1996). Fetal and maternal blood oxygen affinity: a comparative study in llamas and sheep. Comparative biochemistry and physiology. Part A, Physiology.115, 111-5. 
Mulder, T. L., van Golde, J. C., Prinzen, F. W. \& Blanco, C. E. (1997). Cardiac output distribution in the chick embryo from stage 36 to 45 . Cardiovascular Research 34, 525-8.

Mulder, A. L., van Golde, J. C., Prinzen, F. W. \& Blanco, C. E. (1998). Cardiac output distribution in response to hypoxia in the chick embryo in the second half of the incubation time. Journal of Physiology (London) 508, 281-7.

Mulder, A. L., Golde, J. M., Goor, A. A., Giussani, D. A. \& Blanco, C. E. (2000). Developmental changes in plasma catecholamine concentrations during normoxia and acute hypoxia in the chick embryo. Joumal of Physiology (London) 527, 593-599.

Reller, M. D., Burson, M. A., LOHR, J. L., MORTON, M. J. \& THORnBurg, K. L. (1995). Nitric oxide is an important determinant of coronary flow at rest and during hypoxemic stress in fetal lambs. American Journal of Physiology 269, H2074-81.

Reuss, M. L., PARER, J. T., HARRIS, J. L. \& KRUEGER, T. R. (1982). Hemodynamic effects of alpha-adrenergic blockade during hypoxia in fetal sheep. American Journal of Obstetrics and Gynecology 142, 410-5.

RYCHKOV, G. Y., ADAMS, M. B., MCMILLEN, I. C. \& RoBeRTS, M. L. (1998). Oxygen-sensing mechanisms are present in the chromaffin cells of the sheep adrenal medulla before birth. Journal of Physiology (London) 509, 887-93.

TANGALAKIS, K., LUMBERS, E. R., MORITZ, K. M., TOWSTOlesS, M. K. \& WinTOUR, E. M. (1992). Effect of cortisol on blood pressure and vascular reactivity in the ovine fetus. Experimental Physiology 77, 709-17.

VAN BEL, F., SOLA, A., RomAn, C. \& RUdOLPH, A. M. (1995). Role of nitric oxide in the regulation of the cerebral circulation in the lamb fetus during normoxemia and hypoxemia. Biology of the Neonate 68, 200-10.

van Oosterhout, M. F., Willigers, H. M., Reneman, R. S. \& Prinzen, F. W. (1995). Fluorescent microspheres to measure organ perfusion: validation of a simplified sample processing technique. American Journal of Physiology 269, H725-33.

WASSERMAN, G. F. \& BERNARD, E. A. (1970). Adrenaline content of the chick embryo adrenal gland during development. Acta Physiologica Latino Americana 20, 171-173. 
$108 \mid$ 


\title{
ChAPTER 6
}

\section{Sympathetic control of the cardiovascular response to}

\section{acute hypoxaemia in the chick embryo}

\begin{abstract}
A.L.M. Mulder' ${ }^{1}$, A. Miedema', J.G.R. De Mey' ${ }^{2}$, D.A. Giussani ${ }^{3}$, C.E. Blanco ${ }^{1}$
\end{abstract}

${ }^{1}$ Department of Paediatrics, Research Institute Growth and Development (GROW), Maastricht University, Maastricht, The Netherlands.

${ }^{2}$ Department of Pharmacology \& Toxicology, Cardiovascular Research Institute Maastricht (CARIM) Maastricht University, Maastricht, The Netherlands.

${ }^{3}$ Department of Physiology, University of Cambridge, Downing Street, Cambridge CB2 3EG,

United Kingdom

AMERICAN JOURNAL OF PHYSIOLOGY, REgulatory INTEGRATIVE AND COMPARATIVE PHYSIOLOGY 2002, in press 
$110 \mid$ CHAPTER 6

\section{ABSTRACT}

In response to an acute hypoxemic insult, the mammalian fetus shows a redistribution of the cardiac output in favor of heart and brain. Peripheral vasoconstriction contributes to this response and is partly mediated by the release of catecholamines. Two mechanisms of catecholamine release in the fetus are reported: 1) neurogenic sympathetic stimulation, and 2) nonneurogenic via a direct effect of hypoxemia on chromaffin tissues. In the present study the effects of sympathetic blockade were studied on plasma catecholamine release and cardiac output distribution in response to acute hypoxemia in the chick embryo at different stages of incubation. Only at the end of the incubation period sympathetic blockade markedly attenuated the increase in plasma catecholamine concentrations and resulted in a greater fraction of the cardiac output distributed to the carcass. However, these effects did not prevent a significant increase in cardiac output to the brain and heart during acute hypoxemia. These data imply that, in the chick embryo, the contribution of neurogenic mechanisms on the catecholaminergic response to acute hypoxemia becomes greater by the end of the incubation period. 


\section{INTRODUCTION}

Hypoxaemia in the fetus, resulting largely from placental dysfunction or umbilical blood flow impairment, has been postulated to be a major cause of neonatal neurological damage and morbidity (Mann 1986; Shields \& Schifrin 1988). During gestation fetal cardiovascular responses develop in order to maintain organ blood flow and minimise damage of sensitive tissues during episodes of hypoxaemia (for review see Hanson 1988; Giussani et al. 1994; Green 2001). The mechanisms mediating the fetal cardiovascular response to hypoxaemia are triggered by carotid chemoreceptor stimulation, which elicits bradycardia, hypertension and a redistribution of the cardiac output in favour of the adrenal gland, the heart, and the brain (Giussani et al. 1993). Neural sympathetic stimulation and endocrine vasopressor substances such as catecholamines contribute to peripheral vasoconstriction, prioritising the fetal cardiac output away from the periphery to the more vital organs (Hanson 1988; Giussani et al. 1994; Green 2001). Previous studies from our laboratory have demonstrated the importance of catecholamine release in the cardiovascular response to an episode of acute hypoxaemia in the chick embryo. At the end of the incubation period, plasma concentrations of catecholamines increase markedly in response to acute hypoxaemia (Mulder et al. 2000) and treatment of the chick embryo with the $\square$-adrenergic receptor antagonist phentolamine prevented the redistribution of the cardiac output away from the peripheral circulations (Mulder et al. 2001).

In fetal sheep (Comline et al. 1965; Cheung 1990; Rychkov et al. 1998) and neonatal rats (Seidler \& Slotkin 1985) at least two mechanisms mediating catecholamine release in response to hypoxaemia have been described. First, prior to functional innervation of the adrenal glands, hypoxaemia may stimulate chromaffin cells directly to promote catecholamine release into the circulation. Secondly, following the establishment of innervation to the adrenal gland, hypoxaemia may stimulate adrenal catecholamine release via neurogenic mechanisms. The present study was designed to discriminate between neurogenic and non-neurogenic mechanisms mediating catecholamine release, and to determine at which stage of development sympathetic innervation of the adrenal gland contributes to catecholamine release in the chick embryo. The sympathetic ganglion blocker hexamethonium was used to inhibit sympathetic stimulation in response to acute hypoxaemia. The distribution of the cardiac output and changes in plasma catecholamine concentrations were determined in response to acute hypoxaemia in chick embryos treated with hexamethonium and control chick embryos infused with saline at different stages of development. The study tested the hypothesis that sympathetic blockade has a greater effect on 
112 CHAPTER 6

cardiac output distribution and on catecholamine release in response to hypoxaemia in chick embryos at the end of the incubation period compared with chick embryos at earlier stages of development.

\section{METHODS}

\section{PREPARATION}

Fertilized eggs of White Leghorn chickens were maintained in a commercial incubator at a temperature of $38^{\circ} \mathrm{C}$ and a humidity of $60 \%$. At the desired developmental stage, the eggs were transferred to a clinical infant incubator and catheterised as previously described in detail (Mulder et al. 1997). In brief, eggs were opened at the air cell and placed in a holder within a Plexiglas box. A polyethylene catheter stretched by heat to a diameter of 100 $\mu \mathrm{m}$ was inserted in a chorioallantoic vein. The catheter was fixed to the eggshell using clay. Later, the catheter was used for injections of fluorescent microspheres and for injections of either hexamethonium or saline solution. Throughout the procedure, the oxygen concentration in the box was maintained by supplied mixtures of warmed and humidified $\mathrm{N}_{2}$ and $\mathrm{O}_{2}$, delivered at a constant flow of $5 \mathrm{I} \cdot \mathrm{min}^{-1}$.

\section{EXPERIMENTAL PROTOCOL}

All experiments complied with the Dutch law for animal experimentation and the Guiding Principles for Research involving Animals and Human Beings. A total of 120 chick embryos were used in this study. At 3 advancing incubation times, day 11 , day 15 and day 19 of incubation, 10 chick embryos were randomly assigned to a control group and 10 to an experimental group. Cardiac output distribution was determined by injection of $15 \mu \mathrm{m}$ fluorescent microspheres (Fluospheres ${ }^{\star}$ Molecular Probes Inc, Eugene, Oregon, USA), suspended in saline and $0.05 \%$ Tween $80\left(1,000,000\right.$ spheres. $\left.\mathrm{ml}^{-1}\right)$ as previously described (Mulder et al. 1997). Before injection, the microspheres were thoroughly mixed and vortexed. The number of microspheres injected was based on a minimum number of 400 microspheres per sample, that should guarantee a relative error of less than $5 \%$ (Prinzen \& Glenny, 1994). In each control and each experimental group, at each stage of incubation, 0.04 $\mathrm{ml}(40,000$ spheres) of the suspension of blue-green fluorescent microspheres were injected fifteen minutes after catheterisation. Following this, each control group was injected with saline $(\mathrm{NaCl} 0.9 \%)$ and each experimental group was treated with hexamethonium (Hexamethonium Bromide, Sigma Chemical Company) at a dose of $25 \mu \mathrm{g} \cdot \mathrm{g}^{-1}$ in $5 \mu \mathrm{l} \cdot \mathrm{g}^{-1}$ of embryo. The dose of 
hexamethonium used $\left(25 \mu \mathrm{g} \cdot \mathrm{g}^{-1}\right)$ was three to four times the dose reported to achieve complete blockade of the autonomic nervous system for 6 hours in fetal sheep (Brace \& Brittingham 1986). Five minutes later 40,000 red fluorescent microspheres were injected to determine the effect of autonomic blockade on basal cardiac output distribution. One minute later, acute hypoxaemia was induced by changing the supplied gas mixture to the box to $100 \% \mathrm{~N}_{2}$. Previous studies have shown that this regimen results in a fall in the arterial $\mathrm{PO}_{2}$ of the chick embryo from $37.7 \mathrm{mmHg}$ to $8.7 \mathrm{mmHg}$ (Mulder et al. 2000). After 5 minutes of hypoxaemia 40,000 crimson fluorescent microspheres were injected to determine the effect of autonomic blockade on cardiac output distribution during the hypoxaemic challenge. The experiment ended 5 minutes after normoxia was re-established. The chick embryos were sacrificed immediately after the end of the experiment by decapitation and the chorioallantoic membrane, brain, heart, lungs, intestine, liver and the yolk sac were dissected for determination of microsphere distribution.

In another 60 chick embryos, changes in plasma catecholamine concentrations in response to acute hypoxaemia were determined before and after treatment with hexamethonium at day 15 and 19 of incubation. Measurements of catecholamine concentrations were not made at day 11 as previous studies have shown that acute hypoxaemia does not increase plasma catecholamine concentrations until day 13 of the incubation period (Mulder et al. 2000). Arterial blood samples for determination of plasma catecholamine concentrations required at least $0.3 \mathrm{ml}$ of blood. Therefore, only one arterial blood sample was taken from any one chick embryo to minimize blood loss. At 15 and 19 days of incubation, chorioallantoic artery blood samples $(0.3-1.0 \mathrm{ml})$ were obtained on the $5^{\text {th }}$ minute of normoxia $(21 \%$ $\mathrm{O}_{2}$ in the Plexiglas box, $\mathrm{n}=10$ in each group), on the $5^{\text {th }}$ minute of hypoxaemia ( $100 \%$ of $N_{2}$ in the Plexiglas box, $n=10$ in each group) and on the $5^{\text {th }}$ minute of hypoxaemia after treatment with hexamethonium ( $n=10$ in each group).

\section{MEASUREMENTS}

\section{MICROSPHERE DISTRIBUTION}

Organs and the remaining carcass were digested in test tubes in a $2 \mathrm{M}$ ethanol-KOH solution. The microspheres were isolated from the homogenate by centrifugation, a method shown to result in ca. $100 \%$ recovery of microspheres (van Oosterhout et al. 1995). The dye was extracted with $3 \mathrm{ml}$ of 2-(2-ethoxyethoxy) ethylacetate and the fluorescence measured by fluorimetry using a LS-50B fluorispectrometer (Perkin Elmer). No correction for spectral overlap was used since the excitation and emission spectra of the three dyes 
$114 \mid$ CHAPTER 6

were well separated. The fraction of cardiac output that was directed to the tissue was expressed as the level of the fluorescence, corrected for background, of the sample, divided by the sum of fluorescence of all tissues.

\section{PLASMA CATECHOLAMINE CONCENTRATION}

Chorioallantoic arterial blood samples were collected into heparinized syringes. Blood was drawn into test tubes filled with $25 \mu \mathrm{l}$ of glutathione / heparin solution (10 mg.ml ${ }^{-1}$ glutathione, 5000 IU heparin. $\mathrm{ml}^{-1}$ ). Samples were centrifuged $\left(8{ }^{\circ} \mathrm{C}, 2400 \times \mathrm{g}\right)$ for 15 minutes and plasma stored at $-35^{\circ} \mathrm{C}$. Plasma concentrations of adrenaline and noradrenaline were measured using fluorescence High Pressure Liquid Chromatography (HPLC), as previously described in detail (van der Hoom et al. 1989). The lower limit of detection of the assay was $0.46 \mathrm{pg} \cdot \mathrm{ml}^{-1}$ for adrenaline and $0.98 \mathrm{pg} \cdot \mathrm{ml}^{-1}$ for noradrenaline.

\section{ANALYSIS OF DATA}

All data were processed using SPSS statistical software (SPSS Inc.). Data are expressed as median with interquartile range or as mean \pm S.E.M., as appropriate. Statistical significance of comparisons within groups was assessed using one way repeated measures ANOVA, and for between group comparisons using the Mann Whitney $U$ test. Significance was accepted when $P<0.05$.

\section{RESULTS}

THE EFFECT OF AUTONOMIC NERVOUS SYSTEM BLOCKADE ON BASAL CARDIAC OUTPUT DISTRIBUTION

Basal cardiac output distribution in both groups showed large fractions of the cardiac output directed to the CAM, yolk sac and carcass and relatively small fractions directed to heart, lungs, brain, liver and intestine (Table 1 and Figure 1). Following treatment with hexamethonium small changes in cardiac output distribution were observed. At day 11 of incubation, the fraction of the cardiac output directed to the heart was increased in the hexamethonium treated group compared to the control group. At day 15 the fraction directed to the intestine was decreased in the hexamethonium treated group. At day 19 no differences in cardiac output distribution were found between treated and control embryos. 
Table 1 Effect of autonomic nervous system blockade on basal cardiac output distribution.

Day 11 Day 15 Day 19

\begin{tabular}{lcccccc} 
& control & $\begin{array}{c}\text { hexa- } \\
\text { methonium }\end{array}$ & control & $\begin{array}{c}\text { hexa- } \\
\text { methonium }\end{array}$ & control & $\begin{array}{c}\text { hexa- } \\
\text { methonium }\end{array}$ \\
\hline Heart & 1.91 & 2.75 & 4.25 & 3.96 & 4.80 & 3.60 \\
Lungs & $(1.14-2.20)$ & $(2.18-3.20)$ & $(4.10-4.80)$ & $(3.75-4.31)$ & $(3.60-5.45)$ & $(3.30-7.01)$ \\
& 0.41 & 0.60 & 1.02 & 0.92 & 1.00 & 1.35 \\
Brain & $(0.26-0.50)$ & $(0.40-0.65)$ & $(0.84-1.60)$ & $(0.80-1.39)$ & $(0.50-1.82)$ & $(0.86-2.79)$ \\
& 3.99 & 3.65 & 4.04 & 4.00 & 5.49 & 4.60 \\
CAM & $(3.20-4.59)$ & $(2.20-4.68)$ & $(3.60-5.02)$ & $(3.57-4.67)$ & $(4.60-6.25)$ & $(3.40-4.97)$ \\
& 46.75 & 45.53 & 19.90 & 29.41 & 32.80 & 31.08 \\
Liver & $(40.02-52.31)$ & $(37.30-50.22)$ & $(15.22-28.40)$ & $(19.76-38.76)$ & $(26.54-38.93)$ & $(25.93-41.10)$ \\
& 1.79 & 1.95 & 2.94 & 2.58 & 2.27 & 1.70 \\
Intestine & $(1.19-2.70)$ & $(1.72-2.30)$ & $(2.50-4.60)$ & $(2.20-3.87)$ & $(1.65-2.81)$ & $(1.36-2.16)$ \\
& 2.00 & 2.60 & 5.40 & 3.78 & 5.49 & 4.51 \\
Yolk sac & $(1.78-2.90)$ & $(1.60-3.90)$ & $(5.17-5.74)$ & $(3.13-4.25)$ & $(4.90-6.63)$ & $(3.73-6.50)$ \\
& 13.44 & 15.35 & 6.92 & 6.62 & 2.99 & 4.05 \\
Carcass & $(12.50-18.76)$ & $(9.39-17.27)$ & $(4.80-8.10)$ & $(6.00-8.49)$ & $(2.15-3.64)$ & $(3.10-4.61)$ \\
& 27.64 & 29.48 & 52.94 & 47.21 & 46.99 & 44.31 \\
& $(24.07-30.20)$ & $(24.66-33.20)$ & $(49.10-56.90)$ & $(42.00-54.58)$ & $(38.86-48.23)$ & $(39.40-51.10)$ \\
\hline
\end{tabular}

Presented are median percentages and interquartile ranges of cardiac output directed to each organ after injection of saline (control group) or hexamethonium (hexamethonium group).

$\bullet P<0.05$ compared with baseline.

\section{THE EFFECT OF AUTONOMIC NERVOUS SYSTEM BLOCKADE ON CARDIAC OUTPUT REDISTRIBUTION IN RESPONSE TO ACUTE HYPOXAEMIA}

With advancing incubation time, cardiac output was preferentially distributed to the brain and the heart at the expense of the liver, yolk sac, intestines and carcass during acute hypoxaemia (Table 2 and Figure 2). The fraction of the cardiac output directed to the heart increased in response to acute hypoxemia on all three days of incubation studied. The fraction directed to the brain increased significantly from day 15 of incubation. In response to acute hypoxemia the cardiac output fraction directed to the yolk sac decreased on all three days of incubation, whereas the fraction directed to the liver and carcass decreased significantly from day 15 of incubation. The cardiac output directed to the intestines increased in response to acute hypoxemia on day 11 , but significantly decreased on day 19 of incubation. Interestingly, during acute hypoxemia the fraction of cardiac output to the heart showed a significant progressive increase from day 11 to day 19 of incubation. 
Table 2 Cardiac output distribution in the chick embryo during basal conditions and after 5 minutes of hypoxaemia in the control group and the hexamethonium treated group at three incubation times.

\begin{tabular}{llll} 
Day 11 & Baseline & Hypoxemia control & $\begin{array}{l}\text { Hypoxemia } \\
\text { hexamethonium }\end{array}$ \\
\hline Heart & $2.00(1.30-2.30)$ & $2.54(2.16-3.00)^{*}$ & $3.14(2.90-4.10)^{*}$ \\
Lungs & $0.30(0.30-0.48)$ & $0.84(0.40-1.01)^{*}$ & $0.60(0.50-0.87)$ \\
Brain & $2.90(2.43-3.73)$ & $4.54(3.64-5.46)$ & $3.10(2.17-3.30)$ \\
CAM & $54.35(44.67-55.75)$ & $60.33(55.60-65.00)^{*}$ & $59.45(53.65-68.70)$ \\
Liver & $1.70(1.46-2.40)$ & $1.46(0.98-1.75)$ & $1.33(0.70-1.77)^{*}$ \\
Intestine & $1.67(1.49-2.50)$ & $2.55(2.38-2.94)^{*}$ & $2.55(1.90-3.75)^{*}$ \\
Yolk sac & $14.86(12.13-17.05)$ & $2.60(1.10-3.72)^{*}$ & $3.47(2.50-3.90)^{*}$ \\
Carcass & $23.55(20.59-28.19)$ & $25.13(21.04-32.20)^{*}$ & $27.56(19.09-28.20)$
\end{tabular}

\begin{tabular}{llll} 
Day 15 & Baseline & Hypoxemia control & $\begin{array}{l}\text { Hypoxemia } \\
\text { hexamethonium }\end{array}$ \\
\hline Heart & $3.40(2.84-3.85)$ & $7.50(6.60-8.54)^{*}$ & $5.73(4.94-6.05)^{*} \ddagger$ \\
Lungs & $0.90(0.70-1.10)$ & $1.65(1.30-2.09)^{*}$ & $1.87(1.40-2.28)^{*}$ \\
Brain & $3.94(3.00-4.20)$ & $6.10(4.66-7.85)^{*}$ & $5.00(4.48-5.79)^{*}$ \\
CAM & $29.20(23.65-38.11)$ & $32.22(26.50-37.90)^{*}$ & $48.53(37.53-50.60)^{*}$ \\
Liver & $4.10(2.70-5.20)$ & $1.29(0.90-1.61)^{*}$ & $1.20(0.88-1.65)^{*}$ \\
Intestine & $3.26(2.64-4.20)$ & $4.70(3.80-5.10)^{*}$ & $3.30(2.62-3.97)^{\ddagger}$ \\
Yolk sac & $5.70(4.40-8.40)$ & $0.62(0.40-1.26)^{*}$ & $1.10(0.35-1.60)^{*}$ \\
Carcass & $48.80(40.24-52.02)$ & $43.96(39.44-47.93)^{*}$ & $37.10(32.30-41.54)^{*}$
\end{tabular}

\begin{tabular}{llll} 
Day 19 & Baseline & Hypoxemia control & $\begin{array}{l}\text { Hypoxemia } \\
\text { hexamethonium }\end{array}$ \\
\hline Heart & $4.49(3.29-5.20)$ & $11.70(10.52-13.23)^{*}$ & $15.15(12.96-17.30)^{*}$ \\
Lungs & $1.20(0.70-1.61)$ & $0.63(0.43-1.32)$ & $1.00(0.90-1.39)$ \\
Brain & $5.56(4.28-6.67)$ & $12.60(8.35-14.55)^{*}$ & $11.46(10.50-13.50)^{*}$ \\
CAM & $28.63(20.50-36.20)$ & $40.15(34.38-52.35)$ & $29.88(27.00-38.87)$ \\
Liver & $3.00(2.16-4.60)$ & $0.69(0.50-1.79)^{*}$ & $1.10(0.71-1.30)^{*}$ \\
Intestine & $5.60(4.97-6.74)$ & $1.20(0.44-1.88)^{*}$ & $1.37(1.00-1.90)^{*}$ \\
Yolk sac & $2.80(2.50-4.00)$ & $0.37(0.25-0.63)^{*}$ & $1.14(0.46-2.52)^{*} \ddagger$ \\
Carcass & $46.80(40.49-51.60)$ & $29.50(24.36-34.11)^{*}$ & $37.60(31.87-40.22)^{*} \ddagger$ \\
\hline
\end{tabular}

Presented are median percentages and interquartile ranges of cardiac output directed to each organ. ${ }^{*} P<0.05$ compared with baseline $\ddagger P<0.05$ compared with control group 

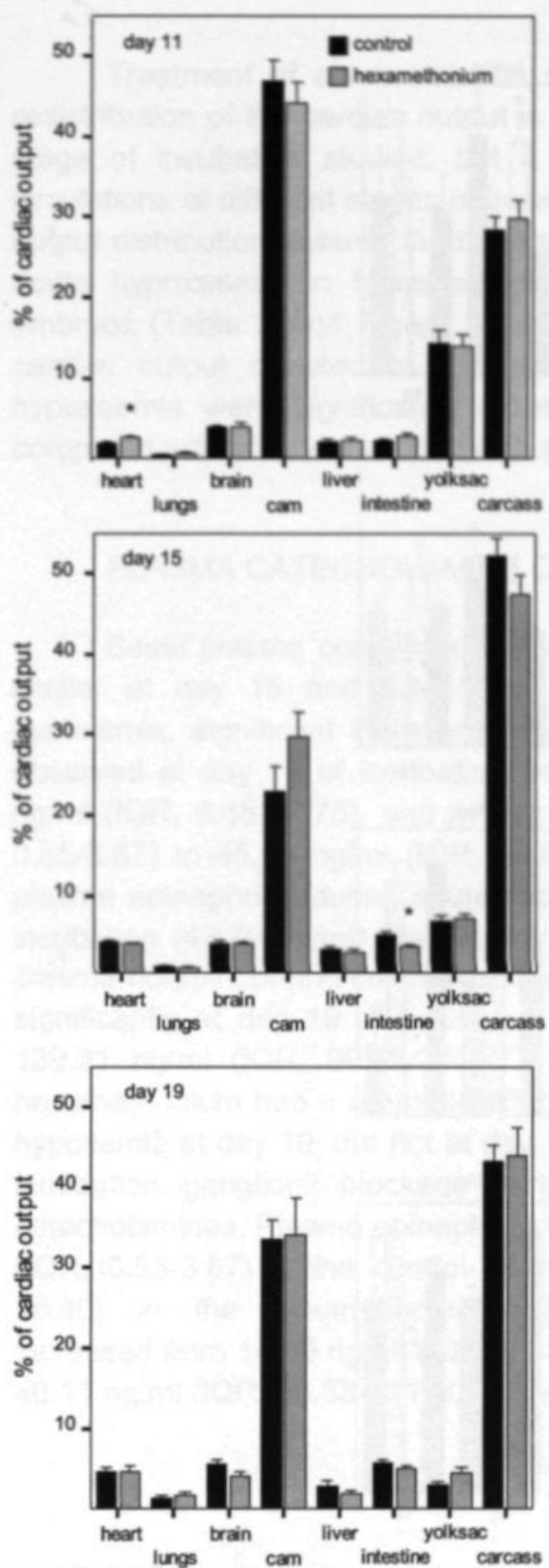

Fig 1 The effect of autonomic nervous system blockade on basal cardiac output distribution. Bars represent the mean percentage of the cardiac output directed to the organ with the standard error of the mean measured after treatment with saline (control group) or hexamethonium. * Significant difference $(P<0.05)$ compared with control group. 

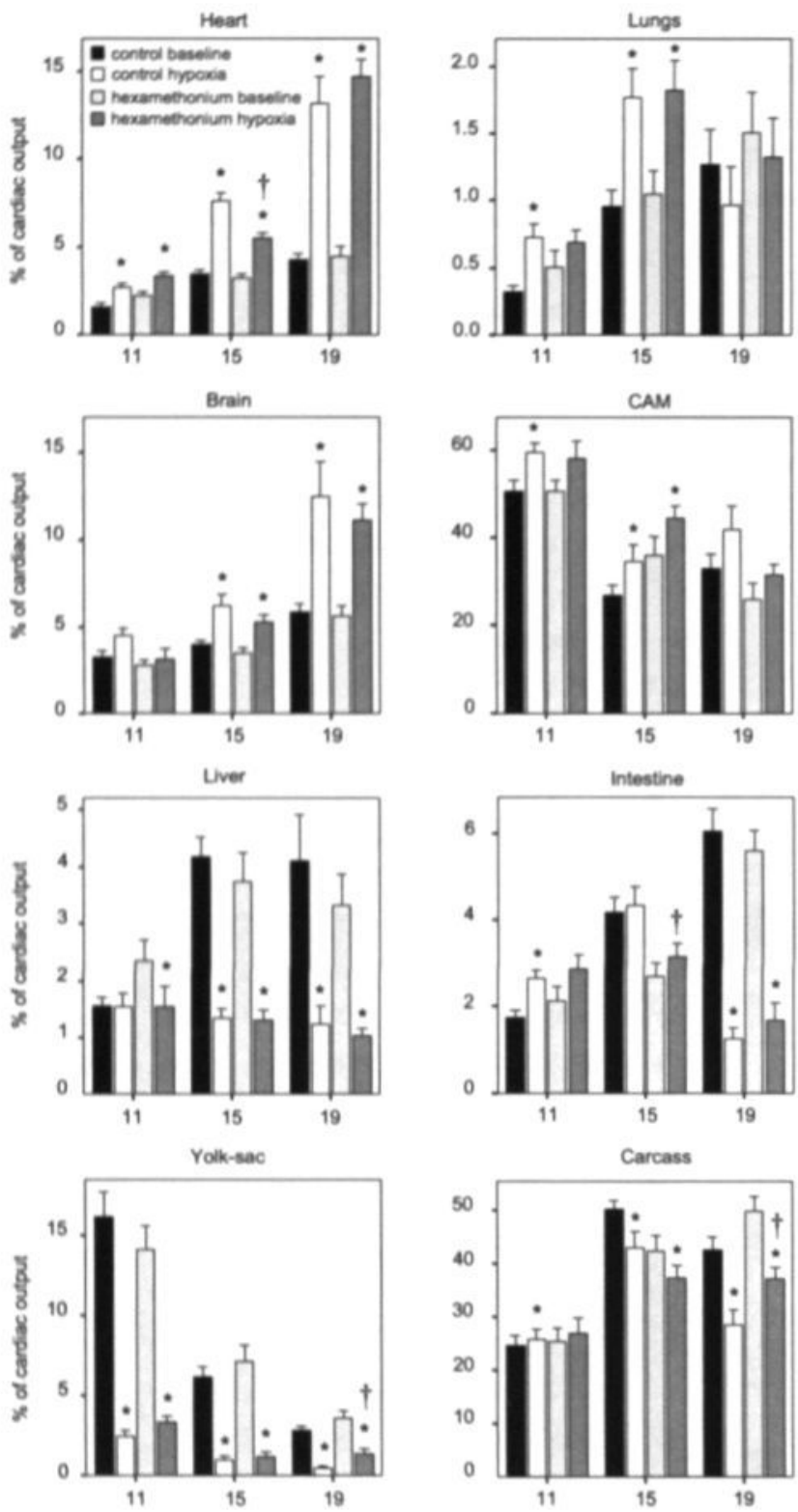

Fig. 2. The effect of autonomic nervous system blockade on cardiac output redistribution in response to acute hypoxaemia. Bars represent the mean percentage of the cardiac output with the standard error of the mean. "Significant difference $(P<0.05)$ compared with baseline levels. + Significant difference $(P<0.05)$ compared with control group. 
Treatment of chick embryos with hexamethonium did not prevent a redistribution of the cardiac output in favour of the heart and the brain at any stage of incubation studied, but it did have an effect on some regional circulations at different stages of incubation. At day 15, the increase in cardiac output distribution towards the heart and the intestines was diminished during acute hypoxaemia in hexamethonium-treated embryos relative to control embryos (Table 2 and Figure 2). Similarly, at day 19, the fractions of the cardiac output directed to the yolk sac and the carcass during acute hypoxaemia were significantly greater in hexamethonium-treated embryos compared with embryos infused with saline.

\section{PLASMA CATECHOLAMINE CONCENTRATIONS}

Basal plasma concentrations of epinephrine and norepinephrine were similar at day 15 and day 19 of incubation (Figure 3). During acute hypoxemia, significant increases in plasma epinephrine concentration were observed at day 15 of incubation from $0.78 \mathrm{ng} / \mathrm{ml}$ (IQR, 0.3-4.15) to 18.10 $\mathrm{ng} / \mathrm{ml}$ (IQR, 6.48-26.75), and at day 19 of incubation from $1.71 \mathrm{ng} / \mathrm{ml}$ (IQR, $0.55-3.67$ ) to $45.50 \mathrm{ng} / \mathrm{ml}$ (IQR, 39.00-68.66) (Figure 3). The increment in plasma epinephrine during acute hypoxemia was much greater at day 19 of incubation $(43.79 \mathrm{ng} / \mathrm{ml})$ than at day $15(17.32 \mathrm{ng} / \mathrm{ml})(P<0.05)$. Similarly, plasma norepinephrine concentrations during acute hypoxemia only increased significantly at day 19 of incubation from $14.50 \mathrm{ng} / \mathrm{ml}$ (IQR, 9.55-49.90) to $139.31 \mathrm{ng} / \mathrm{ml}$ (IQR, 99.49-203.27). Treatment of the chick embryo with hexamethonium had a dramatic effect of catecholamine release during acute hypoxemia at day 19, but not at day 15 of incubation (Figure 3). At day 19 of incubation, ganglionic blockade markedly attenuated the increase in plasma catecholamines. Plasma epinephrine concentration increased from $1.71 \mathrm{ng} / \mathrm{ml}$ (IQR, 0.55-3.67) in the control normoxia group to $14.70 \mathrm{ng} / \mathrm{ml}$ (IQR, 9.9438.40 ) in the hexamethonium-hypoxia group. Plasma norepinephrine increased from $14.50 \mathrm{ng} / \mathrm{ml}$ (IQR, 9.55-49.90) in the control normoxia group to $40.11 \mathrm{ng} / \mathrm{ml}$ (IQR, 23.58-111.60) in the hexamethonium-hypoxia group. 

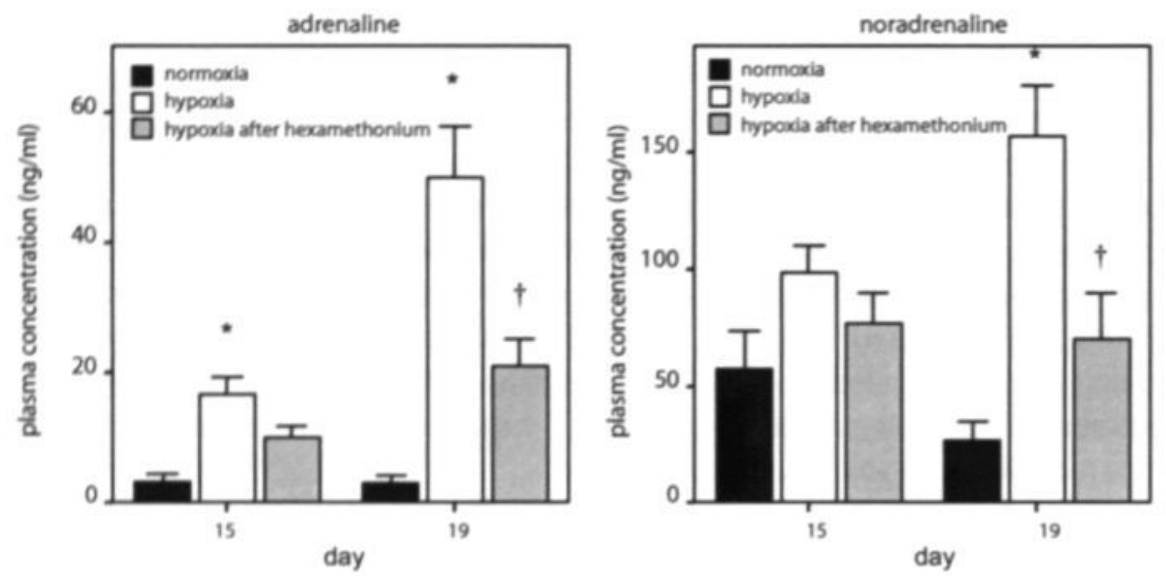

Fig 3 The effect of autonomic nervous system blockade on plasma catecholamine concentrations in response to acute hypoxaemia. Bars represent the mean plasma concentration with the standard error. - Significant difference $(P<0.05)$ compared with normoxia. + Significant difference $(P<0.05)$ compared with hypoxia

\section{DISCUSSION}

The present study was designed to investigate the contribution of neurogenic and non-neurogenic mechanisms in mediating increases in plasma catecholamine concentrations during acute hypoxaemia, and to determine at which stage of development sympathetic innervation of the adrenal gland contributes to catecholamine release, in the chick embryo. The study tested the hypothesis that sympathetic blockade with hexamethonium has a greater effect on catecholamine release and the distribution of cardiac output during acute hypoxaemia in chick embryos at the end of the incubation period compared with chick embryos at earlier stages of development.

In human (Lagercrantz 1998) and sheep (Jones et al. 1988) fetuses and in chick embryos (Epple et al. 1992), the major sources of circulating catecholamines are the adrenal glands, para-aortic chromaffin tissue and spill over from postganglionic sympathetic nerve terminals. Jones et al. (1988) showed that in fetal sheep the increase in plasma adrenaline was totally abolished, and the increase of noradrenaline $90 \%$ reduced, in response to hypoxaemia following adrenal demedullation. This suggests that in fetal sheep the increase in circulating plasma catecholamines in response to hypoxaemia is primarily from adrenal medullary origin. In the adult chicken both adrenaline and noradrenaline are secreted as sympathetic neurotransmitters (DeSantis et al. 1975), suggesting that in the adult chicken postganglionic sympathetic nerves might have a greater contribution to the plasma concentrations of both 
adrenaline and noradrenaline. To date, the contribution of neuronal spill over to circulating plasma concentrations of catecholamines is unknown for the chick embryo.

Previous studies in fetal sheep (Comline \& Silver 1961; Cheung 1990) and neonatal rats (Seidler \& Slotkin 1985) have demonstrated that catecholamine release in response to a stressor, such as acute hypoxaemia, occurs in immature animals before the functional innervation of the adrenal gland is established. This non-neurogenic response is attributed to the direct effect of hypoxia on chromaffin cells (Rychkov et al. 1998). When functional innervation of the adrenal gland is established, catecholamine release becomes largely dependent on neurogenic stimulation and the mature adrenal gland is comparatively insensitive to the direct effects of hypoxia. Evidence for these statements is provided by experiments in late gestation fetal sheep in which hexamethonium abolished the increase in plasma catecholamines in response to acute hypoxaemia (Cheung 1990). Furthermore, when innervation of the adrenal gland was prevented in neonatal rats by surgical denervation of the adrenals prior to the onset of splanchnic nerve function, the nonneurogenic ability of the adrenals to release catecholamines was maintained (Slotkin \& Seidler 1988). The non-neurogenic ability to release catecholamines in response to acute hypoxaemia appears to be an important mechanism for fetal and neonatal survival until the establishment of the sympathetic nervous system. In the present study, treatment of the chick embryo with the ganglion blocker hexamethonium did not influence catecholamine release in response to hypoxaemia at day 15 of incubation. This suggests that at this stage of incubation, catecholamine release into plasma is governed by non-neurogenic, direct effects on the adrenal gland in the chick embryo. In contrast, at day 19 of incubation, adrenal catecholamine release was significantly reduced, but not abolished, in chick embryos treated with hexamethonium. This suggests that late in the incubation period, as the chick embryo approaches hatching, its adrenals appear to become more dependent on neural sympathetic stimulation, although they remain sensitive to a direct stimulatory effect of hypoxaemia.

The development of the sympatho-adrenal system in various species shows remarkable differences in maturation at birth. For example, the lamb is very mature at birth and has a well developed sympathetic innervation. From 0.86 gestation, adrenal stimulation via the splanchnic nerve results in catecholamine release which is blocked by hexamethonium (Comline \& Silver 1961). Furthermore at 0.9 gestation, catecholamine release into plasma in response to acute hypoxaemia is completely dependent on sympathetic stimulation (Cheung 1990). In contrast, in the rat, sympathetic innervation to 
the adrenal gland develops, almost completely, after birth. In the rat, splanchnic innervation of the adrenal gland is non-functional until the first postnatal week (Slotkin et al. 1980). In 1 day old rats hypoxia causes a nonneurogenic depletion of adrenal catecholamines. This response is prevented by sympathetic blockade from day 8 (Seidler \& Slotkin 1985). The present study in the chick embryo demonstrates that functional innervation of the adrenal gland takes place from day 19 of incubation, just prior to the onset of internal pipping and hatching.

Compared to the control group only small changes in basal cardiac output distribution were observed in the chick embryos after treatment with hexamethonium. The fraction of the cardiac output directed to the heart increased only at day 11 and the fraction to the intestines decreased only at day 15 of incubation. In late gestation fetal sheep hexamethonium is known to reduce blood pressure and heart rate (Cheung 1992), however no data are available on the effects of ganglionic blockade on regional blood flow for the ovine fetus. In chick embryos between day 12 to 21 of incubation, hexamethonium has no influence on basal heart rate nor mean arterial pressure (Crossley \& Altimiras 2000; van Golde, personal communication). Sympathetic tone thus seems to play an unimportant role in the control of basal cardiovascular function in the chick embryo. Since hexamethonium does not only block the sympathetic, but also parasympathetic, activity, past and present data also suggest that the parasympathetic nervous system does not contribute to the control of basal cardiovascular function in the chick embryo. Accordingly, previous investigations in our laboratory have shown that treatment of the chick embryo with atropine has no effect on basal blood pressure nor heart rate (van Golde et al. 1998).

In the present study, it is of interest that treatment of the chick embryo with hexamethonium significantly attenuated the increase in plasma catecholamines and resulted in a greater fraction of the cardiac output directed to the carcass compared with the control group during acute hypoxaemia at day 19 of incubation. However, cardiac output was still preferentially distributed to the brain and the heart in chick embryos treated with hexamethonium at day 19 of incubation. Previous studies from our laboratory show that absence of peripheral vasoconstriction in response to hypoxaemia, in phentolamine treated chick embryos, prevents the redistribution of the cardiac output towards the heart and brain. This suggests that peripheral vasoconstriction in response to hypoxaemia is essential to facilitate the cardiac output redistribution towards the heart and brain. Furthermore, in the day 19 hexamethonium treated chick embryos the rise in plasma catecholamines, although attenuated, still might have been sufficient to induce 


\section{SYMPATHETIC CONTROL $\mid 123$}

peripheral vasoconstriction and cardiac output redistribution. In contrast, studies in late gestation fetal sheep show that sympathetic blockade prevents the increase in fetal arterial blood pressure and results in collapse of the fetal cardiovascular system and death during acute hypoxaemia (Cheung 1990). Combined, these findings suggest that near term the sheep fetus is more dependent than the chick embryo on autonomic functions for the maintenance of perfusion of oxygen sensitive circulations during acute hypoxaemia and the chick embryo more dependent on endocrine functions, at least until day 19. Furthermore, mechanisms in addition to peripheral vasoconstriction may contribute to the redistribution of the cardiac output to maintain oxygen delivery to the myocardial and cerebral circulations during acute hypoxaemia in the chick embryo close to hatching. Potential mechanisms include local vasodilatation in response to release of nitric oxide, adenosine, prostaglandins and adrenomedullin. In fetal sheep both nitric oxide and adenosine have been shown to contribute to the redistribution of cardiac output towards the brain and heart in response to acute hypoxaemia. Blockade of nitric oxide synthase markedly attenuates the redistribution of the cardiac output towards the brain (van Bel et al. 1995; Green et al. 1996) and the heart (Reller et al. 1995). In addition, the hypoxia derived vasodilator metabolite adenosine has been shown to dilate both cerebral (Kurth \& Wagerle 1992) and coronary (Reller et al. 1995) arteries. Furthermore, studies in newborn pigs demonstrate that prostaglandins may contribute to cerebral vasodilatation in response to hypoxaemia (Leffler \& Parfenova 1997). Hypoxaemia might induce adrenomedullin expression in vascular endothelial cells (Ogita et al. 2001), but the role of adrenomedullin in the fetal response to hypoxaemia on regional blood flow is until now unknown.

\section{PERSPECTIVES}

The data presented show that embryonic treatment with the ganglion blocker hexamethonium markedly attenuated the increase in plasma catecholamine concentrations during acute hypoxemia at day 19 , but not at day 15 , of incubation. In addition, embryonic treatment with hexamethonium diminished the redistribution of the cardiac output away from the carcass and the yolk sac, at day 19 , but not at day 15 , of incubation. However, the effect of hexamethonium on these peripheral circulations at day 19 of incubation did not prevent a significant increase in cardiac output to the brain and heart during acute hypoxemia. In combination, these data support the hypothesis tested in this study and imply that the contribution of neurogenic mechanisms mediating increases in plasma catecholamine concentrations during acute hypoxemia becomes greater by the end of the incubation period in the chick 
embryo. Simultaneously, non-neurogenic mechanisms are expected to become less important and eventually disappear as is described previously in mammalian species (Comline \& Silver, 1965; Slotkin et al. 1988; Cheung, 1990). In the chick embryo it is not reported at what stage of development the non-neurogenic mechanism of catecholamine release disappears. Subsequent studies should address this subject by testing the present protocol on the catecholaminergic response to acute hypoxemia in hatchlings and older chickens. In addition, the mechanisms mediating the maturational changes in the circulatory response to hypoxemia are not fully understood. Glucocorticoid secretion is believed to play an important role in the maturation of essential organ systems and the fetal response to intrauterine stressors (Liggins, 1976). Recent studies provide information on the chicken genome (Schmid et al. 2000), which shows the conservation of large syntenic regions between the human and chicken genomes (Burt et al. 2000). This is important since it opens the opportunity for further studies on the effects of specific prenatal conditions, such as hypoxemia, on gene expression.

\section{ACKNOWLEDGEMENTS}

The authors thank F.W. Prinzen (Department of Physiology) and J. Hekking (Department of Anatomy-Embryology) for valuable advice on the study.

\section{REFERENCES}

BRACE, R. A. \& BRITTINGHAM, D. S. (1986). Fetal vascular pressure and heart rate responses to nonlabor uterine contractions. American Journal of Physiology 251, R409-16.

Burt, D. W., C. Bruley, I. C. Dunn, C. T. Jones, A. Ramage, A. S. Law et al. (1999). The dynamics of chromosome evolution in birds and mammals. Nature 402, 411-413.

CHEUnG, C. Y. (1990). Fetal adrenal medulla catecholamine response to hypoxia-direct and neural components. American Journal of Physiology 258, R1340-6.

CHEUNG, C. Y. (1992). Autonomic and arginine vasopressin modulation of the hypoxia-induced atrial natriuretic factor release in immature and mature ovine fetuses. American Journal of Obstetrics and Gynecology 167, 1443-53.

COMLINE, R. S., SIIVER, I. A. \& SILVER, M. (1965). Factors responsible for the stimulation of the adrenal medulla during asphyxia in the foetal lamb. Journal of Physiology 178, 211-238. 
COMLINE, R. S. \& SILVER, M. (1961). The release of adrenaline and noradrenaline from the adrenal glands of the foetal sheep. Joumal of Physiology 156, 424-444.

Crossley, D., 2ND \& ALtimiRAS, J. (2000). Ontogeny of cholinergic and adrenergic cardiovascular regulation in the domestic chicken (Gallus gallus). American Joumal of Physiology 279, R1091-8.

DeSAntis, V. P., LANGSfeld, W., LindmaR, R. \& Loffelholz, K. (1975). Evidence for noradrenaline and adrenaline as sympathetic transmitters in the chicken. British Journal of Pharmacology 55, 343-50.

Epple, A., GiLL, T. S. \& NiB8ıO, B. (1992). The avian allantois: a depot for stress-released catecholamines. General and Comparative Endocrinology 85, 462-76.

Giussani, D. A., Spencer, J. A., Moore, P. J., Bennet, L. \& Hanson, M. A. (1993). Afferent and efferent components of the cardiovascular reflex responses to acute hypoxia in term fetal sheep. Joumal of Physiology 461, 431-49.

GIUSSANI, D. A., SPEnCER, J. A. D. \& HANSON, M. A. (1994). Fetal cardiovascular reflex responses to hypoxaemia. Fetal and Maternal Medicine Review 6, 17-37.

GREEN, L. R. (2001). Programming of endocrine mechanisms of cardiovascular control and growth. Journal of the Society of Gynecologic Investigation 8, 57-68.

Green, L. R., Bennet, L. \& HANSON, M. A. (1996). The role of nitric oxide synthesis in cardiovascular responses to acute hypoxia in the late gestation sheep fetus. Joumal of Physiology 497, 271-7.

HANSON, M. A. (1988). The importance of baro- and chemoreflexes in the control of the fetal cardiovascular system. Journal of Developmental Physiology 10, 491-511.

Jones, C. T., Roebuck, M. M., WALKer, D. W. \& Johnston, B. M. (1988). The role of the adrenal medulla and peripheral sympathetic nerves in the physiological responses of the fetal sheep to hypoxia. Journal of Developmental Physiology 10, 17-36.

KURTH, C. D. \& WAGERLE, L. C. (1992). Cerebrovascular reactivity to adenosine analogues in 0.6-0.7 gestation and near-term fetal sheep. American Joumal of Physiology 262, H1338-42.

LAGERCRANTZ, H. (1998). Sympathoadrenal mechanisms during development. In Fetal and Neonatal Physiology, ed. Polin, R. A. \& Fox, W. W., pp. 220-225. W.B. Saunders Company, Philadelphia

Leffler, C. W. \& PARfenova, H. (1997). Cerebral arteriolar dilation to hypoxia: role of prostanoids. American Journal of Physiology 272, H418-24.

LIGGINS, G. C. (1976) Adrenocortical-related maturational events in the fetus. American Journal of Obstetrics and Gynecology 126, 931-94.

MANN, L. I. (1986). Pregnancy events and brain damage. American Journal of Obstetrics and Gynecology 155, 6-9. 
Mulder, A. L., Golde, J. M., Goor, A. A., Giussani, D. A. \& Blanco, C. E. (2000). Developmental changes in plasma catecholamine concentrations during normoxia and acute hypoxia in the chick embryo. Journal of Physiology 527, 593-599.

MULDER, A. L. M., VAN GOOR, C. A., GIUSSANI, D. A. \& BLANCO, C. E. (2001). Alpha-adrenergic contribution to the cardiovascular response to acute hypoxemia in the chick embryo. American Journal of Physiology 281, R2004-R2010

Mulder, T. L., van Golde, J. C., Prinzen, F. W. \& Blanco, C. E. (1997). Cardiac output distribution in the chick embryo from stage 36 to 45 . Cardiovascular Research 34, 525-8.

OgITA, T., HASHIMOTO, E., YAMASAKI, M., NAKAOKA, T., MATSUOKA, R., KIRA, Y. \& FUuITA, T. (2001). Hypoxic induction of adrenomedullin in cultured human umbilical vein endothelial cells. Journal of Hypertension 19, 603-8.

PRINZEN, F.W., GLENnY, R.W. (1994). Developments in non-radioactive microsphere techniques for blood flow measurement. Cardiovascular Research 28, 1467-1475

RELIER, M. D., BURSON, M. A., LOHR, J. L., MORTON, M. J. \& THORnBURG, K. L. (1995). Nitric oxide is an important determinant of coronary flow at rest and during hypoxemic stress in fetal lambs. American Joumal of Physiology 269, H2074-81.

RYchKov, G. Y., AdAMS, M. B., MCMillen, I. C. \& RoBeRTS, M. L. (1998), Oxygen-sensing mechanisms are present in the chromaffin cells of the sheep adrenal medulla before birth. Joumal of Physiology 509, 887-93.

SEIDLER, F. J. \& SLOTKIN, T. A. (1985). Adrenomedullary function in the neonatal rat: responses to acute hypoxia. Journal of Physiology 358, 1-16.

SHIELDS, J. R. \& SCHIFRIN, B. S. (1988). Perinatal antecedents of cerebral palsy. Obstetrics and Gynecology 71, 899-905.

SLOTKIN, T. A. \& SEIDLER, F. J. (1988). Adrenomedullary catecholamine release in the fetus and newborn: secretory mechanisms and their role in stress and survival. Journal of Developmental Physiology 10, 1-16.

SLOTKIN, T. A., SMITH, P. G., LAU, C. \& BAREIS, D. L. (1980). Functional aspects of development of catecholamine biosynthesis and release in the sympathetic nervous system. In Biogenic Amines in Development, ed. Parvez, H. \& Parvez, S., pp. 29-48. Elsevier / North Holland, Amsterdam

Schmid, M., L. Nanda, M. Guttenbach, C. Steinlein, M. Hoehn, M. Schartl et al. (2000) First report on chicken genes and chromosomes 2000. Cytogenetics and Cell Genetics 90, 169-218.

VAN Bel, F., SOLA, A., ROMAN, C. \& RUdOLPH, A. M. (1995). Role of nitric oxide in the regulation of the cerebral circulation in the lamb fetus during normoxemia and hypoxemia. Biology of the Neonate 68, 200-10.

VAN DER HOORN, F. A., BOOMSMa, F., MAN IN 'T Veld, A. J. \& SCHALEKAMP, M. A. (1989) Determination of catecholamines in human plasma by high-performance liquid 
chromatography: comparison between a new method with fluorescence detection and an established method with electrochemical detection. Joumal of Chromatography 487, 17-28.

VAN Golde, J. C., MuldeR, A. L. M. \& BlanCO, C. E. (1998). Parasympathetic contribution to the cardiovascular response to acute hypoxia in the chick embryo. Pediatric Research 43 , 56A.

van Oosterhout, M. F., Willigers, H. M., Reneman, R. S. \& Prinzen, F. W. (1995). Fluorescent microspheres to measure organ perfusion: validation of a simplified sample processing technique. American Journal of Physiology 269, H725-33. 
${ }_{128} \mid$ 
SUMMARY AND DISCUSSION | 129

Chapter 7

Summary and General Discussion 
Prenatal and perinatal hypoxaemic events may lead to severe injury of the brain, resulting in lifelong impairment in cognitive and motor functions. Understanding the pathophysiology involved in these events is the first step in the prevention of serious complications. Until now all our knowledge of the fetal responses to hypoxaemia is derived from studies in mammalian fetuses. In these studies maternal and placental factors might have influenced the fetal response to hypoxaemia and therefore might not reflect a direct fetal response. In this thesis therefore, we present data on prenatal responses to hypoxaemia in a non-mammalian fetal animal model, the chick embryo.

\section{MAIN FINDINGS}

The studies in the present thesis demonstrated that the chick embryo is a feasible animal model for research on the fetal cardiovascular system.

In chapter 2 is presented the distribution of the cardiac output under baseline conditions in the chick embryo. The basal cardiac output distribution showed remarkable resemblance with the cardiac output distribution in fetal sheep as described by Jensen et al. (1991). A large fraction of the cardiac output was directed to the chorioallantoic membrane, which represents the equivalent of the placenta in mammalian species, and relatively small fractions were distributed to heart, lungs, brain and intestine. Compared to the sheep fetus, the cardiac output fraction to the lungs was small and remained small until the end of the incubation period, while in the sheep fetus the fraction increases to around $10 \%$ (Jensen et al. 1991). Both in utero and in ovo the lungs do not contribute to the process of gas exchange. The physiological relevance of the increase in blood flow to the lungs towards the end of gestation in the sheep fetus remains unclear, but it may contribute to the maturation of pulmonary tissue in preparation for postnatal life. With increasing incubation time the fraction of the cardiac output directed to the extra-embryonic circulation of the chorioallantoic membrane and the yolk sac decreased and as a consequence blood was directed to the embryo. This change in cardiac output distribution during development is also described in fetal sheep, in which the fraction of the cardiac output directed to the placenta decreases in favour of the fetus.

In chapter 5 the effect of $\alpha$-adrenergic blockade on basal cardiac output distribution is described. Treatment with phentolamine resulted in small changes in basal cardiac output distribution, suggesting small contributions of $\alpha$-adrenergic mechanisms to basal vascular tone. Moreover, sympathetic blockade with hexamethonium, as shown in chapter 6 , resulted in small 
changes in basal cardiac output distribution mainly at day 11 and 15 of incubation.

The responses of the chick embryo to an acute hypoxaemic insult showed remarkable similarities with those found in mammalian fetuses. In chapter 3 the effect of acute hypoxaemia on cardiac output distribution in the chick embryo is described. Acute hypoxaemia induced a centralization of the cardiac output to the heart and the brain away from the carcass, liver and intestine. In addition, plasma catecholamine concentrations increased in response to hypoxaemia (chapter 4). Furthermore, previous work from our laboratory demonstrated that in the chick embryo acute hypoxaemia evokes a bradycardia and a decrease in chorioallantoic blood flow (van Golde et al. 1997). These observations in the chick embryo demonstrate a clear response of the embryo to acute hypoxaemia without any direct influence from the mother animal or the placenta. These data may support the concept that in mammalian species maternal and placental factors do not have a major contribution to the fetal response to hypoxaemic events.

The experimental model allowed us to study the response to hypoxaemia at different time points of incubation, since the instrumentation was applicable from day 10 to day 19 of incubation, corresponding with approximately $50 \%$ to $90 \%$ of the total incubation period. As described in chapter 3 clear developmental changes were observed in the response to acute hypoxaemia in the chick embryo. Peripheral vasoconstriction became progressively more intense towards the end of the incubation period and also the release of catecholamines, in particular adrenaline, progressively increased (chapter 4). Although only a few studies in mammalian fetuses report on developmental changes in the response to hypoxaemia, a similar maturational pattern has been described as we have found in the chick embryo. In fetal sheep peripheral vasoconstriction is reported from $65 \%$ of gestation (Iwamoto et al. 1989) and the release of catecholamines in response to hypoxaemia is reported from $60 \%$ of gestation (Iwamoto et al. 1989), increasing progressively towards term (Comline \& Silver, 1961; Widmark et al. 1989). These data and our data combined support the concept that the fetal response to hypoxaemia matures with advancing gestation. However, an important question is whether the more mature response in the older fetuses is more effective in preventing organ damage and fetal death than the less mature response as seen at $50-60 \%$ of gestation. Our data do not provide the answer. In our studies no embryo died after 5 minutes of hypoxaemia and we did not study the possible damaging effect of hypoxaemia on different organs. Van Golde (2001) reported data on intestinal damage after repetitive episodes of hypoxaemia in chick embryos from day 11 to day 
19 of incubation. Intestinal damage was demonstrated at day 19 of incubation and not at day 11 and day 15 . This is consistent with our findings presented in chapter 3 that vasoconstriction in the intestinal vascular bed is only present at day 19 of incubation and not at day 11 and day 15. Bennet et al. (1999) demonstrated that fetal sheep at 0.6 gestation are able to survive a 30 minute period of asphyxia by complete umbilical cord occlusion. After 3-5 hours a secondary period of profound hypotension and hypoperfusion occurred, putting the fetuses at high risk of severe organ damage. In addition, the premature fetus appears to be able to survive more prolonged periods of asphyxia than the near- term fetus. However, survival is associated with exposure to prolonged periods of hypotension and hypoperfusion with a consequently greater risk of severe neural damage (Gunn et al. 2001) The chick embryo may be a feasible experimental model in future studies to investigate whether hypoxaemic insults at different times of incubation lead to damage of organs, such as the heart and the brain.

Furthermore, we found that in the chick embryo the centralization of the cardiac output to the heart and the brain during hypoxaemia is highly dependent on $\alpha$-adrenergic mechanisms. As shown in chapter $5 \alpha$ adrenoreceptor blockade abolished the preferential blood flow to the brain and attenuated the increase in blood flow to the heart. This suggests that peripheral vasoconstriction is extremely important in preserving adequate blood flow and oxygen delivery to the central tissues. Local vasodilator mechanisms may also play a role in centralising the cardiac output during hypoxaemia. However, in the absence of peripheral vasoconstriction they do no longer preserve cerebral blood flow. This is in contrast with data from fetal sheep experiments, which show that under hypoxemic conditions alphaadrenergic receptor blockade does not affect carotid blood flow (Giussani et al. 1993) or cerebral blood flow (Reuss et al. 1982).

In addition, plasma catecholamine concentrations were measured during normoxia and after 5 minutes of hypoxaemia as described in chapter 4 . Basal plasma concentrations of noradrenaline and adrenaline in the chick embryo appeared to be very high compared to mammalian fetuses. Also in the adult chicken plasma catecholamine concentrations are remarkably higher than in the human species (Nishimura et al. 1981). This can contribute to a higher blood pressure reported in adult chickens compared to most mammalian species.

In chapter 6, the role of the autonomic nervous system in the response to acute hypoxaemia was studied. Until the $19^{\text {th }}$ day of incubation the contribution appeared to be small. However, from the $19^{\text {th }}$ day of incubation 
the release of catecholamines was markedly attenuated by autonomic ganglion blockade. This finding suggests that with innervation of the adrenal glands at the end of the incubation period the release of catecholamines upon a hypoxaemic insult comes partially under control of the sympathetic nervous system. Before this developmental stage, catecholamines are released by an alternative mechanism, probably due to the direct effect of hypoxaemia on chromaffin cells (Rychkov et al. 1998). These two mechanisms of catecholamine release resemble those that are well documented in fetal sheep and the fetal calf (Comline \& Silver, 1966). In fetal sheep the direct effect of hypoxaemia on catecholamine release from the adrenal gland becomes less important towards term, when functional innervation of the adrenal gland is completed. In the fetal calf this change in regulation of catecholamine release happens somewhat later, after birth. In the chick embryo we found that both mechanisms are present at day 19 of incubation. So far, we were not able to study these mechanisms in older chick embryos or hatchlings. However, we assume that a similar transition as in fetal sheep in the control of catecholamine release will occur around the time of hatching.

In this context it is important to note that the chicken hatchling is rather precocious and mostly self-supporting in contrast to most mammalian species, including the human. The chicken is more mature after hatching compared to altricial birds (Tazawa \& Whittow, 2000). The same comparison can be made for mammalian species. The sympathetic nervous system in lambs and calves is fairly well developed at birth, in contrast to rat pups, in which the sympathetic nervous system develops largely after birth (Lagercrantz, 1998). Most fetal animal models used, including fetal sheep, llama and the chick embryo are relatively mature at "birth" compared to the human newborn.

The mechanisms responsible for the maturation of specific components of the fetal cardiovascular and endocrine responses to acute hypoxaemia are largely unknown. However, some common mechanisms in normal fetal maturation may be important. Glucocorticoids have been shown to have a wide range in maturational effects in utero (Fowden et al. 1998). In many species including the human, plasma cortisol concentrations progressively rise towards the end of gestation. Glucocorticoids are particularly well known to promote pulmonary maturation (Bolt et al. 2001). Cardiovascular function is also influenced by glucocorticoids. Cortisol infusion in fetal sheep results in increases in blood pressure and decreases in heart rate variability (Wood ot al. 1987). Injection of betamethason in fetal sheep followed by premature caesarean delivery 48 hours later improved postnatal cardiac output and cardiac contractility. In addition, blood pressure increased with a concomitant rise in vascular resistance compared with control animals (Padbury et al. 
1995). Adrenal maturation is largely dependent on ACTH secretion (Winter, 1998). The late gestational rise in glucocorticoids may be responsible for the adrenal increase in phenylethanolamine $\mathrm{N}$-methyltransferase, the enzyme responsible for the conversion of noradrenaline to adrenaline (Bohn et al. 1981; Adams et al. 1998), resulting in increased plasma adrenaline concentrations and adrenergic responses at the end of gestation, as discussed in chapter 4. Furthermore, glucocorticoids have an important role in the maturation of kidney, liver and gut function (Fowden et al. 1998).

Glucocorticoids appear to trigger maturation by switching the cell cycle from proliferation to differentiation (Fowden et al. 1998). This is mediated, at least in part, by alterations in gene expression and tissue content of IGF. In fetal sheep cortisol is responsible for the developmental down-regulation of IGF-II gene (Li et al. 1993), which will reduce the drive for fetal growth and may act as a signal for cell differentiation. Some maturational effects of glucocorticoids appear to be specific for particular periods in development. This may be explained by ontogenic changes in glucocorticoids receptor density and 11 beta hydroxysteroid dehydrogenase activity (Yang, 1992). Cortisol might influence directly gene expression via glucocorticoid response elements on the promotor regions of genes (Fowden et al. 1998). Alternatively, cortisol might act indirectly by triiodothyronine. Plasma triiodothyronine is known to rise concomitantly with cortisol as a result of the cortisol-induced deiodination of thyroxine to triodothyronine. Also triiodothyronine is known to promote specific gene expression (Fowden et al. 1998). Thyroidectomy at mid gestation in fetal sheep leads to reduced bodyweight and length at term and delayed maturation of skin, skeleton, lungs and neuromuscular systems (Fowden, 1995). Moreover, thyroidectomy at mid gestation results in blunted cardiovascular and catecholaminergic responses to acute hypoxaemia in late gestation fetal sheep (Walker \& Schuijers, 1989). Whether glucocorticoids and/or thyroid hormones mediate the maturation of the cardiovascular responses to hypoxaemia in the chick embryo is unknown.

Interestingly, repetition of intrauterine stress episodes may alter fetal responses. Studies from Giussani et al. (1997) and Green et al. (2001) in fetal sheep showed that repeated umbilical cord occlusions attenuated the change in fetal heart rate and blood pressure in response to the cord occlusion. However, Steyn et al. (1998) did not find any change in any response to repeated moderate hypoxaemia in late gestation fetal sheep. In addition, Unno (1997) et al. found an attenuated cortisol release after repeated cord occlusions, despite an intact ACTH response. 


\section{EXPERIENCES WITH THE MODEL}

The early chick embryo during the first days of incubation is a wellknown animal model for cardiovascular research with regard to cardiac development and mechanics (Clark, 1989), angiogenesis (Le Noble et al. 1993) and cardiovascular pharmacology and toxicology (Bkaily et al. 1991). However, the late chick embryo, from the second half of incubation, is a rather new animal model for the study of fetal cardiovascular responses. From a methodological view the chick embryo in the late incubation period offers the unique possibility to study direct fetal responses. Furthermore, the instrumentation and the experimental procedures are simple and easy to perform. The blood vessels in the chorioallantoic membrane are easily accessible without major invasive procedures, leaving the embryo within its amniotic sac in ovo. After some training the instrumentation with a venous catheter in a chorioallantoic vein is not difficult using a light microscope. Induction of hypoxaemia by changing the environmental air, is simple and relatively non-invasive.

On the other hand the chick embryo has limitations when used as an animal model for fetal cardiovascular responses. The blood volume of the chick embryo is limited. The estimated blood volume in chick embryos ranges from $1.34 \mathrm{ml}$ at day 11 of incubation to $3.40 \mathrm{ml}$ at day 18 (Yosphe-purer $e$ t al. 1953). This limits the number of blood samples that can be obtained to one or two at most. In all our experiments the procedure of blood sampling was performed at the end of the experiment.

During the experiments for measuring the cardiac output distribution it was not possible to measure changes in absolute cardiac output and blood pressure. This would have given more information on changes in blood flow to the organs and vascular tone. The design of the studies imposed by the model limited us to describe only the relative changes in cardiac output distribution.

When the eggshell is opened for instrumentation, chronic experiments over several days or weeks are less appropriate due to the risk of infection. Combined, these characteristics make the chick embryo less suitable for complex experiments which require chronic instrumentation but very suitable for acute experiments with one or a few simple measurements. In addition, the chick embryo may be used in chronic experiments not requiring opening of the eggshell, such as studies on chronic hypoxia and malnutrition (Ruijtenbeek et al. 2000; Miller et al. 2002) .

Our data present variability. However, this was not so large as to prevent us to find meaningful changes. The variability found is at large not so different as found in other methods like radioactive microspheres. 
Furthermore, it would be unreasonable to expect a small variability in the results since what we measure is only a split second of a physiological reality. The variability in our data might reflect biological variability or variability inherent to the method. The fluorescent microsphere technique has been shown to be a reliable method and comparable with radioactive microsphere techniques with very small inherent errors (van Oosterhout et al. 1995). The preparation could have induced some stress response, although the preparation was designed to be as less invasive as possible and after the preparation time was left for the embryo to recover from the manipulation. In addition, season-dependent changes were observed in chick embryo size, percentage of fertilized eggs and embryo viability. Furthermore, chick embryos do not hatch all at the same time. There are differences of 1 - 2 days, which might reflect a difference in maturational stage.

\section{PERSPECTIVES}

The present data together with the work of van Golde (thesis 1999), Ruijtenbeek (2000) and Miller (2002) demonstrate that the chick embryo is a feasible animal model for fetal cardiovascular research with a striking resemblance in the responses to hypoxaemia with the mammalian fetus. We now have collected a set of basal data, which opens possibilities for further studies on the physiological mechanisms mediating these responses to acute hypoxaemia, and how they may alter by adverse conditions in this animal model. For instance, the role of other circulating vaso-active substances like vasopressin, angiotensin, or neuropeptide $Y$ in the chick embryo response to hypoxaemia has to be further clarified. In addition, the role of local vaso-active factors like nitric oxide, lactate and adenosine may be subject for further studies. The effectiveness of the fetal response to acute hypoxaemia in protecting the fetus from death and fetal organs from hypoxic damage at different stages of gestation is poorly described, but important to document. Further studies should also address the mechanisms responsible for the maturation of more specific components of the fetal response with gestation.

Furthermore, a large amount of literature shows the link between birth weight and health in adult life. Low birth weight, largely resulting from placental dysfunction, increases the risk for hypertension in later life (Barker et al. 1990) and death from coronary heart disease (Barker et al. 1993). Intrauterine circumstances disturb normal fetal development, eventually resulting in fetal growth retardation and an increased risk for cardiovascular disease in later life. The chick embryo offers interesting possibilities to study the effects of situations resembling placental dysfunction during fetal development. 
Placental dysfunction causes both fetal malnutrition and fetal chronic hypoxaemia. Since the chick embryo has no placenta it offers the opportunity to study the influence on fetal growth, cardiovascular development and circulatory control of both factors separately or combined in varying proportions (Ruijtenbeek et al. 2000; Miller et al. 2002).

Finally, recent studies provided information on the chicken genome (Schmid et al. 2000). Surprisingly, the chicken genome shows extensive conservation of large syntenic regions between the human and chicken genomes (Burt et al. 1999). This may be important since it opens the opportunity for further studies in the chick embryo on the effects of specific prenatal conditions, such as hypoxaemia and malnutrition, on gene expression which may be particularly relevant to the human situation.

\section{REFERENCES}

Adams, M. B., Philuips, I. D., SimonettA, G. \& McMillen, I. C. (1998). Differential effects of increasing gestational age and placental restriction on tyrosine hydroxylase, phenylethanolamine $\mathrm{N}$-methyitransferase, and proenkephalin A mRNA leveis in the fetal sheep adrenal. Journal of Neurochemistry 71, 394-401.

BARKER, D. J., BULL, A. R., OSMOND, C. \& SimmonDS, S. J. (1990). Fetal and placental size and risk of hypertension in adult life. British Medical Joumal 301, 259-62.

BARKER, D. J., OSMOND, C., Simmonds, S. J. \& WieLD, G. A. (1993). The relation of small head circumference and thinness at birth to death from cardiovascular disease in adult life. British Medical Journal 306, 422-6.

Bennet, L., Rossenrode, S., Gunning, M. I., Gluckman, P. D. \& GunN, A. J. (1999). The cardiovascular and cerebrovascular responses of the immature fetal sheep to acute umbilical cord occlusion. Journal of Physiology (London) 517, 247-57.

Bkaily, G., Jacques, D., Sculptoreanu, A., Yamamoto, T., Carrier, D., Vigneault, D. \& SPERELAKIS, N. (1991). Apamin, a highly potent blocker of the TTX- and Mn2(+)-insensitive fast transient $\mathrm{Na}+$ current in young embryonic heart. Journal of Molecular and Cellular Cardiology 23, 25-39.

BOHN, M. C., GoldSTEIN, M. \& BLACK, I. B. (1981). Role of glucocorticoids in expression of the adrenergic phenotype in rat embryonic adrenal gland. Developmental Biology 82, 1-10.

Bolt, R. J., van Weissenbruch, M. M., Lafeber, H. N. \& Delemarre van de WaAl, H. A. (2001). Glucocorticoids and lung development in the fetus and preterm infant. Pediatric Pulmonology 32, 76-91. 
Burt, D. W., Bruley, C., DunN, I. C., Jones, C. T., RAMAge, A., LAW, A. S., MORrice, D. R., PATON, I. R., SMith, J., WindsoR, D., SAZANOV, A., Fries, R. \& WAdDINGTON, D. (1999). The dynamics of chromosome evolution in birds and mammals. Nature 402, 411-3.

CLARK, E. B. (1989). Growth, morphogenesis and function: the dynamics of cardiac development. In Fetal, neonatal and infant heart disease., ed. Moller, J. H., Neal, W. \& Lock, J., pp.1-17. Appleton-Century-Crofts, New York.

COMLINE, R. S. \& SILVER, M. (1961). The release of adrenaline and noradrenaline from the adrenal glands of the foetal sheep. Journal of Physiology (London) 156, 424-444.

COMUINE, R. S. \& SILver, M. (1966). Development of activity in the adrenal medulla of the foetus and new-born animal. British Medical Bulletin 22, 16-20.

FowDEN, A. L. (1995). Endocrine regulation of fetal growth. Reproduction, Fertility and Development 7, 351-63.

FOWDEN, A. L., LI, J. \& FORHEAD, A. J. (1998). Glucocorticoids and the preparation for life after birth: are there long-term consequences of the life insurance? The Proceedings of the Nutrition Society 57, 113-22.

Giussani, D. A., Spencer, J. A., MOORE, P. J., Bennet, L. \& Hanson, M. A. (1993). Afferent and efferent components of the cardiovascular reflex responses to acute hypoxia in term fetal sheep. Joumal of Physiology (London) 461, 431-49.

GUnN, A. J., QUAEDACKers, J. S., GUAN, J., HEINEMAN, E. \& BENNET, L. (2001). The premature fetus: not as defenseless as we thought, but still paradoxically vulnerable? Developmental Neuroscience 23, 175-9.

IWAMOTO, H. S., KAUfMAN, T., KEIL, L. C. \& RUDOLPH, A. M. (1989). Responses to acute hypoxemia in fetal sheep at 0.6-0.7 gestation. American Journal of Physiology, Heart and Circulation Physiology 256, H613-20.

JENSEN, A., ROMAN, C. \& RUDOLPH, A. M. (1991). Effects of reducing uterine blood flow on fetal blood flow distribution and oxygen delivery. Journal of Developmental Physiology 15, 309-23.

LAGERCRANTZ, H. (1998). Sympathoadrenal mechanisms during development. In Fetal and neonatal physiology, ed. Polin, R. A. \& Fox, W. W., pp.220-225. W.B. Saunders company, Philadelphia.

le Noble, F. A., Schreurs, N. H., van StraAten, H. W., SlaAf, D. W., Smits, J. F., Rogg, H. \& STRUIJKER BOUDIER, H. A. (1993). Evidence for a novel angiotensin II receptor involved in angiogenesis in chick embryo chorioallantoic membrane. American Joumal of Physiology, Regulatory, Integrative and Comparative Physiology 264, R460-5.

LI, J., SAunders, J. C., GILMOUR, R. S., SILVER, M. \& Fowden, A. L. (1993). Insulin-like growth factor-ll messenger ribonucleic acid expression in fetal tissues of the sheep during late gestation: effects of cortisol. Endocrinology 132, 2083-9. 
Miluer, S. L., Green, L. R., Peebles, D. M., Hanson, M. A. \& Blanco, C. E. (2002). Effects of chronic hypoxia and protein malnutrition on growth in the developing chick. American Joumal of Obstetrics and Gynecology 186, in press.

NishimuRA, H., NAKAMURA, Y., TAYOR, A. A. \& MADEY, M. A. (1981). Renin-angiotensin and adrenergic mechanisms in control of blood pressure in fowl. Hypertension 3, 141-9.

PAdeury, J. F., POLK, D. H., ERVIN, M. G., BerRY, L. M., IKEgAMI, M. \& JOBE, A. H. (1995). Postnatal cardiovascular and metabolic responses to a single intramuscular dose of betamethasone in fetal sheep born prematurely by cesarean section. Pediatric Research $\mathbf{3 8}$, 709-15.

Reuss, M. L., PARER, J. T., HARRIS, J. L. \& Krueger, T. R. (1982). Hemodynamic effects of alpha-adrenergic blockade during hypoxia in fetal sheep. American Journal of Obstetrics and Gynecology 142, 410-5.

Ruijtenbeek, K., le Noble, F. A., Janssen, G. M., Kessels, C. G., Fazzi, G. E., Blanco, C. E. \& DE MEY, J. G. (2000). Chronic hypoxia stimulates periarterial sympathetic nerve development in chicken embryo. Circulation 102, 2892-7.

RYCHiKOV, G. Y., ADAMS, M. B., MCMILLEN, I. C. \& ROBERTS, M. L. (1998), Oxygen-sensing mechanisms are present in the chromaffin cells of the sheep adrenal medulla before birth. Journal of Physiology (London) 509, 887-93.

Schimid, M., Nanda, I., Guttenbach, M., Steinlein, C., Hoehn, M., Scharth, M., Hanf, T., Weigend, S., Fries, R., Buerstedde, J. M., Wimmers, K., Burt, D. W., SMith, J., A'HARA, S., LaW, A., Griffin, D. K., Bumstead, N., KAufman, J., ThOMSON, P. A., Burke, T., Groenen, M. A., Crooijmans, R. P., Vignal, A., Fillon, V., Morisson, M., Pitel, F., Tixier Boichard, M., ladjali MOHAmmedi, K., Hillel, J., Maki Tanila, A., Cheng, H. H., Delany, M. E., Burnside, J. \& MizUNO, S. (2000). First report on chicken genes and chromosomes 2000. Cytogenetics and Cell Genetics 90, 169-218.

TAZAWA, H. \& Whittow, G. C. (2000). Incubation Physiology. In Sturkie's Avian Physiology, ed. Whittow, G. C., pp.617-634. Academic Press, San Diego, U.S.

VAN Golde, J., Mulder, T. \& Blanco, C. E. (1997). Changes in mean chorioallantoic artery blood flow and heart rate produced by hypoxia in the developing chick embryo. Pediatric Research 42, 293-8.

VAN Golde, J., TibBoel, D., OKazAKI, T. \& Blanco, C. E. (2001). Extent of Intestinal Damage in the Developing Chick Embryo After Repetitive Hypoxia Under Normoxic or Hyperoxic Conditions. Journal of Pediatric Gastroenterology and Nutrition 32, 567-72.

van Oosterhout, M. F., Willigers, H. M., Reneman, R. S. \& Prinzen, F. W. (1995). Fluorescent microspheres to measure organ perfusion: validation of a simplified sample processing technique. American Journal of Physiology, Heart and Circulation Physiology 269, H725-33.

WALKER, D. W. \& SChUIJERS, J. A. (1989). Effect of thyroidectomy on cardiovascular responses to hypoxia and tyramine infusion in fetal sheep. Journal of Developmental Physiology 12, 337-45. 
WIDMARK, C., HOKEgARD, K. H., LAgerCrantz, H., LILJA, H. \& ROSEN, K. G. (1989). Electrocardiographic waveform changes and catecholamine responses during acute hypoxia in the immature and mature fetal lamb. American Joumal of Obstetrics and Gynecology 160. 1245-50.

WiNTER, J. S. D. (1998). Fetal and Neonatal Adrenocortical Physiology. In Fetal and Neonatal Physiology, ed. Polin, R. A. \& Fox, W. W., pp.2447-2459. W. B. Saunders Company, Philadelphia, U.S.A.

WoOd, C. E., CHEUNG, C. Y. \& BRACE, R. A. (1987). Fetal heart rate, arterial pressure, and blood volume responses to cortisol infusion. American Journal of Physiology, Regulatory Integrative and Comparative Physiology 253, R904-9.

YANG, K. (1992). Regulation of gene expression in the ovine fetus. Joumal of Reproduction and Fertility. Supplement 45, 85-95.

YosPHE-PURER, Y., FENDRICH, J. \& DAVIES, A. M. (1953). Estimation of the blood volumes of embryonated hen eggs at different ages. American Journal of Physiology 35, 178-180. 


\section{SAMENVATTING}

Ondanks dat in de laatste decennia de perinatale zorg voor de ongeboren foetus en de pasgeborene sterk is verbeterd, ontstaat nog altijd bij 1 op de 1000 levend geboren kinderen spasticiteit ten gevolge van cerebrale schade. Dit kan slechts voor een klein deel $(10 \%)$ verklaard worden door problemen rondom de geboorte. Momenteel groeit dan ook het inzicht dat de oorzaak van de cerebrale schade mogelijk ook in een vroeger stadium, voor de geboorte, gezocht moet worden. Bepaalde ziekten van de zwangere vrouw zoals hypertensie, pre-eclampsie en HELLP syndroom kunnen de functie van de placenta ernstig beperken. Hierdoor kan intra-uterien een ongunstig foetaal milieu ontstaan waardoor de foetus wordt blootgesteld aan ondervoeding en chronische hypoxie. Bovendien kunnen intra-uteriene afklemming van de navelstreng en uteriene contracties perioden van acute foetale hypoxie veroorzaken. Een goed begrip van de pathofysiologie van deze foetale bedreigingen in de baarmoeder, is een eerste begin in de preventie van cerebrale schade. Meerdere onderzoeksgroepen hebben zich bezig gehouden met de bestudering van de foetale reacties op hypoxie. Uit studies, voornamelijk bij zwangere schapen, is gebleken dat de foetus aan het eind van de zwangerschap op hypoxie reageert met een daling van de hartslag. een stijging van de bloeddruk en een herverdeling van de cardiac output ten gunste van vitale organen zoals het hart en de hersenen. Deze centralisatie van de cardiac output wordt veroorzaakt door vasoconstrictie van het perifere vaatbed in combinatie met vasodilatatie in de vitale organen. Hierbij spelen zowel neurogene factoren (het autonoom zenuwstelsel) als endocriene factoren (b.v. catecholamines, vasopressine) een belangrijke rol. Het betreft hier uitsluitend studies bij zoogdieren. Bij zoogdieren is het echter mogelijk dat maternale en ook placentale factoren invloed hebben op de foetale reactie. Bijvoorbeeld, tijdens hypoxie kunnen stresshormonen zoals catecholamines en glucocorticoïden, bij moeder vrijkomen. Deze kunnen via de placenta de foetus bereiken en de foetale reactie beïnvloeden. Ook vanuit de placenta kunnen tijdens hypoxie stoffen vrijkomen zoals prostaglandines en adenosine, die effect hebben op de foetus. Om deze reden werd besloten om in dit proefschrift de foetale reacties op hypoxie te beschrijven in een ander diermodel dat geen directe connecties met de moeder en geen placenta heeft: het kippenembryo. 
142 | SAMENVATTING

\section{BEVINDINGEN}

Uit de studies in dit proefschrift werd duidelijk dat het kippenembryo een bruikbaar proefdiermodel is om het foetaal cardiovasculair systeem te onderzoeken.

In hoofdstuk 2 wordt de verdeling van de cardiac output over de verschillende organen van het kippenembryo beschreven onder basale omstandigheden. Het bleek dat de verdeling van de cardiac output grote overeenkomsten toont met de verdeling zoals die beschreven is bij foetale lammeren. Een groot deel van de cardiac output werd geleid naar het chorioallantois membraan. Dit membraan bekleedt de binnenzijde van de eierschaal en verzorgt de gasuitwisseling van het embryo, vergelijkbaar met de placenta bij zoogdieren. Relatief kleine fracties van de cardiac output werden geleid naar het hart, hersenen, longen en abdominale organen. In vergelijking met foetale lammeren werd bij kippenembryo's gezien dat het deel van de cardiac output dat naar de longen gaat relatief klein is en dat dit niet toeneemt tegen het einde van de broedtijd. Bij foetale lammeren neemt dit deel wel toe tot $\sim 10 \%$ van de cardiac output. Het is niet geheel duidelijk wat de fysiologische waarde hiervan is, aangezien de longen in utero en in ovo geen bijdrage leveren aan de gasuitwisseling. Met het verstrijken van de broedtijd neemt het deel van de cardiac output dat naar het embryo gaat toe en neemt het deel dat naar de extra-embryonale circulaties gaat (chorioallantois membraan en dooierzak) af; hetgeen ook bij foetale zoogdieren wordt beschreven.

In hoofdstuk 5 en hoofdstuk 6 wordt het effect van a-adrenerge receptor blokkade, respectievelijk autonoom zenuwstelsel blokkade, beschreven op de basale verdeling van de cardiac output in het kippenembryo. $\mathrm{Na}$ behandeling met phentolamine, een niet selectieve $\alpha_{1}$ en $\alpha_{2}$ adrenerge receptor blokker, werden kleine veranderingen in de basale verdeling van de cardiac output geconstateerd. Dit suggereert een beperkte invloed van $\alpha$-adrenerge mechanismen op de basale vaattonus. Blokkade van het sympathisch zenuwstelsel door middel van hexamethonium, een ganglion blokker van het autonoom zenuwstelsel, gaf eveneens kleine veranderingen in de basale verdeling van de cardiac output, met name op dag 11 en 15 van de broedtijd.

Het effect van acute hypoxie op de verdeling van de cardiac output in het kippenembryo wordt beschreven in hoofdstuk 3. Acute hypoxie veroorzaakte een centralisatie van de cardiac output. Procentueel ging er meer bloed naar de hersenen en het hart, ten koste van de darmen, lever en karkas. Naast deze centralisatie van de cardiac output werd een stijging 


\section{SAMENVATTING $\mid 143$}

geconstateerd van de plasma adrenaline en noradrenaline concentraties tijdens hypoxie (hoofdstuk 4). Verder toonde eerder onderzoek van onze groep bij kippenembryo's (van Golde 1997) aan dat acute hypoxie bovendien resulteert in een bradycardie en een afname van de bloedstroom naar het chorioallantois membraan. Deze observaties samen bevestigen dat het kippenembryo, zonder enige invloed van moeder of placenta, in staat is op acute hypoxie te reageren. Bovendien komen de reacties bij het kippenembryo in grote lijn overeen met de reacties zoals die beschreven zijn bij de zoogdier foetus. Dit suggereert dat de foetale reactie op hypoxie bij zoogdieren niet afhankelijk is van maternale of placentale factoren.

Bij het kippenembryo werd de reactie op acute hypoxie op verschillende tijdstippen tijdens de broedtijd bestudeerd. De totale broedtijd van het kippenembryo bedraagt 21 dagen en de experimenten werden verricht vanaf dag 10 tot dag 19 van de broedtijd. Tijdens de ontwikkeling werden duidelijke veranderingen in de reacties van het embryo geconstateerd. Perifere vasoconstrictie in reactie op acute hypoxie nam progressief toe tegen het einde van de broedtijd. Dit ging gepaard met procentueel meer bloed naar de hersenen en het hart. Ook de toename van de plasma catecholamine concentraties, met name adrenaline, in reactie op acute hypoxie werd groter naarmate de broedtijd verder vorderde. Bij zoogdieren werden tot nu toe in slechts enkele studies de veranderingen van de foetale respons op hypoxie tijdens de ontwikkeling beschreven. Ook deze studies beschrijven een toename in perifere vasoconstrictie en catecholamine afgifte. Deze observaties en de observaties bij het kippenembryo ondersteunen het concept dat de foetale reactie op acute hypoxie rijpt tijdens de foetale ontwikkeling. Het is echter niet duidelijk hoe effectief de foetale reactie op hypoxie is in het voorkomen van mortaliteit en orgaanschade, op de verschillende tijdstippen tijdens de ontwikkeling.

De centralisatie van de cardiac output tijdens acute hypoxie lijkt van belang te zijn om voldoende zuurstof transport naar de hersenen en het hart te kunnen behouden. Deze centralisatie wordt veroorzaakt door perifere vasoconstrictie en door locale vasodilatatie in de vaatbedden van de betreffende organen. In hoofdstuk 5 wordt beschreven wat er gebeurt als de perifere vasoconstrictie in reactie op hypoxie geblokkeerd wordt door middel van een a-adrenerge receptor blokker, phentolamine. De procentuele afname van de cardiac output naar het karkas werd niet meer gezien, wat betekent dat de perifere vasoconstrictie adequaat geblokkeerd werd. De toename in cardiac output naar de hersenen werd eveneens niet meer gezien, er was zelfs sprake van een afname. Dit betekent dat in het kippenembryo de toename in bloedstroom naar de hersenen tijdens hypoxie afhankelijk is van 
perifere vasoconstrictie, ondanks eventuele vasodilatatoire mechanismen. De toename van de procentuele cardiac output naar het hart tijdens acute hypoxie was wel aanwezig, zij het in beduidend mindere mate. Dit kan verklaard worden door het $\beta$-adrenerg vasodilatatoir effect van catecholamines op het coronair vaatbed.

De perifere vasoconstrictie en de daarmee samengaande centralisatie van de cardiac output tijdens hypoxie is bij het kippenembryo sterk afhankelijk van $\alpha$-adrenerge receptor stimulatie door catecholamines (hoofdstuk 5). Catecholamines worden vrijgemaakt na sympathische stimulatie uit sympathische zenuwuiteinden en uit chromaffine cellen in de bijnieren of paraaortaal gelegen paraganglia. Chromaffine cellen kunnen echter ook direct gestimuleerd worden door hypoxie. Bij de zoogdier foetus is beschreven dat bij de immature foetus catecholamines voornamelijk door hypoxie zelf vrijkomen en niet door sympathische stimulatie. Rondom de geboorte komt echter het vrijmaken van catecholamines uit de chromaffine cellen onder controle van het sympathisch zenuwstelsel en verdwijnt de directe gevoeligheid voor hypoxie. Door middel van hexamethonium, een ganglion blokker van het autonoom zenuwstelsel, werd bij het kippenembryo de bijdrage van het sympathisch zenuwstelsel aan de respons op hypoxie onderzocht op verschillende momenten tijdens de broedtijd (hoofdstuk 6). Tot en met dag 15 van de broedtijd had behandeling met hexamethonium weinig effect op de respons op hypoxie van het kippenembryo. Op dag 19 werd echter een duidelijk effect gezien op het vrijkomen van catecholamines in respons op hypoxie. In de met hexamethonium behandelde groep was de toename in plasma catecholamine concentraties duidelijk verminderd. Dit verhinderde echter niet de centralisatie van de cardiac output. Deze observatie suggereert dat tot en met dag 15 van de broedtijd catecholamines vrijkomen door directe stimulatie van chromaffine cellen door hypoxie en niet door sympathische stimulatie. Op dag 19 van de broedtijd komt het vrijmaken van catecholamines tijdens hypoxie deels onder invloed van het sympathisch zenuwstelsel. Het lijkt aannemelijk dat enige dagen later het sympathisch zenuwstelsel volledig verantwoordelijk zal zijn voor het vrijmaken van catecholamines, zoals beschreven bij zoogdier foetussen.

\section{ERVARINGEN MET HET KIPPENEMBRYO}

Vanuit methodologisch oogpunt biedt het kippenembryo de unieke mogelijkheid om foetale cardiovasculaire reacties te bestuderen zonder invloed van maternale of placentale factoren. De studies beschreven in dit proefschrift, tonen aan dat het kippenembryo hiervoor een bruikbaar model is 
met belangrijke voordelen zoals de gemakkelijke toegang tot de bloedvaten in het chorioallantois membraan voor instrumentatie, de korte broedtijd van 21 dagen en de lage kosten. Nadelen zijn het geringe bloedvolume en de gevoeligheid voor infecties na openen van het ei. Dit maakt naar onze mening het kippenembryo uitermate geschikt voor acute experimenten met of zonder instrumentatie, maar ook voor chronische experimenten, mits het ei niet geopend hoeft te worden voor instrumentatie.

De observaties beschreven in dit proefschrift vormen samen met het werk van onder anderen van Golde (proefschrift 1999), Ruijtenbeek en Blanco een goede basis voor verdere studies in het kippenembryo met betrekking tot foetale cardiovasculaire reacties. Aanvullende studies naar de rol van andere dan $\alpha$-adrenerge mechanismen in de foetale respons op acute hypoxie zouden in dit model verder uitgezocht kunnen worden. Enige voorbeelden zijn de rol van vasopressine, angiotensine, neuropeptide $Y$ en de rol van locale vasodilatatoire factoren zoals NO, lactaat en adenosine. Ook de mate van effectiviteit van de respons in de zin van overleving en orgaanschade moet verder onderzocht worden op verschillende tijdstippen tijdens de broedtijd. Een belangrijke onderzoeksvraag is ook welke factoren verantwoordelijk zijn voor de rijping van de foetale respons op hypoxie.

Een andere interessante toepassing van het kippenembryo model ligt in studies naar de mechanismen verantwoordelijk voor de Barker hypothese. De engelse epidemioloog D. Barker toonde aan dat een laag geboortegewicht geassocieerd is met een verhoogd risico op hart en vaatziekten op latere leeftijd (Barker et al. 1990; Barker et al. 1993). Blijkbaar beïnvloeden intrauteriene omstandigheden, die resulteren in foetale groeiachterstand, de foetale ontwikkeling zodanig dat er een verhoogd risico ontstaat op hart en vaatziekten. Placenta disfunctie is een belangrijke oorzaak voor het achterblijven van de foetale groei. Hierbij wordt de foetus blootgesteld aan chronische ondervoeding en chronische hypoxie. Omdat het kippenembryo geen placenta heeft kan in dit model chronische ondervoeding en chronische hypoxie apart van elkaar bestudeerd worden en kan het effect op de foetale groei, de ontwikkeling van het hart en vaatstelsel en de regulatie hiervan onderzocht worden (Ruijtenbeek et al. 2000; Miller et al. 2002).

Tenslotte is ook van de kip de laatste jaren veel bekend geworden over het genoom. Het blijkt dat tussen het humaan en kip genoom grote overeenkomstige regionen geconserveerd zijn gebleven (Burt et al. 1999; Schmid et al. 2000). Dit maakt het kippenembryo tevens geschikt om de invloed van prenatale omstandigheden, zoals hypoxie en ondervoeding, te 
146 | SAMEnVATting

bestuderen op de expressie van bepaalde genen, die bijvoorbeeld bijdragen aan de ontwikkeling van het hart en vaat stelsel. 


\section{DANKWOORD}

Promoveren doe je niet alleen. "Het ei" wat nu gelegd is is tot stand gekomen met hulp van velen. Graag wil ik iedereen die mij de afgelopen jaren bij dit proefschrift geholpen heeft van harte bedanken. Een aantal mensen wil ik in het bijzonder bedanken voor hun bijdrage aan dit proefschrift.

Mijn promotor Carlos Blanco, dank ik voor de aangename wijze waarop hij mij bij de onderzoeken gestimuleerd heeft. Op het juiste moment de juiste steun in de rug. Niet alleen bij het onderzoek, maar ook in de kliniek. Ik ben blij dat ik in zijn team mag werken.

I want to thank my copromoter Dino Giussani for his very valuable comments on all the protocols and the manuscript.

Ik dank de medewerkers van de vakgroep Anatomie / Embryologie, met name Johan Hekking en Paul van Dijk die ten allen tijde bereid waren te adviseren en te helpen bij de experimenten.

Ik dank de medewerkers van de vakgroep Fysiologie, met name Frits Prinzen en Anita Rousseau voor hun expertise in de fluorescerende microsfeer methode.

Jo De Mey wil ik bedanken voor zijn opbouwende kritiek tijdens de onderzoeks besprekingen van de "kippenëmbryogroep".

Jolanda van Golde bedank ik voor de fijne samenwerking met name in de opbouwfase van het kippenembryomodel.

Graag bedank ik Carolien van Goor en Annemieke Miedema voor hun aandeel in het vele werk van de experimenten.

Ik dank mijn collega's Wiel Maertzdorf, Piet Degraeuwe, Mark van der Hoeven, Danilo Gavilanes en Eduardo Villamor voor hun flexibiliteit en de collegiale sfeer die in onze groep heerst. Hierdoor is het mogelijk om tot onderzoek te komen.

Ik wil Mascha Mulder - Akerboom bedanken voor haar hulp bij de illustraties.

Ik dank mijn paranimfen en wijn-confrères Raymond Vankan en Jules Knippenbergh, voor de vele uren gezelligheid, hetgeen ongetwijfeld heeft geleid tot uitstel van het totstandkomen van dit proefschrift. 
Ook wil ik mijn ouders bedanken. Zij hebben mij van jongs af aan het vertrouwen en de mogelijkheden gegeven om mij verder te kunnen ontwikkelen en vol interesse mijn studie gevolgd.

Tot slot bedank ik Anke, voor je geduld en liefde. Jij staat altijd klaar als steun en toeverlaat voor mij en ons gezinnetje. Bij jou is het altijd fijn om thuis te komen. Ik vind het heerlijk zoals wij samen met onze kinderen kunnen leven. 


\section{CURRICULUM VITAE}

Twan Mulder werd geboren op 2 juli 1964 in Leende, Noord Brabant. In 1982 werd het eindexamen Gymnasium $\beta$ gehaald aan de scholengemeenschap Augustinianum te Eindhoven, waarna een aanvang werd gemaakt aan de studie Geneeskunde aan de Universiteit Maastricht. In 1986 werd het doctoraal examen gehaald en in 1988 het artsexamen. In 1989 werd de militaire dienstplicht vervuld. In 1990 was hij kortdurend werkzaam als arts-assistent Cardiologie in ziekenhuis de Goddelijke Voorzienigheid te Sittard en daarna als arts-assistent Kindergeneeskunde in het academisch ziekenhuis Maastricht. In 1991 werd gestart met de opleiding Kindergeneeskunde in het Sophia Kinderziekenhuis te Rotterdam (opleider prof. dr. H.K.A. Visser). De opleiding werd in 1993 voortgezet in het academisch ziekenhuis Maastricht (opleiders prof. dr. R.H. Kuijten en prof. dr. C.E. Blanco). Het laatste jaar van de opleiding werd gevolgd in het De Wever ziekenhuis te Heerlen (opleider P.M.V.M. Theunissen). Van 1996 tot 1999 werd de opleiding tot kinderarts-neonatoloog gevolgd bij prof. dr. C.E. Blanco in het academisch ziekenhuis Maastricht. Tevens werd toen een aanvang gemaakt aan het onderzoek beschreven in dit proefschrift. Sinds 1999 is hij werkzaam als kinderarts-neonatoloog bij de vakgroep kindergeneeskunde van het academisch ziekenhuis Maastricht. Tijdens de opleiding in het Sophia Kinderziekenhuis werd dialyseverpleegkundige Anke Berger "geschaakt" met wie hij sinds 1995 gelukkig getrouwd is. Samen hebben zij drie kinderen, Wouter, Fleur en Bastiaan. 
